\title{
Comparison of SHANK3 deficiency in animal models: phenotypes, treatment strategies, and translational implications
}

\author{
Jan Philipp Delling ${ }^{1 *}$ (D) and Tobias M. Boeckers ${ }^{1,2^{*}}$
}

\begin{abstract}
Background: Autism spectrum disorder (ASD) is a neurodevelopmental condition, which is characterized by clinical heterogeneity and high heritability. Core symptoms of ASD include deficits in social communication and interaction, as well as restricted, repetitive patterns of behavior, interests, or activities. Many genes have been identified that are associated with an increased risk for ASD. Proteins encoded by these ASD risk genes are often involved in processes related to fetal brain development, chromatin modification and regulation of gene expression in general, as well as the structural and functional integrity of synapses. Genes of the SH3 and multiple ankyrin repeat domains (SHANK) family encode crucial scaffolding proteins (SHANK1-3) of excitatory synapses and other macromolecular complexes. SHANK gene mutations are highly associated with ASD and more specifically the Phelan-McDermid syndrome (PMDS), which is caused by heterozygous 22q13.3-deletion resulting in SHANK3-haploinsufficiency, or by SHANK3 missense variants. SHANK3 deficiency and potential treatment options have been extensively studied in animal models, especially in mice, but also in rats and non-human primates. However, few of the proposed therapeutic strategies have translated into clinical practice yet.

Main text: This review summarizes the literature concerning SHANK3-deficient animal models. In particular, the structural, behavioral, and neurological abnormalities are described and compared, providing a broad and comprehensive overview. Additionally, the underlying pathophysiologies and possible treatments that have been investigated in these models are discussed and evaluated with respect to their effect on ASD- or PMDS-associated phenotypes.

Conclusions: Animal models of SHANK3 deficiency generated by various genetic strategies, which determine the composition of the residual SHANK3-isoforms and affected cell types, show phenotypes resembling ASD and PMDS. The phenotypic heterogeneity across multiple models and studies resembles the variation of clinical severity in human ASD and PMDS patients. Multiple therapeutic strategies have been proposed and tested in animal models, which might lead to translational implications for human patients with ASD and/or PMDS. Future studies should explore the effects of new therapeutic approaches that target genetic haploinsufficiency, like CRISPR-mediated activation of promotors.
\end{abstract}

Keywords: SHANK3, Autism spectrum disorder, ASD, Phelan-McDermid syndrome, PMDS, Therapy

\footnotetext{
*Correspondence: jan.delling@uni-ulm.de; tobias.boeckers@uni-ulm.de

Any views expressed are those of the author(s) and not necessarily those of

the funders.

${ }^{1}$ Institute for Anatomy and Cell Biology, Ulm University, Albert-Einstein-Allee

11, Ulm, 89081, Germany

${ }^{2}$ Ulm Site, DZNE, Ulm, Germany
}

(c) The Author(s). 2021, corrected publication 2022 Open Access This article is licensed under a Creative Commons Attribution 4.0 International License, which permits use, sharing, adaptation, distribution and reproduction in any medium or format, as long as you give appropriate credit to the original author(s) and the source, provide a link to the Creative Commons licence, and indicate if changes were made. The images or other third party material in this article are included in the article's Creative Commons licence, unless indicated otherwise in a credit line to the material. If material is not included in the article's Creative Commons licence and your intended use is not permitted by statutory regulation or exceeds the permitted use, you will need to obtain permission directly from the copyright holder. To view a copy of this licence, visit http://creativecommons.org/licenses/ by/4.0/. The Creative Commons Public Domain Dedication waiver (http://creativecommons.org/publicdomain/zero/1.0/) applies to the data made available in this article, unless otherwise stated in a credit line to the data. 


\section{Background}

Genes of the SH3 and multiple ankyrin repeat domains (SHANK) family encode a class of crucial multifunctional scaffolding proteins, whose disruption is highly associated with autism spectrum disorder (ASD) and more specifically the Phelan-McDermid syndrome (PMDS), which results from SHANK3-haploinsufficiency or heterozygous SHANK3 variants that alter function.

\section{Autism spectrum disorder (ASD)}

ASD represents a neurodevelopmental disorder that is highly heritable [1] and heterogeneous, spanning a wide range of clinical manifestations. Generally, ASD is a subgroup within the diagnostic category of "Neurodevelopmental Disorders" in the fifth edition of the American Psychiatric Association's Diagnostic and Statistical Manual of Mental Disorders (DSM-5). Core symptoms that characterize ASD comprise persistent deficits in social communication and interaction, as well as restricted, repetitive patterns of behavior, interests, or activities. Additionally, sensory anomalies and varying levels of intellectual disability are frequently observed. The symptoms must be present in early childhood and cause clinically significant functional impairment [2]. Furthermore, ASD can occur concurrently with other psychiatric or neurological disorders. Among these comorbidities, anxiety, depression, attention-deficit hyperactivity disorder (ADHD), and epilepsy are diagnosed rather frequently in ASD patients [3]. The severity of symptoms is influenced by environmental as well as genetic factors and covers a wide range of possible manifestations from subtle social deficits, to intellectual disability or severely affected linguistic skills $[4,5]$.

Commonly ASD is perceived as a rare condition, which is at odds with the estimated prevalence of 1 in 132 in the 2010 Global Burden of Disease study, equating to 52 million cases globally [6]. Gender ratios reported in cohorts of ASD patients range from 2:1 to $5: 1[7,8]$ implying a more frequent occurrence in males.

The abovementioned heterogeneity originates from a wide range of genetic and nongenetic etiologies, which are often unknown. The underlying pathophysiological mechanisms that lead to ASD-associated phenotypes are also not fully understood. The fact that twin and family studies consistently demonstrate high concordance rates and a heritability ranging from 40 to $90 \%$ provides convincing evidence for a large genetic contribution to ASD [9-11]. In fact, ASD ranks amongst the most heritable medical diagnoses [1]. Fittingly, the number of genes and genomic regions, which are associated with ASD is estimated to be in the hundreds [12-15]. The size of these genetic changes ranges from a single nucleotide to DNA-segments stretching up to millions of bases known as copy number variations (CNV) [12, 13, 16-18]. It has been estimated that
$10-20 \%$ of ASD patients are affected by rare point mutations or CNVs, most of them de novo $[14,16,19]$.

ASD risk genes are often involved in many functional processes that unfold spatiotemporally across development and various brain regions. Despite the obvious challenges of disentangling the underlying dynamics of such multifunctional genes that might also be sexdependent, converging pathways have been identified. Proteins encoded by ASD risk genes are mostly involved in processes related to fetal brain development, chromatin modification, and regulation of gene expression in general, as well as the structural and functional integrity of synapses. [15, 16, 19-26]. Among others SHANK1-3 and genes from the $N L G N$ - and $N R X N$-family encode synaptic proteins that are crucial for the development or functioning of brain circuits, which contribute to ASD etiology [27-29]. Disruption of ASD-associated genes like NLGN1 [30], NLGN2 [31, 32], NLGN3 [33-37], NLGN4X [38, 39], NRXN1 [40-42], or NRXN2 [43, 44], but also CACNA1C [45], CNTNAP2 [46], and GABRB3 [47], is often exploited to replicate ASD phenotypes in animal models. Additionally, several studies have identified glutamatergic neurons during cortical development [48, 49] and the striatum [50] as points of convergence for ASD.

Apart from genetic etiology, environmental factors have been associated with an increased risk of ASD, including hypoxic birth trauma, advanced parental age, maternal obesity, gestational diabetes mellitus, zinc deficiency, and valproate intake during pregnancy [51-54].

\section{SHANK gene family}

SHANKs (SHANK1-3), which are also known as prolinerich synapse-associated proteins (ProSAPs), were initially described as proteins that primarily localize to the postsynaptic density (PSD) of excitatory synapses [5559], which is an electron dense thickening underneath the postsynaptic membrane of glutamatergic synapses. It comprises a great multitude of proteins, which form a wide macromolecular complex that is illustrated in Fig. 1. Among these proteins are other scaffolding and adaptor proteins (e.g., DLGAP1, SHANKs), receptors, channels, and signaling molecules (e.g., NMDAR, AMPAR, GRM, CAMK2), but also cell adhesion proteins like NLGNs or constituents of the cytoskeleton (e.g., actin) [60, 61].

As so-called master scaffolding proteins, which are expressed in the central nervous system (CNS) and peripheral nervous system (PNS, somatic and autonomic), SHANKs interact with and thus arrange intermediate scaffolding proteins at the PSD, which profoundly influences synaptic development and function [55-68]. A quaternary complex in the PSD built from DLG4 (also known as PSD95), DLGAP1 (also known as SAPAP1 or GKAP), SHANK, and HOMER proteins connects metabotropic and ionotropic NMDA type glutamate 


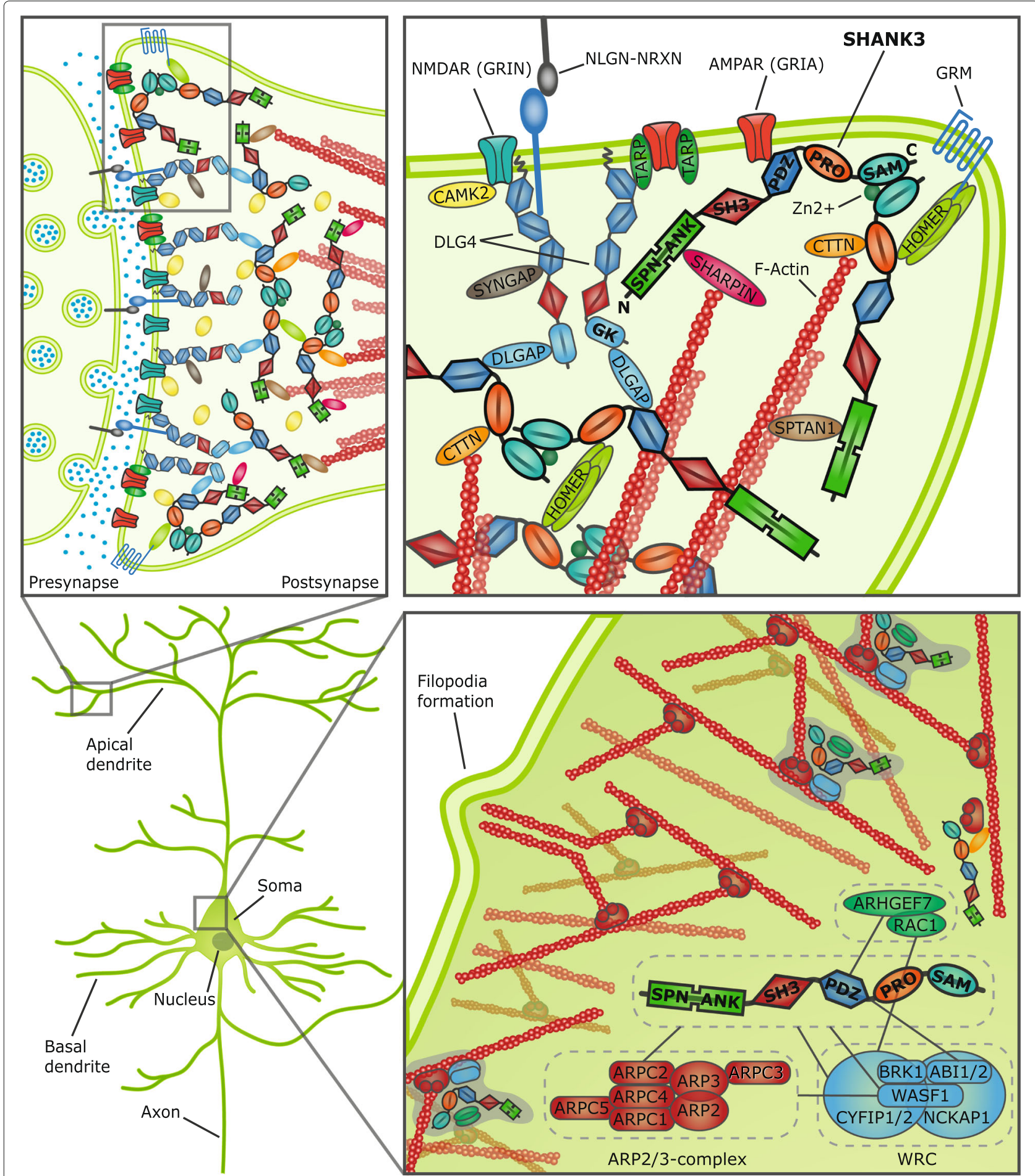

Fig. 1 Macromolecular complexes within the interactome of SHANK3. The multiple layers of the functional units in the central nervous system are shown in succession. In the left lower corner a hippocampal pyramidal neuron is depicted. At the top an overview of a synaptic contact and a detailed illustration of the multiple connections between the different interaction domains of SHANK3 and other synaptic proteins is shown. On the right, putative macromolecular assemblies associated to cellular actin nucleation, which include SHANK3, are shown in the soma. SHANK3 localizes to the postsynaptic density (PSD). The PSD is an electron dense thickening underneath the postsynaptic membrane of glutamatergic synapses. It comprises a great multitude of proteins, which form a wide macromolecular complex. Interaction between SHANK3 and other proteins is mediated by six protein domains, which are depicted by form and color in this image: The SPN-, ANK-, SH3-, PDZ-, PRO-, and SAM-domain. A subset of SHANK3-interacting proteins is illustrated here. DLG4 (or PSD95) is also depicted by its functional domains (PDZ, SH3, GK) to emphasize that different proteins can contribute similar domains to the structural composition of the PSD. Membrane-associated guanylate (Continued on next page) 
Fig. 1 (Continued from previous page) kinases (MAGUKs) such as DLG4 also serve as major organizers of synapses, by forming a modular interface between the multiple layers of the PSD. For instance, DLG4, DLGAP, SHANK3 and HOMER connect GRM and NMDAR complexes. An additional connection of this complex to the cytoskeleton is mediated by SHANK3's interaction with CTTN, SHARPIN, SPTAN1, and other proteins. Depending on its configuration, the SPN-domain prevents the binding of SPTAN1 to the ANK-domain. The ARP2/3-complex is crucial for actin nucleation and polymerization. By its interaction with the WAVE regulatory complex (WRC), components of the RAC1-pathway, and ARPC2 itself, SHANK3 might mediate their influence on actin dynamics. PSD: Postsynaptic density, SHANK: SH3 and multiple ankyrin repeat domains, SPN:

SHANK/ProSAP/N-terminal, SH3: Src homology 3, PDZ: PSD95/DlgA/Zo-1, PRO: Proline-rich, SAM: Sterile alpha motif, ANK: Ankyrin repeats

receptor complexes, which might facilitate their interaction [55-57, 59, 64, 65, 67]. Notably, a rather stable pool of SHANK proteins lies closer to the postsynaptic membrane, while another dynamic pool resides more proximally. The stable but not the dynamic pool seems to be able to bind to DLGAP1 [69].

Through dynamic changes of their molecular composition and chemical modification of synaptic proteins, neuronal synapses are regulated during development and throughout life, altering their shape, quantity, and overall strength $[63,70]$. SHANK proteins are crucial in many of these and associated processes. Thus, it is not surprising that mutations leading to dysfunctional synaptic proteins, including SHANKs, result in synaptic and circuitry defects [71]. Accordingly, SHANK gene mutations are generally associated with human neuropsychiatric and neurodevelopmental disorders. Defects in SHANK genes, but especially $S H A N K 3$, can be causative for idiopathic ASD and ASD-associated syndromes such as the PMDS, but also schizophrenia and intellectual disability [27, 28, 72-77].

\section{SHANK3}

The SHANK3 (human) or Shank3 (rodents) gene is located on chromosome 15E3 in mice, on 7q34 in rats, and on 22q13.3 in humans. Shank3 is subject to alternative usage of its 6 promotors and additional mRNA splicing $[78,79]$, resulting in multiple mRNA transcripts and enabling the generation of a great variety of protein isoforms. These findings have led to the prediction of isoform transcripts named Shank3a-f, of which Shank3a and e are enriched in the striatum, Shank3c and d are predominantly expressed in the cerebellum, and Shank3b is evenly expressed at very low levels across the brain [79]. Accordingly, western blot analysis has shown an array of different proteins detected by SHANK3 antibodies also depending on their epitopes [80]. However, studies on SHANK3 isoforms have largely focused on mRNA transcripts. Thus, it remains to be clarified how exactly the various transcripts translate into proteins. Nevertheless, this multitude of isoforms enables differential expression patterns across the stages of brain development, brain regions, cell types, and even subcellular structures [79, 81-83], suggesting isoform-specific functions. For example, SHANK3b, which lacks the PRO- and SAMdomain, exhibits nuclear localization, whereas SHANK3a, SHANK3c, and SHANK3e that contain those domains form cytoplasmic clusters [79]. SHANK3a and SHANK3c seem to be the isoforms that primarily localize to excitatory synapses [79]. With recent advances in the prediction of protein structures in silico, it might be possible to determine how the predicted isoforms of SHANK3 differ on a three-dimensional level [84-86].

Tissue-specific expression of these different isoforms is also regulated by epigenetic mechanisms [81, 87, 88] Notably, DNA methylation within the SHANK3 gene and isoform expression was altered in human brain tissue of ASD patients [89].

Shank3 mRNA expression is high in the heart and moderate in the brain and spleen [66]. In the nervous system, Shank3 mRNA is enriched in the cortex (especially layers 2-4), hippocampus, amygdala, cerebellum (granule cells), striatum, thalamus, spinal cord, and dorsal root ganglia [82, 90-92]. As opposed to the other SHANKs, SHANK3 is highly enriched at cortico-striatal glutamatergic synapses [90].

The interactome of SHANK3 covers a wide variety of proteins, which are involved in many cellular processes $[93,94]$. Aside from interactors, which represent a common core interactome involved in scaffolding, processes of the PSD in general, or regulation of the actin cytoskeleton, the majority of interacting proteins varies depending on the brain region. This might enable the functional diversity of SHANK3. Common interactors include the HOMER and DLGAP family, but also actin-associated proteins. Interactors, which are related to the cytoskeleton include subunits of the ARP2/3-complex as major mediator of actin nucleation and constituents of the associated WAVE regulatory complex, such as ABI1, WASF1, and CYFIP2 [93-96]. Interestingly, these common interaction profiles also seem to encompass proteins related to myelin- and mitochondrion-associated processes [96]. Other exemplary categories, which fit the brain-regiondependent SHANK3 interactome, include GTP binding, gluconeogenesis, cell-cell adhesion, or endocytosis [93, 96]. Apart from unbiased proteomic approaches to characterize the interactome of SHANK3, single proteins have been identified, which directly bind to SHANK3. Among 
these are proteins, which are crucial for dendritic spine formation, synaptic transmission and plasticity, cytoskeleton regulation, and the localization of SHANK3 to the PSD [56, 58, 59, 65, 94, 97-103].

The abovementioned highly complex protein-protein interactions of SHANK3 are mediated by its domains. The longest isoform of SHANK3 in mice comprises six highly conserved domains: SHANK/ProSAP/N-terminal (SPN), ankyrin repeats (ANK), Src homology 3 (SH3), PSD95/DlgA/Zo-1 (PDZ), proline-rich (PRO), and sterile alpha motif (SAM). For instance, the ANK-domain binds to SHARPIN [98], SPTAN1 (also known as $\alpha$-fodrin) [99], and CTNND2 [104], while the PDZ-domain interacts with DLGAP1 (which binds to DLG4) [59], GRIA1 (also known as GluA1 or GluR1 subunit of ionotropic AMPA type glutamate receptors) [100], and CTNNB1 as crucial constituent of the Wnt signaling pathway [105]. A SPN-domain at the $\mathrm{N}$-terminus binds to the ANKdomain and limits its ability to interact with SHARPIN or SPTAN1 [97]. The PRO-region encompasses the binding motifs for HOMER $[65,101]$ and CTTN [59]. SHANK3's ability to self-multimerize in a zinc-dependent manner depends on the SAM-domain $[59,102]$. Synaptic targeting of SHANK3 is mediated by a conserved C-terminal region that includes the SAM-domain [58], while several nuclear localization signals are responsible for its translocation to the nucleus [105].

Among the remaining interaction partners of SHANK3 are kinases like MAPK1 (also known as ERK2), PRKACA, GSK3B, CSNK2, or RPS6KA2/3 [106, 107]. Notably, murine SHANK3 is phosphorylated by MAPK1 at 18 residues, 3 of which have also been observed in vivo and shown to increase SHANK3 turnover and degradation if phosphorylated. Accordingly, activation of constituents belonging to the MAPK/ERK-pathway, like IGF1R, KIT, PKA, RAF1, MAP2K1, or MAPK1, lead to destabilization of SHANK3. Other proteins like TRIO, TAF1, and SIK1 were shown to stabilize SHANK3 [106]. In addition phosphorylation of a serine at position 685 by PKA facilitates the interaction of SHANK3 with ABI1 [94], while interaction with CTTN is prevented by RPS6KA3-mediated phosphorylation [107].

Generally, it has been shown that SHANK-proteins undergo degradation upon activity-dependent ubiquitination [108], which is influenced by DLGAP1 [109] and regulates their abundance at the synapse.

Aside from its role in postsynapses, SHANK3 also localizes to presynaptic specializations in hippocampal neurons [110], afferent nerve terminals in the spinal cord and peripheral terminals of the skin [92], the neuromuscular junction and the Z-disc of skeletal muscle tissue, where it binds to ACTN2 [111]. Additionally, SHANK3 translocates from synapses to the nucleus in an activitydependent manner [112] and mediates Ca-dependent signaling to the nucleus via interaction with CAMK2A and L-type calcium channels [113]. Recently, it has also been observed that SHANK3 is involved in TRPV1mediated pain processing in the dorsal root ganglia and spinal cord [92].

\section{SHANK-associated ASD and Phelan McDermid syndrome (PMDS)}

A connection between SHANK-mutations and ASD has been established in several human genetic studies [27, 28, $72-74,76,77]$ and was further validated in animal models targeting Shank1 [114-117], Shank2 [118-121], or Shank3 [78, 80, 82, 83, 90, 92, 94, 118, 122-140]. Behavioral phenotypes, like increased repetitive routines, abnormal social behavior, elevated anxiety levels, impaired neuronal physiology, and altered PSD levels of HOMER, DLGAPs, NMDARs, AMPARs and other proteins, typify SHANK3-deficient murine animal models [78, 83, 90, 94, 118, 122, 124-128, 130, 132]. These resemble some neuropsychiatric disorders in humans. It was estimated in a meta-analysis that approximately $1 \%$ of all ASD-cases are accounted for by truncating mutations in the SHANK gene family [73]. This is a surprisingly high percentage, considering the etiological diversity of ASD. Notably, no truncating SHANK1/2/3-mutations, but mutations, which were predicted to be damaging (PolyPhen-2) were found in $4.7 \%$ of the healthy controls [73]. Additionally, SHANK3 mutations have been observed in both asymptomatic parents and their ASD-diagnosed children [28]. Thus, such non-truncating SHANK mutations might not be causative for ASD by themselves, but rather contribute to its development in a susceptible genetic and environmental setting.

The PMDS was the first heterozygous neurodevelopmental disorder associated with SHANK mutation [27]. Genetically PMDS is caused by a 22q13.3 deletion and clinically presents with hypotonia, impaired language skills, ASD, and various other symptoms [27, 141, 142]. Apart from classical deletions, the PMDS can be caused by ring chromosomes and unbalanced translocations, but also by SHANK3 point mutations [73, 143-145]. In nearly all PMDS patients, SHANK3 is affected, and it is assumed that SHANK3 haploinsufficiency is the major causative factor of their neurodevelopmental and behavioral deficits, although deletions that do not include SHANK3 also result in certain subphenotypes of PMDS [142, 146-149]. Genetic screening of patients with ASD, which was not due to a heterozygous loss of the gene, also found SHANK3 mutations [28, 73, 74, 76, 150]. Many SHANK3 mutations in humans affect exon 21 and are associated with intellectual disability [73]. Although SHANK1 and SHANK2 mutations are also associated with ASD [73, 77], cognitive deficits are more severe in patients with SHANK3 mutations [73]. Clinical screen- 
ing for SHANK mutations might thus be reasonable, since they represent a potential monogenic and syndromic etiology of ASD [73].

\section{Main text \\ Phenotypes and pathophysiology in animal models of SHANK3 deficiency}

Various strategies targeting Shank3 to mimick pathologies that are observed in PMDS patients have been applied in rodent and non-human primate models. These include the constitutive knockout (KO) models of Shank3 that affect different exons and thus also a different number its six promotors. These KO strategies result in isoformspecific deletion patterns, leaving some isoforms intact, which might even lead to their compensatory overexpression $[125,151]$. Conditional KO-models (cKO) have been used to study the effects of promotor-driven cell-typespecific SHANK3 deficiency, which has connected certain neuron populations or brain regions to subphenotypes of mutant animals. Alternatively, mutations that have previously been associated to ASD in human patients are studied using knock in (KI) strategies. A conditional KI (cKI) model has also been used to reexpress SHANK3 at later stages of development. In this review, all models, which are covered, were assigned a code. The nomenclature used for this code was defined according to the abovementioned strategies of genetic intervention and consists of two parts, which are separated by a vertical bar. The first part of the nomenclature depicts the targeted exons of Shank3, and the second represents the affected domain and an associated mutation or a promotor-driven Cre-expression, if present.

An alternative nomenclature would additionally refer to the remaining SHANK3 protein isoforms, since whole exon deletions or point mutations affecting similar regions were reported to result in markedly different isoform compositions. For example, in ex21|PRO mice, the absence of major high-molecular isoforms, increased lowmolecular isoforms, and the appearance of a new lowmolecular band were observed [125]. Models mimicking point mutations within the same exon presented with different isoform patterns. Mice of the model ex21|PROInsG3680 showed an almost complete loss of SHANK3 [127], whereas ex21|PRO-InsG3728 introducing the same mutation described in human patients [28] and a Neostop cassette resulted in the loss of major high-molecular isoforms, increased low-molecular isoforms, and the appearance of a new low-molecular band [126], comparable to ex21|PRO-mice. ex21|PRO-R1117X resulted in the loss of major isoforms and the expression of a predicted truncated high-molecular protein [127]. Notably, some missense point mutations, as established in the model ex17|PRM-S685I, do not alter the isoform pattern [94]. An isoform-based nomenclature would be in need of a standardized report on isoform composition across all models investigated, also using antibodies targeting different regions of the protein to cover all of its putative isoforms. This information is currently not available for all models covered in this review. Although it is not feasible to generate a detailed and consistent nomenclature based on protein-isoforms of SHANK3, the models which were summarized under the same term in the nomenclature described above, generally present with similar isoform patterns.

It is important to note that many behavioral studies aim to correlate aberrant behavioral patterns in mutant mice or other model organisms with symptoms in human patients. The interpretation of such behaviors is at least to some extent subjective and sometimes even questionable. Nevertheless, behavioral abnormalities in the animal models covered in this review are categorized according to symptoms and comorbidities, which are frequently observed in ASD or the PMDS. This serves to establish a common ground, which enables comparability between the different animal models and human behavior. Due to the abovementioned subjectiveness, the reader is encouraged to treat those interpretations with caution as one could also argue that rodent behavior should not be humanized.

\section{Behavioral traits}

Social behavior Among other symptoms, ASD is defined by an impairment of social interacion, which often manifests as difficulties in the approach to social situations, reciprocal social interaction, and verbal but also nonverbal communication. Although PMDS patients often meet the criteria of ASD and display severe impairments of language and communication [152], neural responses to communicative vocal sounds and orienting to social stimuli were less affected in PMDS patients when compared to patients with idiopathic ASD [153]. These differential findings and the fact that an ASD diagnosis is not present in all PMDS patients suggest that SHANK3-deficient animals should not necessarily present with profound social behavioral deficits. Accordingly, such deficits have been reported, however with variability, in SHANK3-deficient animals. Rodent social behavior is highly influenced by experimental conditions and handling. Slight differences in protocols of the most commonly used test, the threechambered social approach test could also be explanatory for the differences observed between cohorts of animals with identical or similar alterations of the Shank3 gene.

Here, social behavior was categorized in three subdomains: social motivation/interaction, social recognition, and social communication. For instance, the frequently measured social preference in three-chamber tests or free interaction in social dyads were included in social motivation/interaction, while social novelty preference tasks 
were categorized as tests of social recognition. Analysis of socially induced ultrasonic vocalizations or social olfactory preference tasks in rodents were regarded as tests of social communication.

Abnormal behavioral patterns concerning social motivation or interaction have been consistently observed in the murine models ex4-22|ALL [128, 130], ex4-9|ANK [78, 80, 124, 154-156], ex11|SH3 [123, 157], ex1316|PDZ [83, 90, 155, 158-166], and ex14-16|PDZ [131], although deficits were not recapitulated for some of these models in single studies [129, 167, 168]. Other modeling strategies mimicking mutations affecting the PRO-domain or a proline-rich motif (PRM) associated to ABI1, which have been found in ASD-patients, such as ex21|PRO-InsG3680 [127] or ex17|PRM-S685I [94], and ex21|PRO-R1117X [127], harboring a schizophreniaassociated mutation, also resulted in abnormal social interaction behavior. Notably, conditional $\mathrm{KO}$ in ex1316|PDZ-Advillin ${ }^{C r e}$ targeting somatosensory neurons or ex13-16|PDZ-Cdx2 ${ }^{\text {Cre }}$ targeting the caudal part of the embryo and neural tube, thus sparing the brain, was sufficient to induce aberrant social motivation and interaction [140]. Similarly, SHANK3-deletion in dorsal telencephalic excitatory neurons and glia (ex14-16|PDZ-Emx1 ${ }^{\mathrm{Cre}}$ ) [133] or all GABAergic neurons (ex14-16|PDZ-Viaat ${ }^{\mathrm{Cre}}$ ) [131] resulted in such deficits. Cre-expression, and thus deletion of Shank3 in neocortical excitatory neurons (ex422|ALL-NEX $\left.{ }^{\mathrm{Cre}}\right)$, Dlx5/6-positive GABAergic forebrain neurons (ex4-22|ALL-Dlx5/6 ${ }^{\mathrm{Cre}}$ ), which include various subclasses of neocortical interneurons but also MSNs as principal striatal projection neurons [169-174], DRD1(ex4-22|ALL-Drd1 ${ }^{\mathrm{Cre}}$ ) and DRD2-positive neurons (ex422|ALL-Drd2 ${ }^{\mathrm{Cre}}$ ) [129], did not induce the phenotype previously observed in the constitutive KO model [128], though it has to be noted that such deficits of constitutive $\mathrm{KO}$ mice were also not replicated in this study. Mixed evidence and even conflicting results concerning social interaction deficits were observed in the models ex9|ANK [82, 175], ex13|PDZ [139, 176], ex21|PRO [125, 177-179], and the rat model ex6|ANK [134, 180]. Intact social motivation and interaction was described in the analysis of the models ex4-7|ANK [90], ex8|ANK-Q321R [132], ex21|PRO-InsG3728 [126], and ex11-21|SH3-PRO in rats [135].

Another dimension of social behavior is the recognition of previously encountered conspecifics, which can also be deficient if basal social interaction behavior seems to be unaffected.

Such deficits of social recognition were observed in the animals of ex4-22|ALL [128], ex4-7|ANK [90], ex11|SH3 [123], ex13|PDZ [139, 176], ex21|PRO [125, 178, 179], and the rat models ex6|ANK [134] or ex11-21|SH3-PRO [135]. A single study on the model ex21|PRO did not replicate the abovementioned deficits [177]. ASD- or schizophrenia-associated mutations in the murine models ex21|PRO-InsG3680 and ex21|PRO-R1117X [127] elicited deficitary social recognition as well. In conditional KO-models targeting somatosensory neurons in ex13-16|PDZ-Advillin ${ }^{\text {Cre }}$ or the caudal embryo, including the neural tube in ex13-16|PDZ-Cdx2 ${ }^{\mathrm{Cre}}$ abnormal social recognition was recapitulated [140]. Mixed evidence concerning the ability to recognize familiar conspecifics was observed in the model ex13-16|PDZ [90, 155, 161, 164, $166,168]$, where some studies found aberrant social recognition, while it seemed to be intact in others. No deficits of social recognition were found in the murine models ex4-9|ANK [78, 80, 167], ex9|ANK [82, 175], ex1416|PDZ [131], and ex21|PRO-InsG3728 [126]. Similarly, specific deletion of SHANK3 in dorsal telencephalic excitatory neurons and glia (ex14-16|PDZ-Emx1 $\left.{ }^{\mathrm{Cre}}\right)$ [133], or GABAergic neurons (ex14-16|PDZ-Viaat ${ }^{\mathrm{Cre}}$ ) [131] did not cause dysfunctional social recognition.

The communication of rodents in social contexts is a complex and multidimensional behavior, which is most frequently studied via recordings of ultrasonic vocalizations during social interaction, but can also be analyzed using other modalities.

Abnormalities concerning social communication behaviors were consistently observed in mice of the models ex4-22|ALL [128, 129], ex4-9|ANK [78, 80, 124, 155], ex13-16|PDZ [155, 158, 159, 163], ex14-16|PDZ [131], and ex17|PRM-S685I [94], although single studies did not observe differences compared to wildtype animals $[130,162]$. Findings were not consistent in two studies focusing on the rat model ex6|ANK $[134,180]$. The models ex9|ANK [82], ex21|PRO [125], and ex11-21|SH3PRO in rats [135] showed social communication skills, which were undistinguishable from wildtype animals. Mice from the models ex8|ANK-Q321R [132], ex21|PROInsG3680 [127], and ex21|PRO-R1117X [127] harboring mutations associated to neuropsychiatric disorder also showed normal social communication in the modalities, which were investigated. Conditional $\mathrm{KO}$ in the model ex14-16|PDZ-Viaat ${ }^{\text {Cre }}$ targeting all GABAergic neurons [131] replicated these deficits, whereas SHANK3 deletion in dorsal telencephalic excitatory neurons and glia, neocortical excitatory neurons, GABAergic forebrain neurons, or DRD1-/DRD2-positive neurons as established in the models ex14-16|PDZ-Emx1 ${ }^{\text {Cre }}$ [133], ex4-22|ALL$\mathrm{NEX}{ }^{\mathrm{Cre}},-\mathrm{Dlx} 5 / 6^{\mathrm{Cre}},-\mathrm{Drd} 1^{\mathrm{Cre}}$, or -Drd2 ${ }^{\mathrm{Cre}}$ [129] did not cause aberrant social communication.

Stereotypies The second set of core symptoms, by which ASD is defined, includes repetitive behaviors with restricted interests and perseveration [2], which are often summarized under the term stereotypy. Such stereotypies can be regarded as the most robust phenotype in many models of SHANK3 deficiency. Excessive grooming with 
or without development of skin lesions is a commonly observed repetitive behavior in SHANK3-mutant rodents.

Increased self grooming and other repetitive behaviors have been consistently reported in the models ex422|ALL [128-130], ex11|SH3 [123], ex13|PDZ [139, 176], ex13-16|PDZ [83, 90, 155, 159, 160, 162-164, 166, 168, 181-183], ex14-16|PDZ [131], ex21|PRO [125, 178, 179], and ex11-21|SH3-PRO in rats [135]. Interestingly, in murine models ex21|PRO-InsG3680 [127] and ex8|ANKQ321R [132], which mimick ASD-associated mutations, increased repetitive behavior was observed, whereas this was not the case in ex21|PRO-R1117X [127] mice, which harbor a schizophrenia-associated mutation. Additionally, cell-specific KO of SHANK3 in neocortical excitatory neurons, dorsal telencephalic excitatory neurons and glia, all or forebrain GABAergic neurons, and DRD2-positive neurons (ex14-16|PDZ-Emx1 Cre, -Viaat ${ }^{\mathrm{Cre}}$ [131, 133], ex4-22|ALL-NEX ${ }^{\mathrm{Cre}},-\mathrm{Dlx} 5 / 6^{\mathrm{Cre}},-\mathrm{Drd} 2^{\mathrm{Cre}}$ [129]), but not in DRD1-positive neurons (ex4-22|ALL-Drd1 Cre [129]) was sufficient to induce repetitive behavior. Repetitive behavior was also described in mice of the model ex4-9|ANK, but findings were inconsistent across multiple studies [78, 80, 124, 155, 167]. Animals of the models ex9|ANK [82], ex17|PRM-S685I [94], ex21|PROInsG3728 [126], ex13-16|PDZ-Advillin Cre [140], ex13$16 \mid \mathrm{PDZ}-\mathrm{Cdx} 2^{\mathrm{Cre}}$, or ex6|ANK in rats [134] did not display abnormal repetitive behaviors.

Perseveratory behavior can be observed in tests that demand the reversal of a previously acquired behavior such as in the various maze tasks, primarily targeting cognitive abilities.

The models ex4-22|ALL $[128,130]$, ex11|SH3 [123], and ex21|PRO [125] show perseveration in the reversal part of these tasks, while the models ex13-16|PDZ [90, 155] and ex9|ANK [82] showed normal cognitive flexibility. Mixed evidence was reported in mice of the model ex4-9|ANK [78, 80, 124, 155, 167].

Lastly, restricted interests can be investigated in rodents by analyzing their reinvestigatory behavior or preference for certain objects, for instance in the hole board task or repetitive novel object task. However, such analysis has not been performed very frequently [78, 128-130].

Restricted investigatory behavior has been observed in the murine models ex4-22|ALL [128] and ex49|ANK [78]. Additionally, cell-specific SHANK3-KO in GABAergic neurons of the forebrain as established in mice of the model ex4-22|ALL-Dlx $5 / 6^{\text {Cre }}$ was sufficient to induce this phenotype, whereas targeting neocortical excitatory neurons, DRD1-, or DRD2-positive neurons (ex4-22|ALL-NEX ${ }^{\mathrm{Cre}}$, -Drd1 ${ }^{\mathrm{Cre}}$, -Drd2 $\left.{ }^{\mathrm{Cre}}\right)$ was not [129].

Additional behavioral phenotypes ASD is frequently accompanied by additional behavioral phenotypes and comorbidities. Among these features are anxiety and hyperactivity [152, 184]. Avoidance behavior as observed in pathological demand avoidance (PDA) has also been proposed to be a subtype or symptom of ASD, while it was originally described as independent disorder [185]. A "comorbid" PDA has also been described in a patient harboring a frameshift variant within SHANK3 [186].

In fact, one of the strongest phenotypes in SHANK3deficient mice is an active avoidance behavior, which can be observed for instance in the marble burying test and novelty preference tasks, making it difficult to interpret those tests concerning their original targets. Such avoidance of inanimate objects could also influence the preferences observed in three-chambered tasks testing for sociability, where such objects are often placed in the "non-social" chamber.

Avoidance to novelty or inanimate objects was strong in two strains of the model ex4-22|ALL $[128,130]$, which also showed increased escape attempts, but was also consistently described in mice haboring other deletions or mutations such as ex9|ANK [82], ex11|SH3 [123], ex13-16|PDZ [155, 160, 163, 166], ex21|PRO [125, 178], and ex21|PRO-InsG3728 [126, 187]. It was also observed that targeted $\mathrm{KO}$ in somatosensory neurons or cells of the caudal embryo in mice of the strains ex13-16|PDZAdvillin ${ }^{\mathrm{Cre}}$ or - $\mathrm{Cdx} 2{ }^{\mathrm{Cre}}$ induced such avoidance behavior [140]. Findings were inconsistent in the murine model ex13|PDZ [139, 176]. Avoidance behavior was absent in ex4-9|ANK [80, 124, 155, 167] or ex17|PRM-S685I [94] mice.

Anxiety-like behavior in rodents is often analyzed in paradigms like the elevated plus maze and dark-light emergence task or by thigmotaxis and rearing frequency in the open field. Increased anxiety has been observed in various, but not all murine models of SHANK3 deficiency.

High levels of anxiety were reported in models with the deletions ex4-22|ALL [128-130], ex13-16|PDZ [83, $90,155,159,160,163,164,168,183,188,189]$, ex11-21|SH3-PRO in rats [135], and in mice with schizophrenia- or ASD-associated mutations (ex21|PROR1117X, -InsG3680 [127] or -InsG3728 [126]), while only slight differences were observed in the models ex13|PDZ $[139,176]$ and ex14-16|PDZ [131]. Elevated anxiety levels were also replicated in conditional KO-strategies, inducing SHANK3 deficiency in somatosensory neurons or cells derived from the caudal embryo (ex13-16|PDZAdvillin ${ }^{\mathrm{Cre}}$ or $-\mathrm{Cdx} 2^{\mathrm{Cre}}$ [140]), but also in GABAergic (ex14-16|PDZ-ViaatCre [131]) or DRD1-positive neurons (ex4-22|ALL-Drd1 ${ }^{\text {Cre }}$ [129]). A minor anxious phenotype was observed in mice in which GABAergic neurons were targeted specifically in the forebrain (ex4-22|ALLDlx5/6 $\left.6^{\text {Cre }}[129]\right)$. Findings concerning anxiety-like behavior were not consistent in the models ex4-9|ANK [78, $80,124,155,167]$ and ex21|PRO $[125,178]$, whereas no 
such behavior was reported for animals of the strains ex47|ANK [90], ex9|ANK [82], ex11|SH3 [123], ex6|ANK rats [134, 180], ex8|ANK-Q321R [132], ex17|PRM-S685I [94], ex14-16|PDZ-Emx1 ${ }^{\text {Cre }}$ [133], and ex4-22|ALL-NEX ${ }^{\text {Cre }}$ or -Drd2 ${ }^{\text {Cre }}[129]$.

Increased aggression was described in mice of the model ex11|SH3 [123].

Lastly, an altered circadian rhythm was reported in the murine model ex4-9|ANK [190], but not in ex11|SH3 [157] or ex13-16|PDZ [189].

\section{Neurological phenotypes}

Motor function PMDS patients typically present with variable motor anomalies that persist beyond childhood, especially early-onset hypotonia with a resulting gait disorder, and impaired motor coordination [142, 152]. Accordingly, SHANK3 deficiency in rodents has commonly led to motor dysfunction across various domains, detected as abnormal sensorimotor or neuromuscular function, impaired motor learning, and altered general activity in rodents.

Sensorimotor function is often assessed in tasks such as the rotarod, which primarily targets coordination, by motor reflexes induced through sensory stimuli such as the righting reflex and geotaxis, and by gait analysis. Abnormalities concerning tasks depending on sensorimotor function have been described in SHANK3deficient rodents of the deletion models ex4-22|ALL $[128,130]$, ex4-9|ANK $[78,124,155,167]$, ex11|SH3 [123], and ex13-16|PDZ [83, 155, 159, 183], or mice harboring schizophrenia- and ASD-associated mutations (ex21|PRO-R1117X, -InsG3680 [127] or -InsG3728 $[126,187])$. Notably, single studies did not observe differences between wildtype and mutant mice of some of these strains $[80,90,166]$. Mixed evidence concerning sensorimotor dysfunction has been reported in the murine models ex13|PDZ $[139,176]$ and ex21|PRO $[125,178,179]$. No deficits were described in SHANK3deficient rats (ex6|ANK [134], ex11-21|SH3-PRO [135]), in mice harbouring an ASD-associated mutation localized in a phosphorylation site relevant to the binding of ABI1 (ex17|PRM-S685I [94]), and if SHANK3 was specifically deleted in excitatory neocortical neurons, GABAergic neurons of the forebrain or DRD1-/DRD2positive cells (ex4-22|ALL-NEX ${ }^{\mathrm{Cre}}$, -Dlx5/6 ${ }^{\mathrm{Cre}},-\mathrm{Drd} 1^{\mathrm{Cre}}$, -Drd2 $\left.{ }^{\mathrm{Cre}}[129]\right)$.

Often sensorimotor testing in the accelerating rotarod is combined with an analysis of motor learning capability, which should result in an increasing score across multiple trials. Impaired motor learning was found in the deletion model targeting all isoforms of SHANK3 (ex4-22|ALL [130]), or in models mimicking mutations within exon 21 associated to neuropsychatric disorder (ex21|PRO-InsG3680, -R1117X, -InsG3728 [126, 127, 187]). In addition targeting neocortical excitatory neurons (ex4-22|ALL-NEX ${ }^{\mathrm{Cre}}$ ) was sufficient to induce deficitary motor learning, while SHANK3 deficiency in GABAergic neurons of the forebrain, DRD1- or DRD2-positive neurons (ex4-22|ALL-Dlx5/6 ${ }^{\mathrm{Cre}}$, -Drd1 ${ }^{\mathrm{Cre}}$, -Drd2 ${ }^{\mathrm{Cre}}$ ) was not [129]. Divergent results across multiple studies were reported for the models ex4-9|ANK [78, 80, 124, 167] and ex13-16|PDZ [83, 90, 166, 183]. Motor learning skills were not affected in the murine models ex11|SH3 [123], ex13|PDZ [176], ex21|PRO [125, 178], and ex17|PRMS685I [94].

Neuromuscular function has not been assessed frequently in SHANK3-deficient animals, but can be analyzed via simple methods utilizing a grip strength meter or in a hanging wire task. Interestingly, the only model in which consistent neuromuscular impairments were reported targets exon 11 for deletion (ex11|SH3), implying specific functions of $\mathrm{SH} 3$-domain containing isoforms in the skeletal muscle $[111,123]$. However, neuromuscular dysfunction has also been reported in the deletion models ex4-22|ALL [130] and ex4-9|ANK [78], albeit inconsistently $[124,128,167]$. Intact neuromuscular function was reported in SHANK3-deficient rats of the model ex1121|SH3-PRO [135].

Decreased locomotion in the open field is the most frequently used parameter to analyze the general motor activity of rodents. Hypoactivity has been observed quite frequently and consistently in various models of SHANK3 deficiency including the deletion models ex4-22|ALL [128-130], ex11|SH3 [157], ex13-16|PDZ [83, 155, 159_ 163, 168, 182, 183, 188, 189], ex13|PDZ [139, 176], ex1416|PDZ [131], and ex21|PRO [125, 178, 191], as well as in models mimicking point mutations associated to ASD or schizophrenia (ex21|PRO-InsG3728, -InsG3680, -R1117X [126, 127, 187]). Decreased motor activity was reproduced by targeting all GABAergic neurons (ex14-16|PDZ-Viaat ${ }^{\text {Cre }}$ [131]), GABAergic forebrain neurons, DRD1-positive neurons (ex4-22|ALL-Dlx5/6 ${ }^{\mathrm{Cre}}$ or $\operatorname{Drd} 1^{\mathrm{Cre}}$ [129]), or somatosensory neurons in homozygous

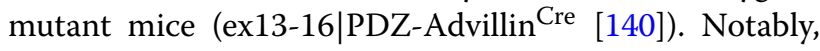
an increased locomotion was reported in ex4-22|ALLNEX ${ }^{C r e}$ or -Drd2 ${ }^{C r e}$ [129], suggesting opposing roles of SHANK3 in different types of neurons or divergent compensatory mechanisms depending on the affected circuitry. But this hypoactive phenotype was not always reported [90], even showing divergent results in the models ex4-9|ANK [78, 80, 124, 155, 167] and ex9|ANK $[82,175]$. Other models with similar or different strategies to target the Shank3-gene, such as ex4-7|ANK [90], ex8|ANK-Q321R [132], ex17|PRM-S685I [94], ex13- 
16|PDZ-Cdx2 Cre [140], ex14-16|PDZ-Emx1 Cre [133], or ex6|ANK $[134,180]$ and ex11-21|SH3-PRO in rats [135], did not show altered motor activity .

Sensory function Hypersensitivity, hyposensitivity, or unusual interest in sensory stimuli is a common feature of ASD [3] and also PMDS patients, who often display an increased pain tolerance [152]. Thus, it is not surprising that abnormal sensory function has also been described in SHANK3-deficient rodents.

Sensory function can be analyzed in various modalities. The most frequently used paradigms focus on nociception or somatosensory function in general, which can be assessed via simple methods such as the tail flick test, certain reflexes, the Frey test, or the hot plate test. But also other modalities, including audition, olfaction, vision, vestibular function, and sensorimotor gating, have been investigated.

Abnormalities of somatosensory function in general, but mostly hyposensitivity to painful stimuli have been described in the models ex4-22|ALL [92, 130], ex11|SH3 [123], ex21|PRO [125], and ex11-21|SH3-PRO in rats [135]. Targeted disruption of SHANK3 in cells of the caudal embryo, somatosensory neurons (ex13-16|PDZ$\mathrm{Cdx} 2^{\mathrm{Cre}}$, -Advillin ${ }^{\mathrm{Cre}}$ [140]), and cells expressing SCN10A (also known as Nav1.8, ex4-22|ALL-Nav1.8 ${ }^{\text {Cre }}$ [92]) was sufficient to induce somatosensory dysfunction. Notably, somatosensory dysfunction concerning light touch stimuli had been described by two studies examining the constitutive SHANK3-deficient model ex13-16|PDZ [159, 192], while in another study somatosensory function as examined by thermo-/nociception was not affected in these mice [163]. Mixed evidence was also reported for the murine model ex4-9|ANK [124, 140, 167], while somatosensory function was not affected in mice of ex8|ANK-Q321R [132].

Generally, other senses like vision $[125,126,130,166$, 193], olfaction [124, 135, 161, 163, 176] or vestibular function $[134,155]$ were not affected in SHANK3-deficient rodents. Although one study using the model ex4-22|ALL found abnormalities in tasks depending on olfaction or vestibular function [130].

Audition is often assessed in parallel to the testing of sensorimotor gating in an auditory prepulse inhibition analysis. Baseline auditory startle responses were impaired in mice of the models ex4-22|ALL $[129,130]$, ex13-16|PDZ [155, 163, 166], and ex21|PRO-InsG3680 or -R1117X [127]. These findings were also replicated by specific targeting of GABAergic forebrain neurons in ex4-22|ALL-Dlx5/6 ${ }^{\text {Cre }}$ mice [129], but not if SHANK3-deficiency was induced in neocortical excitatory neurons (ex4-22|ALL-NEX ${ }^{\text {Cre }}$ [129]), cells of the caudal embryo, or somatosensory neurons (ex13-16|PDZ$\mathrm{Cdx} 2^{\mathrm{Cre}}$, -Advillin $\left.{ }^{\mathrm{Cre}}[140]\right)$. Audition was unaltered in the models ex4-9|ANK [78, 80, 124, 140, 155], ex13|PDZ [139], ex21|PRO [125], and ex17|PRM-S685I [94]. These mice did also display intact sensorimotor gating as measured by prepulse inhibition tests.

Sensorimotor gating was reported to be decreased in the models ex4-22|ALL [129], ex13-16|PDZ [155], and ex21|PRO-InsG3680 or -R1117X [127], although these findings could be influenced by the abovementioned auditory dysfunction. Additionally, some studies found no differences between wildtype and mutant mice of these models [130, 163, 166]. In single studies targeting of GABAergic forebrain neurons in ex4-22|ALL-Dlx $5 / 6^{\text {Cre }}$ mice [129], cells of the caudal embryo, or somatosensory neurons (ex13-16|PDZ-Cdx2 ${ }^{\mathrm{Cre}}$, -Advillin ${ }^{\mathrm{Cre}}$ [140]) was sufficient to disrupt sensorimotor gating, either in an auditory or tactile prepulse inhibition test.

Cognitive function The majority of PMDS patients exhibit a severe or profound intellectual disability [152]. As a consequence, cognitive performance in SHANK3deficient animals has been tested across multiple modalities, involving various brain regions for instance hippocampal or amygdala-dependent paradigms using contextual and cued fear conditioning as measures of associative learning, or spatial learning tasks in various maze configurations.

Basic recognition memory is often assessed by novel object recognition tasks, which require extensive pretesting to ensure the absence of confounding factors. Recognition memory was impaired in the models ex4-22|ALL [130], ex4-9|ANK [78, 80, 124, 140], ex11|SH3 [193], and ex11-21|SH3-PRO in rats [135]. Mice from the models ex8|ANK-Q321R [132], ex9|ANK [82], and ex13-16|PDZ or associated conditional $\mathrm{KO}$ animals $[140,163]$ were unaffected.

Decreased spatial learning was observed in ex4-22|ALL [128, 130], ex9|ANK [82], ex11|SH3 [123], ex21|PRO [125], and ex21|PRO-InsG3728 [126], but not in other models investigated, such as ex6|ANK rats [134], and mice harboring mutations associated to neuropsychiatric disorder (ex21|PRO-InsG3680 or -R1117X [127]). Divergent results were reported for ex4-9|ANK [78, 80, 124, 155, 167], ex13|PDZ [139, 176], and ex13-16|PDZ [90, 155, $162,163,166]$.

Associative learning was not consistently altered in any of the investigated exon specific or mutated models ex4-9|ANK [80, 124, 167], ex13|PDZ [176], ex1316|PDZ [163], ex8|ANK-Q321R [132], or ex6|ANK in rats [134], while it was clearly affected in ex4-22|ALL mice [128-130]. These deficits were not induced by targeting neocortical excitatory neurons or GABAergic forebrain neurons in ex4-22|ALL-NEX ${ }^{\mathrm{Cre}}$ or -Dlx $5 / 6^{\text {Cre }}$ mice [129]. Interestingly, ex4-22|ALL SHANK3-deficient mice showed increased responses in the amygdala- 
dependent paradigm, but impaired associative learning in the hippocampus-dependent task in one study [130]. In a specific task testing for cerebellum-dependent function, heterozygous ex21|PRO mice also displayed deficient associative learning [194].

Striatal-dependent instrumental learning was severely impaired in the model ex4-22|ALL [128], suggesting the involvement of reward-related processes that are required in this task. These could potentially affect social reward circuitry. Together with abnormal functional (hyperactive) and socially induced (hypoactive) connectivity in the cortico-striatal-thalamic circuitry, the resulting ASD-like behaviors might be explainable by these changes [128].

Strong deficits in a paradigm examining perceptual learning were found in the model ex13-16|PDZ [188].

These differential results concerning the various domains of learning and memory could result from the varying expression patterns of SHANK3 isoforms in different brain regions. But these deficits have not been causally related to certain dysfunctional brain circuits.

Despite the fact that ADHD is a frequently described comorbidity of ASD [3], such deficits have seldomly been studied in animal models of SHANK3 deficiency. Impaired attention has only been observed and studied in the murine model ex11|SH3 [193] and the rat model ex6|ANK [134]. Such impairments should thus be reinvestigated in other models. Attention deficits could potentially influence many of the abovementioned behavioral and neurological phenotypes.

Additional neurological phenotypes Since some patients with PMDS or SHANK3-associated ASD suffer from epilepsy $[142,195]$, it is of interest that such a phenotype has only been observed rarely in SHANK3-deficient mice [90]. On the contrary, some studies observed decreased susceptibility to PTZ-induced seizures in the models ex13-16|PDZ [163] and ex8|ANK-Q321R [132].

Furthermore, in the murine model ex21|PRO abnormal sleep patterns have been described [191], recapitulating a common cause of distress for both the PMDS patients themselves and also their parents [142].

\section{Recapitulation of phenotypes in heterozygous animals}

The sections above mainly focused on phenotypes observed in homozygous SHANK3-deficient rodents. Some studies reported that heterozygous SHANK3deficient animals of various models were also affected, albeit less severely and also much less replicated than the phenotypes of homozygous mutants. Due to the fact that PMDS is a haploinsufficiency by definition, heterozygous animals should be studied more frequently, but might need more sensitive testing methods and bigger testing cohorts.

Abnormal social behavior was present in heterozygous mice from models targeting the ankyrin repeats (ex4-
9|ANK [80, 122, 124]), the PDZ-domain (ex13-16|PDZ $[140,196]$, ex13|PDZ $[139,176])$ or the prolin-rich region (ex21|PRO [154, 156, 177, 179, 197-199]), but also in heterozygous SHANK3-deficient rats (ex6|ANK [134, 180], ex11-21|SH3-PRO [135]) and models mimicking mutations associated to ASD or schizophrenia (ex8|ANKQ321R [132], ex17|PRM-S685I [94], ex21|PRO-R1117X [127]).

Stereotypies were observed in heterozygous animals from multiple exon-specific models (ex4-9|ANK [80, 124], ex13-16|PDZ [140, 166], ex13|PDZ [139, 176], ex21|PRO [154, 156, 177, 199], ex11-21|SH3-PRO rat [135]), and in mice harboring an ASD-associated mutation affecting the ANK-domain (ex8|ANK-Q321R [132]).

Avoidance towards inanimate objects was described in heterozygous mice of two exon-specific SHANK3-mutant lines (ex13-16|PDZ [140], ex21|PRO [178]).

Concerning the replication of phenotypes representative of ASD comorbidities, heterozygous mutant rodents of some exon-specific models (ex4-9|ANK [167], ex1316|PDZ [140], ex13|PDZ [139, 176], ex11-21|SH3-PRO rat [135]) or mice with SHANK3 point mutations (ex21|PRO-R1117X [127], ex21|PRO-InsG3680 [127]), which are associated to human neuropsychiatric disorder, exhibited increased anxiety-levels compared to wildtype animals. Aggressive behavior was only described in one study on heterozygous mice of the model ex21|PRO [198].

Finally, neurological symptoms reminiscent of deficient motor skills (ex4-22|ALL [130], ex4-9|ANK [167, 200], ex11|SH3 [123], ex13-16|PDZ [140], ex13|PDZ [139, 176], ex21|PRO [179], ex21|PRO-InsG3680 [127]), abnormal sensory processing (ex4-22|ALL [92, 130], ex13-16|PDZ [140, 201], ex11-21|SH3-PRO rat [135]) or impaired cognitive capabilities (ex4-9|ANK [80, 167], ex13-16|PDZ [140, 188, 201], ex21|PRO [194], ex6|ANK rat [134]) described in PMDS patients were also present in some of the investigated heterozygous rodent models of SHANK3 deficiency.

\section{Structural and functional deficits}

SHANK3-deficient animal models have been extensively investigated concerning disrupted structural or functional features primarily of the brain. Such changes have been observed on the molecular level, for instance as altered protein composition, protein localization, or transcription, but also in physiological processes, such as synaptic transmission or plasticity, and lastly as abnormal morphology.

Molecular changes A great number of proteins is altered, when the Shank3-gene is disrupted. Most of them directly or indirectly interact with SHANK3 and are involved in the mediation of protein-protein interaction themselves, are associated to actin-associated processes 
or the cytoskeleton in general, or represent subclasses of glutamate receptors. Beside these main classes of affected proteins, a wide variety of other proteins and genes have been altered upon SHANK3 deficiency.

Studies have often focused on certain brain regions to analyze these defects, among which the striatum is the most frequently investigated and apparently also the most affected. Multiple proteins involved in the mediation of protein-protein interactions, especially HOMER1 [80, 90, 123, 128, 129, 139, 202], but also HOMER2 [128], HOMER-proteins in general [83, 127, 135], DLG2 [90, 127], DLG4 [80, 94, 127, 135, 139], DLGAP2 [202], and DLGAP3 [83, 90, 127, 128], were decreased in the striatum of mutant animals. Additionally, reduced levels of various glutamate receptor subunits, such as AMPAR-subunits (GRIA1 [135, 202], GRIA2 [80, 83, 90, 127, 139, 202, 203], GRIA3 [80, 139]), NMDAR-subunits (GRIN1 [127, 135, 139, 202, 203], GRIN2A [83, 90, 127, 139], GRIN2B [83, 90, 127, 139, 202]), GRM5 [127], and GRIK5 [202] were observed, mainly in synaptic fractions of the striatum. Another cluster of proteins that was decreased in striatal synapses of SHANK3-deficient animals is associated to actin or the cytoskeleton such as DOCK4 or TRIO [202]. Most interestingly, the other affected proteins of this group and more specifically WASF1 [94], NCKAP1 [202], ABI1 [94], or BAIAP2 [202] are either integral parts or regulators of the WAVE regulatory complex, which is crucial for the RAC1-dependent and ARP2/3-mediated actin polymerization [204]. Other proteins that were found to be decreased in striatal synapses or the striatum in general include the potassium channels KCNJ2 and KCNMA1 [202], the MECP2-associated kinase CDKL5 [202], GNAS [202], SYNGAP1 [127], CYLD [205], and the interneuronmarker PVALB [206]. Although most changes of protein levels showed a trend towards reduction, increased levels of the cell adhesion proteins CNTN2 and CDH4, MYEF2, which serves as a transcriptional repressor of the myelin basic protein, the Akt-regulating E3 ubiquitin-protein ligase TTC3, and members of the ribosomal protein family have been observed in striatal synapses [202]. Contradicting some of the abovementioned results, increased levels of GRIA1 [127] and GRM5 [128] have also been observed in some studies, which could be due to the different genetic targeting of Shank3.

Albeit synaptic protein composition was reported to be especially altered in the striatum, decreased levels of similar groups of proteins were also observed in the hippocampus, affecting HOMER1 [78, 128, 202], HOMER2 [128], HOMER3 [128, 202], GRIA1 [78, 122, 139, 203], GRIN1 [139], GRIN2A [128], and the actinor cytoskeleton-associated proteins ABI1, PFN2, GSN, FARP2, and DOCK3 [202]. Other proteins that were shown to be reduced in hippocampal synapses include SYN3, CYLD, and proteins of the YWHA-family [202].
Furthermore, protein levels of the glutamate receptor subunits GRIN1 [129, 135], GRIN2B [118, 126, 129], and GRM5 [125], the calcium channel subunit CACNA1B, NLGN2, the cytoskeleton-associated kinase FER, the ribosomal protein RPL27A, and ALDH5A1 [202], which is involved in GABA-degradation, were increased in hippocampal synapses. Notably, one study reported increased synaptic DLG4-levels in heterozygous ex11-21|SH3-PRO rats [135].

Analogous to the findings in the striatum and hippocampus, proteins like HOMER1 [123] or HOMER in general [127], DLG2 [127], and DLG4 [127, 177], which are important mediators of protein-protein interactions, were found to be reduced in cortical synapses. Further proteins, which were dysregulated in the cortex, include GRM5 [123], the NMDAR-subunits GRIN1 and GRIN2B [127, 177], SYNGAP1 [127], MAPK [207], the actinisoforms ACTB and ACTG1, but also actin-associated proteins like CFL1, LIMK1, CAPZB, EZR, ITPKA, and RAC1 [177].

Similarly, in prefrontal areas like the anterior cingulate cortex protein levels of HOMER1 [134], GRIA1, GRIA2 [160], GRIN1 [177, 198, 199], GRIN2A [177, 197-199], and GRIN2B $[160,199]$ were reduced. Additional studies described dysregulated levels of CTNNB1 as regulator of Wnt-signaling [154] and ARC as a major regulator of plasticity [156]. These changes were related to increased nuclear HDAC2 [154], EHMT1, and EHMT2 levels [156] in the prefrontal cortex (PFC), which are important epigenetic regulators of gene expression. An increased amount of HDAC2, EHMT1, and EHMT2 generally results in reduced expression of the genes, directly affected by their epigenetic modifications, although indirect effects could also lead to increased gene expression.

Specific analysis of the insular cortex revealed dysregulated markers of inhibitory neurons as increased levels of GAD2, and decreased levels of PVALB were observed. Interestingly, the WFA-positive perineural net surrounding PVALB-positive neurons was also affected [208].

Brain regions other than the abovementioned were not regularly investigated, but decreased levels of thalamic GRIA2 and GRIN1 [203], cerebellar GRIA1 [83], GRIN1 [135] and GRM5 [179], HCN1 in the spinal cord [140], or HCN1 and TRPV1 in dorsal root ganglia [92, 140] have been described in SHANK3-mutant mice. The analysis of whole brain samples additionally revealed generally reduced synaptic amounts of HOMER1 [78], DLGAP1 [78], GRIA1 [78], or GRIA-subunits in general [118], GRIN2A [78], and HCN2 [209].

A single study reported markedly increased levels of general protein synthesis activity in a multitude of brain region like the cortex, hippocampus, amygdala, raphe nucleus, thalamus, hypothalamus, cerebellum, and corpus callosum [207]. 
Notably, compensatory mechanisms among SHANKproteins have been described in the striatum, hippocampus, and cortex. SHANK2 has been observed to be upregulated in whole brain lysates, the striatum [118] and cortex [83, 127]. In addition to the overexpression of remaining SHANK3-isoforms [132], the expression of previously undetected low-molecular SHANK3-isoforms has been reported in all three regions $[125,126,151]$ of SHANK3deficient rodents.

Some proteins, whose levels were altered in certain subcellular compartments, additionally displayed defective subcellular localization, induced by SHANK3 deficiency. Among these proteins are HOMER1 [78, 80, 123, 128, $139]$ and DLG4 [80, 135, 139] as protein-protein interaction mediators, the AMPAR- or NMDAR-subunits GRIA1 [135], GRIA2 [80, 139], GRIA3 [80, 139], GRIN1 [135, 139, 177, 198, 199], GRIN2A [139, 177, 198, 199] and GRIN2B [139, 199], the metabotropic glutamate receptor GRM5 [123, 125, 128], and TRPV1 [92]. Other dislocalized proteins, which are associated to actin or the cytoskeleton, include ABI1, WASF1 [94], and CTNNB1. CTNNB1 specifically localized less to synapses, but more to the nucleus, where it was found to be enriched on the promotors of Hdac2 [154], Ehmt1, and Ehmt2 [156], which might be the reason for their upregulation. Conversely, other studies found that a specific mutation can lead to sequestering of CTNNB1 by SHANK3 in nuclear bodies and thus decrease its functionality as transcriptional activator [105]. This divergent influence resulting from different forms of SHANK3 deficiency reflects the clinical heterogeneity, which can be observed in PMDS-patients.

Fitting their dysregulated subcellular localization, the interaction between HOMER1 and GRM5 was reduced by SHANK3 deficiency [123, 128]. Furthermore, an ASDassociated mutation of SHANK3 at a crucial phosphorylation site was sufficient to disrupt its interaction with ABI1 [94].

Matching the generally observed molecular alterations, SHANK3 deficiency resulted in impaired signaling mediated by metabotropic glutamate receptors (e.g., GRM5) $[123,128]$ and decreased phosphorylation of SYN1, CREB [210], and targets in the PI3K/AKT/MTOR- [178] or MAPK/ERK-pathway [92], also affecting synaptic MAPKphosphorylation [106, 207]. Furthermore, the reduction of crucial components belonging to the RAC1dependent signaling pathway, such as SHANK3-interactor ARHGEF7 or LIMK1, that leads to the phosporylation and thus inactivation of CFL1, might result in an increased actin-depolymerization by the active form of CFL1 [177]. Apart from dysregulated phosphorylation, abnormal S-nitrosylation of STX1A, PPP3C (also known as Calcineurin A), and several proteins involved in ASDassociated processes was recently reported [210].
Most studies have focused on the effects of SHANK3 deficiency on the protein level, but some alterations have also been observed with regard to transcription. Recent advances in RNA-sequencing techniques and their widespread use have enabled the unbiased transcriptomic analysis of certain brain regions. In SHANK3-deficient mice the PFC has so far been the only region investigated by this approach. Hundreds of genes were reported to be altered in these studies [154, 156, 191]. Fitting some of the proteomic changes described above, dysregulated transcripts were often associated to actin-associated processes, cell adhesion, signal transduction pathways and regulation of phosphorylation, developmental processes and cell morphogenesis, regulation of transcription, and regulation of protein stability $[154,156]$. Many affected transcripts, such as Homer1, represented ASD susceptibility genes themselves [156]. Transcripts, which were additionally altered following sleep deprivation compared to baseline conditions, clustered in categories associated to MAPK/GnRH-signaling and the regulation of circadian rythmicity [191].

Validation of some of the altered genes by PCR showed that RNA levels of Arc, Homer1 [156, 197, 198], Grin1 [198], and Sgk2 [197] were reduced in the PFC. Additionally, prefrontal Hdac2- [154], Ehmt1-, and Ehmt2transcript levels [156] were increased, which was accompanied by epigenetic dysregulation. Transcripts of RAC1associated pathways, such as Arhgef7 [154, 199] and Limk1 [154] were reduced, which fits the disrupted actincytoskeleton observed in the PFC [154, 177, 199] and hippocampus [177]. Other studies found striatal Pvalbtranscripts [206] and hippocampal Gabra1-, Gabra2-, or Gabrb1-transcripts of GABA A receptor subunits [211] to be reduced. Importantly, a compensatory increase of Shank1, Shank2 [127], and transcripts of non-deleted Shank3-exons [151] was observed.

Other major factors influencing gene expression in vivo are epigenetic regulatory mechanisms. Fitting the above mentioned dysregulation of HDAC2, EHMT1, and EHMT2, a decreased H3-acetylation and increased levels of $\mathrm{H} 3 \mathrm{~K} 9 \mathrm{~m} 2$ di-methylation especially at the Arc promotor region were observed in the PFC, but not other brain regions of SHANK3-deficient animals [154, 156, 198, 199]. Besides its pathophysiological importance, these findings pointing at epigenetic dysregulation could represent a promising therapeutic target, as epigenetic interventions could normalize expression levels of a multitude of dysregulated genes at once.

Although the majority of studies focus on alterations in the nervous system, dysregulated cytokine levels in SHANK3-deficient mice were recently reported [211]. Another peripheral organ, which seems to be affected by SHANK3 deficiency is the gastrointestinal system, as 
it was observed that TJP1 (also known as ZO-1) was increased in the small intestine, which might affect intestinal barrier function [212]. Additionally, increased bacterial lipopolysaccharide levels were found in the liver, suggesting an increased leakiness of the gastrointestinal system in these mice [212].

Alterations of physiological processes Aside from molecular changes, the resulting dysfunction of physiological processes has been investigated in depth across multiple studies, focusing on crucial neuronal functions, such as synaptic transmission or plasticity. Although it has to be noted that not all abnormalities, which have been described, were reproduced consistently. However, this section will focus on studies that found physiological deficits in SHANK3-deficient animals.

Firstly, basic cellular excitability has been reported to be abnormal in striatal MSNs [128, 129, 182], hippocampal neurons [132, 213], prefrontal neurons [133, 160], thalamic neurons [209], and neurons of lumbar dorsal root ganglia [140].

Measures related to synaptic transmission, which are often dependent on NMDAR or AMPAR functionality, were deficient in the striatum $[80,83,90,94,127$, $128,131,139,164,168,182,214]$, hippocampus [82, 94, 122, 124-126, 129, 135, 177, 187, 200], PFC [82, $127,133,154,156,160,177,197-199]$, and thalamus [209], but also in the somatosensory and visual cortex [140], ventral tegmental area (VTA) [161], and spinal cord [92]. The study of the temporal development of measures related to synaptic transmission has also revealed that synaptic maturation is dysregulated in striatal MSNs [214]. Initially, SHANK3 deficiency resulted in a premature corticostriatal hyperactivity in early developmental stages [214], while the physiological rise of activity was insufficient, which led to depressed striatal activity during adulthood [90, 182, 214]. Interestingly, another study showed that corticostriatal hyperactivity results in different striatal activity patterns in adult mice, when induced at different developmental timepoints. Adult striatal activity was depressed when corticostriatal hyperactivity was induced early-on, which resembles the phenotype of SHANK3 deficiency, whereas it resulted in persistent hyperactivity when induced at later developmental stages [183].

Similar brain regions have been found to exhibit impaired mechanisms of synaptic plasticity, namely the striatum [123, 127, 128, 164, 182], hippocampus [78, 80, 122, 124-126, 134, 135, 139, 200], PFC [134, 160], VTA [161], and spinal cord [92]. A specific form of homeostatic plasticity, which also occurs upon sensory deprivation, was reported to be dysfunctional in the visual cortex of SHANK3-deficient mice [181].
Some studies have further investigated network activity and connectivity in certain neuronal circuits during SHANK3-deficient conditions. Abnormal baseline neuronal activity was observed in the cortex as a whole by EEG-measurement $[132,163]$ or by MEA in primary cortical cultures [215]. Specific brain regions were also analyzed by different methods revealing altered baseline activity in the auditory cortex [216], somatosensory cortex [192], hippocampus, striatum, and prefrontal areas [175], while neuronal activity induced by different types of social interaction was abnormal in the PFC [160, 175, 196], striatum, periaqueductal gray, lateral and medial habenulae, and lateral septum [175]. In addition to an abnormal baseline activity, neuronal activity induced by stimulating the vibrissae was altered in the somatosensory cortex, where hypoactive inhibitory interneurons led to a hyperactivity of excitatory pyramidal neurons [192]. Similarly, an abnormal GABAergic circuitry in the insular cortex led to impaired activity induction via audio-tactile stimuli and deficient multisensory integration [208]. Notably, neuronal activity induced by light touch stimuli was dysregulated in circuits of lumbar dorsal root ganglia [140]. Induced neuronal activity patterns were also disrupted in primary neuronal cultures derived from cortices of SHANK3-deficient mice [215]. Abnormal responses of neuronal circuits to speech sounds were reported in the auditory cortex of SHANK3-deficient rats [216].

Via activity measurements in the PFC during a paired interaction task, it was recently observed that the number of neurons encoding self-experience was increased, while those encoding the other social agent's experience were decreased in SHANK3-deficient mice. Furthermore, there was no differentiation between self- and other-encoding neurons since all other-encoding neurons also responded to self-stimuli. Such a loss of differential neuronal encoding concerning social and other stimuli might be an essential element underlying the behavioral phenotypes of SHANK3-deficient animals [196].

Altered connectivity measures were reported in the cortico-striatal-thalamic circuitry, where an increased baseline functional connectivity between the nucleus accumbens and cingulate cortex or thalamus hindered a sufficient rise of coherence upon social induction of functional connectivity, which could be due to the altered excitability of striatal MSNs mentioned above [128]. Cortico-striatal connectivity was also found to be altered in independent studies, which used different methodologies [158, 214]. Furthermore, periodic synchronized activity patterns, as measure of connectivity in primary cultures, were impaired in cortical neurons of SHANK3deficient mice [215]. Additional brain regions that showed dysregulated connectivity in an fMRI study included the hippocampus, claustrum, regions of the basal fore- 
brain, and many cortical subareas (entorhinal, perirhinal, piriform, retrosplenial, motor, visual, and auditory cortex) [158].

Interestingly, physiological alterations that could hint at inflammatory processes in the cortex, such as astrogliosis and elevated IL6-levels, were reported in SHANK3deficient mice [212]. Furthermore, signs of nitrosative stress were observed in the PFC and striatum [210].

Studies that also investigated non-brain associated phenotypes found a dysregulated microbiome composition in SHANK3-deficient mice, which was targeted to influence behavioral phenotypes $[161,211,212]$.

Morphological abnormalities Changes of the molecular composition and physiology in a tissue are often accompanied by morphological abnormalities, which have also been described especially in the brain of SHANK3deficient animals. Again most of those anomalies have been observed in the striatum, hippocampus, and cortical areas. But this might also be due to the fact that those regions are the ones which many studies relied on in their analysis.

Abnormal dendritic spine or synapse morphology and an aberrant configuration of the dendritic tree in general have been observed in the striatum $[83,90,94,128$, 182], hippocampus [78, 94, 122, 135, 213], regions of the PFC [127, 160, 217], and cerebellum [194]. Ultrastructural analysis additionally revealed an altered PSD morphology in the striatum [90,128], hippocampus [218], and anterior cingulate cortex as part of the PFC [160].

Volumetric analysis by MRI techniques indicated an increased size of the striatum $[90,128]$, pallidum [128, 219], pretectum, superior colliculus, deep mesencephalic nuclei, brainstem, and tegmental areas, such as the substantia nigra and interpeduncular nucleus [128]. Conversely, the hippocampus [219], PFC [158], auditory cortex [158], retrosplenial cortex [158], olfactory areas [128], and the brain as a whole $[219,220]$ showed a decreased volume, while mixed evidence was reported concerning the thalamus $[128,219]$. In addition the size of fiber tracts or their white matter integrity was reduced in the optic tract, fornix, fimbria, stria terminalis, anterior commissure, cerebral peduncle, spinal trigeminal tract, and cingulum of SHANK3-deficient mice [128].

General neuroanatomical examination of the somatosensory cortex, visual cortex, and amygdala uncovered a loss of PVALB-positive interneurons in these regions [140]. Additionally, the number of Purkinje cells in the cerebellum of SHANK3-deficient mice was reported to be reduced [179]. Other studies focusing on the hypothalamus and spinal cord found a reduction of oxytocinpositive hypothalamic neurons [161] and altered morphological properties of lumbar ventral horn motoneurons
[111], which is a finding of great importance, considering that muscular hypotonia represents a hallmark feature of the PMDS. In-depth analysis of skeletal muscle tissue found an impaired maturation and complexity of neuromuscular junctions, as well as altered ultrastructural properties, especially a decreased Z-disc width in samples from ex11|SH3 mice and also PMDS-patients [111].

Another non-brain associated morphological abnormality was found in the small intestine of the murine model ex11|SH3, where the total villi length and ratio of villi length to crypt depth were decreased [212]. Also referring to the abovementioned observation of an altered microbiome [161, 211, 212], the gastrointestinal system might be an interesting peripheral target for further investigation. Since ASD and also the PMDS are frequently associated with gastrointestinal alterations [221-223], and the insular cortex, which has often been described as visceroceptive hub and center of multisensory integration in general [208, 224, 225], is also affected in SHANK3deficient mice, dysregulated visceral signals to the insula or other involved regions might contribute to the overall phenotype by affecting the gut-brain axis [208].

\section{SHANK3 deficiency in non-human primates}

Recently, the CRISPR-Cas9-mediated generation of germline-transmissible mutations in exon 21 of SHANK3 in cynomolgus macaques (Macaca fascicularis) and their F1 offspring was reported [136]. Although the founder animals represented a mixed cohort with non-uniform mutations, they were additionally tested for structural and behavioral abnormalities. MRI-based analysis revealed abnormal connectivity in the PFC, motor cortex, cingulate cortex, thalamus and striatum. Additionally, grey matter volume was generally reduced. Upon behavioral and neurological examination, founder mutants exhibited abnormal social behavior, increased stereotyped behaviors, motor deficits, hypoactivity, attentional deficits, learning impairments, and sleep disturbances [136]. Interestingly, a delayed pupillary light reflex was observed. Abnormal pupillary light reflexes have also been reported in ASD-patients [226].

Another group targeted exons 6 and 12 by CRISPRmediated intervention in macaques [137, 227]. Generally, a lower pregnancy rate was observed and of the three reported pregnancies only one animal was born and survived carrying a mutation in exon 12 . The surviving animal was thus examined by PET-MRI and behavioral analysis [227], while an aborted animal carrying mutations in both exon 6 and 12 was used for molecular and morphological analysis [137]. A general health screening demonstrated a decreased body weight and length, as well as an enamel dysplasia in the surviving individual. Behavioral analysis revealed abnormal social interaction and communication, repetitive behaviors, increased levels 
of anxiety, and exploratory hypoactivity. PET-MRI analysis showed a decreased baseline activity in the cortex, PFC, hippocampus, amygdala, and striatum [227]. On the molecular level, protein amounts of GRIN2B, DLG4, and RBFOX3 (also known as NeuN) were decreased in the PFC, while levels of GFAP were markedly increased. Similarly, in the striatum decreased levels of GRIN2B, DLG4, and RBFOX3, but also GRM5 and DCX were observed. Protein levels of GFAP were also increased in the striatum. Although total levels of HOMER1 were unaffected, it showed an abnormal localization to the cytoplasm in the PFC. Additional morphological analysis revealed a decreased spine density, and a reduced overall percentage and soma size of RBFOX3-positive cells in the PFC, while the proportion of GFAP-positive cells was elevated. These neuroanatomical findings together with the altered protein levels of RBFOX3 and DCX as a neural progenitor marker, suggested a heavily disrupted neurogenesis in this SHANK3-deficient individual [137], which had not been described in murine models.

\section{Multiple knockout of Shank-genes}

Earlier this year, the first double KO-model of SHANK1 and SHANK3 (SHANK1+SHANK3-ex11|SH3) was published [138]. Generally, these mutant mice exhibited a markedly increased mortality, were generally smaller, and brain size was also reduced. On a molecular level these animals exhibited abnormal hippocampal and cortical synaptic protein composition and signaling related to AKT, MAPK, RPS6, and EEF2. Morphologically, both in the cortex and hippocampus a decreased spine density, an abnormal dendritic tree, and impaired PSD structure were observed. In hippocampal slices both excitatory synaptic transmission and plasticity were affected by SHANK deficiency. General cortical activity as measured by EEG was increased in SHANK-mutant animals. On a behavioral level these mice exhibited typical ASD-associated phenotypes. SHANK1 and SHANK3 deficiency resulted in impaired social behavior, increased repetitive, avoidance and perseverative behavior, abnormal spatial learning and recognition memory, as well as decreased sensorimotor capabilities and motor learning. Surprisingly, these animals showed lower levels of anxiety.

\section{SHANK3-overexpression model}

In contrast to the approach of deleting Shank3 to study its biological function and role in human diseases, Shank3EGFP transgenic mice overexpress all major SHANK3 isoforms and exons $[93,151]$. These animals are characterized by a hyperkinetic phenotype that resembles mania. Their hyperactivity was aggravated after injection of amphetamine. Transgenic mice also displayed increased escape behavior, elevated sensorimotor gating, abnormal circadian rhythms, decreased social interactions, seizures, and hyperphagia-like behavior [93]. On a molecular level, SHANK3-transgenic mice habored elevated levels of F-actin $[93,228]$ and an increased spine density, which might be due to SHANK3's influence on its interactors ARPC2 and WASF1, which are both part of the ARP2/3-complex and thus promote actin polymerization [93]. Additionally, the density of excitatory synapses was increased, while it was decreased for inhibitory synapses. This might be due to redistribution of the actin associated proteins ENAH and PFN2 from inhibitory to excitatory synapses. Both are connected to the SHANK3-interactome via WASF1 and $\mathrm{ABI} 1$, but are direct interaction partners of GPHN, a scaffolding protein of inhibitory synapses. Accordingly, excitatory synaptic transmission was increased, while inhibitory transmission was decreased [93]. Additional proteomic analysis revealed more than a hundred dysregulated proteins in striatal PSDs. Interestingly, the only proteins, which were also affected by SHANK3 deficiency rather than overexpression, were HOMER1, CYLD, SPATA2L, and RPL36A [202, 205]. The dysregulation of ribosomal proteins was further validated and increased levels of RPLP1 and RPL36A were observed in striatal synapses, but not in whole cell lysates. Generally, translation in striatal synaptosomes was elevated. With respect to signaling, MAPK-phosphorylation was increased [229], while MTOR-phosphorylation was decreased [228] in the striatum of SHANK3-overexpressing mice. This model was also extensively analyzed by RNA-sequencing in different brain regions, which revealed differential alterations of transcripts. Striatal samples showed changes in categories related to signaling pathways, phosphorylation, cellular metabolism, the ribosome, and others [228, 230]. Furthermore, specific investigation of polysomeassociated transcripts showed increased levels of Drd1 and its downstream target Ppp1r1b [229]. Conversely, in the PFC altered transcripts accumulated in categories associated to synaptic plasticity, the extracellular matrix, the ribosome and spliceosome, and myelination. Alterations related to myelin were validated by PCR and showed decreased levels of Mobp, Mbp, Myrf, $M o g$, and others [230]. Genes, which were found to be increased in the hypothalamus, clustered in categories associated to the ribosome and extracellular matrix, while decreased genes were associated to the synapse, microtubules, or axonal processes [231]. The only altered genes, which were commonly affected across the striatum, PFC, and hypothalamus were Smim30, Gpr85, Cav2, and Kif5a [228, 230, 231]. Gpr85 RNA-levels were additionally increased in the hippocampus, cerebellum, and cortex [230]. Notably, Myelin-related transcripts were only decreased in the PFC, but not in the striatum or hippocampus [230]. Concerning treatment options, transgenic mice responded well to the anticonvulsant drug valproate, which ameliorated the hyperacitve and manic-like 
behaviors but did not influence the observed molecular phenotype [93].

\section{Treatment strategies for SHANK3 deficiency and their influence on subphenotypes in animal models Pharmaceutical compounds}

Based on the abovementioned molecular and physiological abnormalities in SHANK3-deficient animals, multiple pharmaceutical compounds have been proposed as possible treatment options for SHANK3-associated neuropsychiatric disorder. For instance, it has been hypothesized that modulation of glutamate receptors might be beneficial, since AMPAR-, NMDAR-, or GRM5-hypofunction potentially leads to an excitation/inhibition imbalance, which could contribute to some ASD-like phenotypes in SHANK3-mutant mice [123, 128, 160, 162]. But many other strategies to target SHANK3-associated pathophysiology have been investigated. A subset of those treatment strategies is also visualized together with the phenotype observed in the respective model in Figs. 2, 3, and 4 (Table 1).

AMPAR-PAM Positive allosteric modulation (PAM) of the AMPAR via the compound CX546 normalized social deficits of ex13-16|PDZ mice in one study [160], but had no effect on social behavior in another study [162]. Furthermore, AMPAR-PAM attenuated increased repetitive behaviors during social interaction [162] and partly corrected alterations of synaptic transmission in the anterior cingulate cortex [160]. CX546 did not affect the hypoactivity observed in ex13-16|PDZ mice [162].

NMDAR-agonism Treatment of ex13-16|PDZ mutant mice with a partial agonist at the glycine modulatory site of the NMDAR (D-cycloserine) enhanced social interaction behavior, but had no effect on increased repetitive behavior or hypoactivity. Notably, a high dose of D-cycloserine induced hyperactivity in these animals [162].

GRM5-targeting Different approaches to manipulate GRM5 signaling differentially influenced stereotypies and learning deficiency in ex4-22|ALL mice. While a GRM5-antagonist (MPEP) normalized hypoactivity and repetitive behaviors in these animals, a GRM5PAM (CDPPB) improved striatal-dependent instrumental learning, cellular excitability and synaptic plasticity of striatal MSNs, and low synaptic levels of HOMER1. Notably, CDPPB worsened repetitive behavior in ex422|ALL mice [128], while an attenuated phenotype was observed in the murine model ex11|SH3 [123]. Behaviorally, positive allosteric modulation of GRM5 also resulted in an improved social interaction and recognition, normalized spatial learning, and reduced perseverative reversal-deficits in ex11|SH3 mice. Moreover, treatment with CDPPB ameliorated the deficient Calciumsignaling in cortical neurons and normalized GRM5dependent NMDAR-functionality in striatal MSNs of this model [123].

GABAAR-agonism Acute treatment with isoguvacine, a peripherally restricted GABAAR agonist that acts directly on mechanosensory neurons, reduced tactile hyperreactivity in six distinct ASD models, including ex13-16|PDZ SHANK3-deficient mice. Chronic treatment of SHANK3mutant mice additionally improved body condition, brain abnormalities in the somatosensory cortex, anxiety-like behaviors, social deficits, avoidance behavior, and hypoactivity. Memory impairments and repetitive behaviors were not alleviated [140].

Nicotinic acetylcholine receptor (CHRN) PAM The effects of chronic treatment with the PAM of nicotine receptors cotinine during SHANK-deficient conditions was studied in mice of the double-KO model SHANK1+SHANK3-ex11|SH3. Prolonged treatment with cotinine normalized AKT-associated signaling, synaptic plasticity deficits, as well as spine density and dendritic complexity. Behaviorally, cotinine treatment rescued deficits of social behavior and recognition memory. Intriguingly, mortality was lower during treatment. Effects were not long-lasting and phenotypes regressed after the treatment was stopped [138].

MAP2K/MEK-inhibition As it was shown that SHANK3 stability is reduced by activation of the MAPK/ERK-pathway, MAP2K/MEK-inhibition was further explored as possible therapeutic strategy. Indeed it was observed that chronic treatment of WT-mice or SHANK3-deficient animals with PD0325901, a selective, highly potent, and long-lasting MAP2K/MEK-inhibitor, resulted in an increased abundance of SHANK3 in cortical synapses and normalized phosphorylation ratios of MAPK1 in mutant mice. Similar effects were observed, when Pimasertib or Selumetinib, both MAP2K/MEKinhibitors, were applied in a primary cell culture system of cortical neurons [106].

Oxytocin (OXT) Due to its role as a major regulator of mammalian social behavior, OXT has long been proposed as possible point of convergence regarding the social deficits observed in ASD-patients [232]. It has been reported recently that OXT-treatment in ex13-16|PDZ mice rescued social interaction deficits and normalized induced synaptic transmission and plasticity in the VTA, 


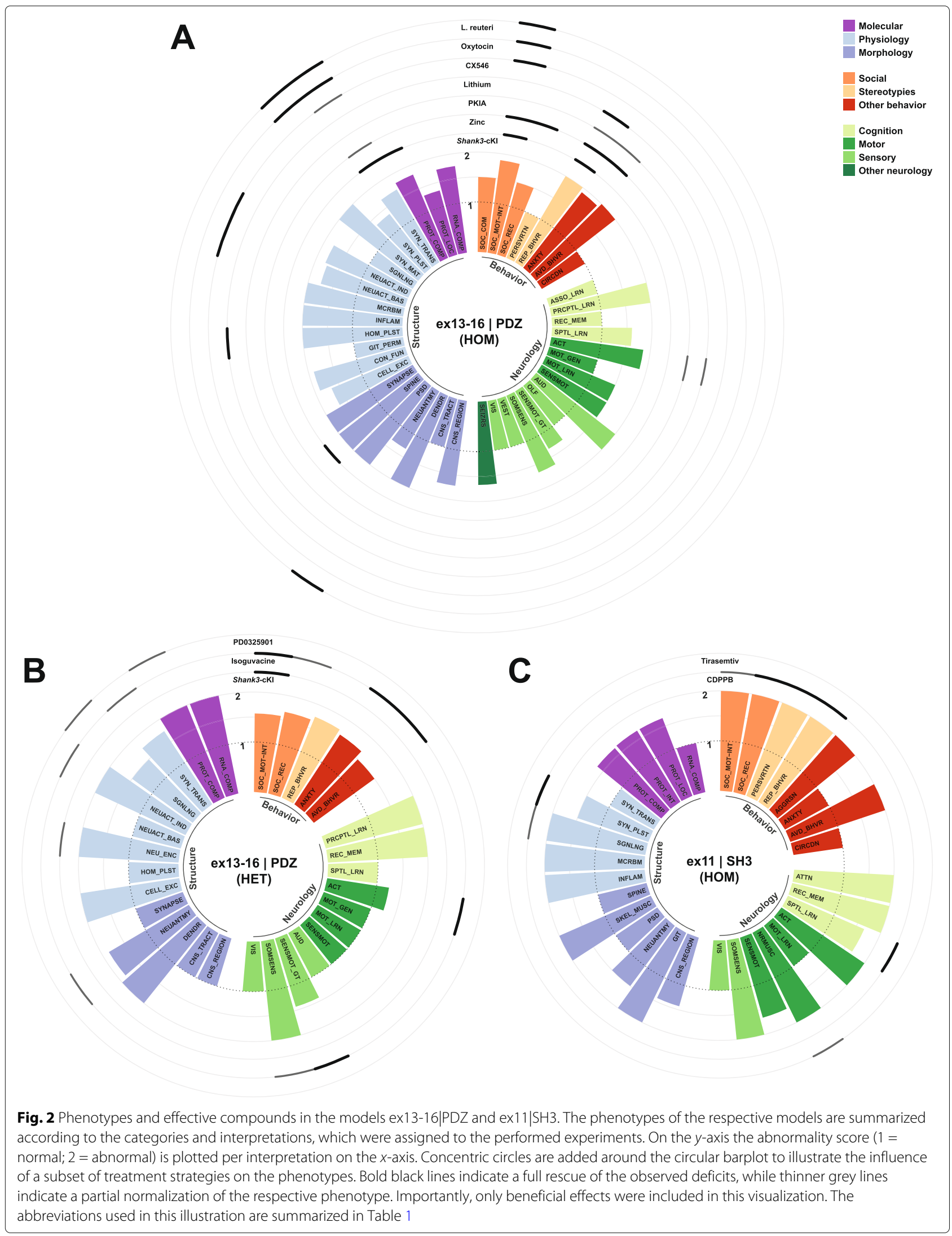




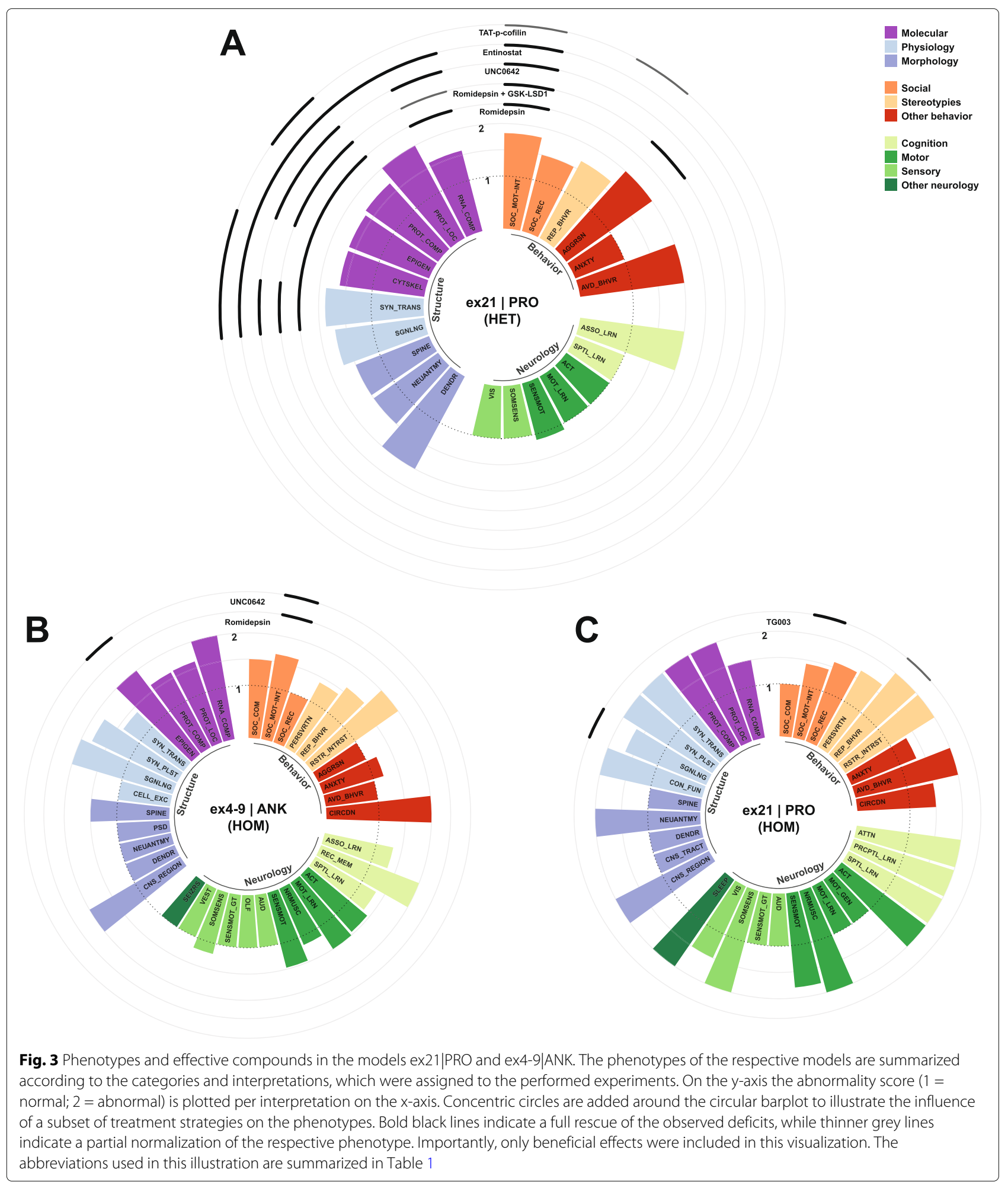

while hypoactivity was not influenced. Notably, the beneficial effects of L. reuteri, which are further discussed below, were dependent on OXTR-signaling [161]. Furthermore, administration of OXT into the left lateral ventricle restored hippocampal synaptic plasticity and alleviated behavioral deficits, such as the impaired long-term social recognition memory and reduced attention levels in the ex6|ANK SHANK3-deficient rat model for PMDS [134]. 


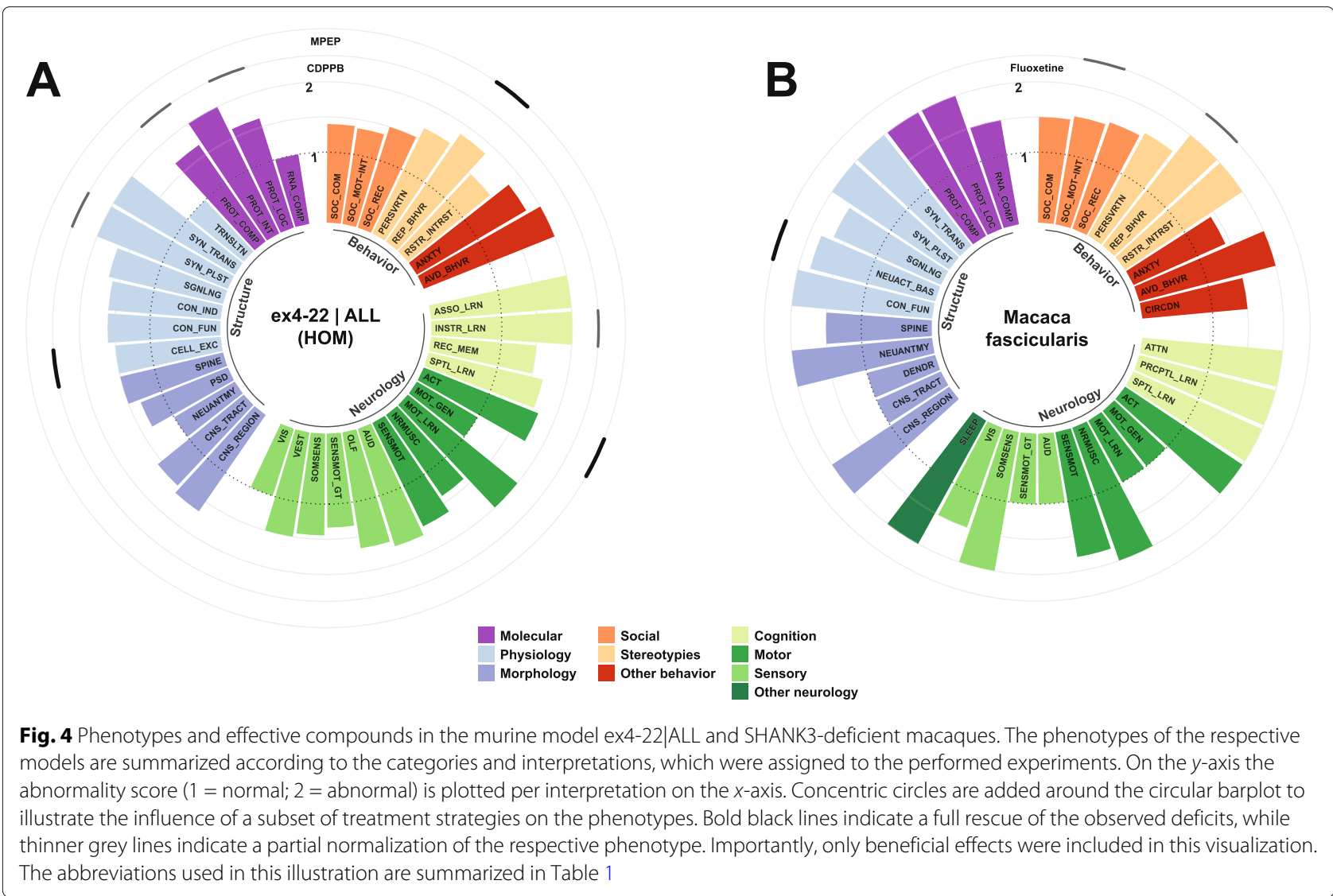

IGF1 IGF1 or an active recombinant peptide (rhIGF1) alleviated deficitary synaptic plasticity and transmission, as well as motor deficits in heterozygous animals of the SHANK3 deficiency model ex4-9|ANK [200]. Additionally, deficits of neuronal morphology and excitatory neurotransmission in SHANK3-deficient rodent neurons and PMDS patient-derived neurons were also improved by application of IGF1 [178].

Lithium (Li) Treatment with Li normalized the deficient mechanisms of homeostatic plasticity in the visual cortex and alleviated the overgrooming behavior in ex1316|PDZ SHANK3-deficient mice. A similar disruption of homeostatic plasticity was also inducible via local RNAimediated knockdown of SHANK3 in the visual cortex, which was also restored either by Li- or GSK3-inhibitortreatment [181]. In another study Li-application resulted in increased SHANK3-levels and rescued the maturation of neuromuscular junctions in a motoneuron-myotube coculture established from SHANK3-deficient PMDSderived hiPSCs [111].

Fluoxetine Fluoxetine, which is a well known so-called selective serotonin reuptake inhibitor (SSRI) and widely used as an antidepressant drug, was tested in a SHANK3deficient macaque. After treatment, the individual showed improved social behavior including previously impaired active or passive social interaction and eye contact, alleviated repetitive behaviors, and normalized brain activity as assessed by PET-MRI.

Targeting of epigenetic mechanisms Chromatin modifications, such as DNA-methylation, histonemethylation or -acetylation, but also histone-acylation, -homocysteinylation, -serotonylation, and others are crucial regulators of gene expression, summarized under the term epigenetics [233]. Recently, evidence has accumulated, which suggests that epigenetic mechanisms are dysregulated in SHANK3-deficient animals and thus enzymes that regulate histone-modifications were explored as therapeutic targets. Multiple studies reported a HDAC dysregulation resulting in decreased H3-acetylation levels in the PFC of mice from the models ex21|PRO [154, 198] and ex4-9|ANK [154], which was induced by an increased nuclear localization of the SHANK3-interactor CTNNB1 to the HDAC2 promoter region [154]. This dysregulation of epigenetic control mechanisms might affect actin-associated signaling like the RAC1-PAK-LIMK1-CFL1 pathway [154].

Because other findings led to the conclusion that these epigenetic changes linked to SHANK3 deficiency might 
Table 1 Categories used in the database and circular barplots. Every data point was assigned to a category, subcategory, and an interpretation

\begin{tabular}{|c|c|c|c|}
\hline Category & Subcategory & Interpretation & Shortcut \\
\hline \multirow[t]{30}{*}{ Structure } & \multirow[t]{6}{*}{ Molecular } & Protein_composition & PROT_COMP \\
\hline & & Protein_localization & PROT_LOC \\
\hline & & Protein_interaction & PROT_INT \\
\hline & & RNA_composition & RNA_COMP \\
\hline & & Cytoskeleton & CYTSKEL \\
\hline & & Epigenetics & EPIGEN \\
\hline & \multirow[t]{15}{*}{ Physiology } & Synaptic_transmission & SYN_TRANS \\
\hline & & Synaptic_plasticity & SYN_PLST \\
\hline & & Homeostatic_plasticity & HOM_PLST \\
\hline & & Cellular_excitability & CELL_EXC \\
\hline & & Signaling & SGNLNG \\
\hline & & Translation & TRNSLTN \\
\hline & & Functional_connectivity & CON_FUN \\
\hline & & Induced_connectivity & CON_IND \\
\hline & & Baseline_neuronal_activity & NEUACT_BAS \\
\hline & & Induced_neuronal_activity & NEUACT_IND \\
\hline & & Neuronal_encoding & NEU_ENC \\
\hline & & Synaptic_maturation & SYN_MAT \\
\hline & & Inflammation & INFLAM \\
\hline & & Microbiome & MCRBM \\
\hline & & GIT_permeability & GIT_PERM \\
\hline & \multirow[t]{9}{*}{ Morphology } & Region & CNS_REGION \\
\hline & & Tracts & CNS_TRACT \\
\hline & & Neuroanatomy & NEUANTMY \\
\hline & & Spines & SPINE \\
\hline & & Synapses & SYNAPSE \\
\hline & & Dendrites & DENDR \\
\hline & & PSD & PSD \\
\hline & & Skeletal_muscle & SKEL_MUSC \\
\hline & & GIT & GIT \\
\hline \multirow[t]{12}{*}{ Behavior } & \multirow[t]{3}{*}{ Social } & Social_motivationinteraction & SOC_MOTINT \\
\hline & & Social_recognition & SOC_REC \\
\hline & & Social_communication & SOC_COM \\
\hline & \multirow[t]{3}{*}{ Stereotypies } & Repetitive_behavior & REP_BHVR \\
\hline & & Perseverative_behavior & PERSVRTN \\
\hline & & Restricted_interests & RSTR_INTRST \\
\hline & \multirow[t]{6}{*}{ Other_behavior } & Anxiety & ANXTY \\
\hline & & Avoidance_behavior & AVD_BHVR \\
\hline & & Aggression & AGGRSN \\
\hline & & Escape_behavior & ESC_BHVR \\
\hline & & Food_intake & FOOD_INT \\
\hline & & Circadian_rhythm & CIRCDN \\
\hline
\end{tabular}

Table 1 Categories used in the database and circular barplots. Every data point was assigned to a category, subcategory, and an interpretation (Continued)

\begin{tabular}{|c|c|c|c|}
\hline Category & Subcategory & Interpretation & Shortcut \\
\hline \multirow[t]{19}{*}{ Neurology } & \multirow[t]{6}{*}{ Cognition } & Spatial_learning & SPTL_LRN \\
\hline & & Associative_learning & ASSO_LRN \\
\hline & & Instrumental_learning & INSTR_LRN \\
\hline & & Perceptual_learning & PRCPTL_LRN \\
\hline & & Recognition_memory & REC_MEM \\
\hline & & Attention & ATTN \\
\hline & \multirow[t]{5}{*}{ Motor } & Activity & $\mathrm{ACT}$ \\
\hline & & Neuromuscular & NRMUSC \\
\hline & & Sensorimotor & SENSMOT \\
\hline & & Motor_learning & MOT_LRN \\
\hline & & Motor_general & MOT_GEN \\
\hline & \multirow[t]{6}{*}{ Sensory } & Somatosensory & SOMSENS \\
\hline & & Sensorimotor_gating & SENSMOT_GT \\
\hline & & Olfaction & OLF \\
\hline & & Vision & VIS \\
\hline & & Audition & AUD \\
\hline & & Vestibular & VEST \\
\hline & \multirow[t]{2}{*}{ Other_neurology } & Seizures & SEIZRS \\
\hline & & Sleep & SLEEP \\
\hline
\end{tabular}

underlie the social deficits in mutant mice, a brief treatment with romidepsin, a highly potent class I histone deacetylase (HDAC) inhibitor, was chosen as a therapeutic. Romidepsin alleviated social deficits in SHANK3deficient mice in both models investigated (ex21|PRO [154, 198] and ex4-9|ANK [154]). The juvenile to lateadolescent period was reported to be the most effective therapeutic window. The treatment had no effect on increased repetitive behaviors [154]. On a molecular basis, HDAC2-inhibition elevated the expression and histone acetylation of Grin $2 a$ and actin-regulatory genes, for instance from the RAC1-pathway. This led to restored NMDAR-functionality and F-actin levels in the PFC of SHANK3-deficient mice. RNA sequencing data additionally showed that the majority of genes downregulated in SHANK3-deficient conditions (enriched in actin cytoskeleton-mediated transport, signal transduction pathways and developmental processes) were normalized following romidepsin treatment. Some genes identified as key ASD risk factors were increased after treatment, which might also be a potential mechanism for the romidepsin-induced rescue of social deficits [154]. An array of additional pharmacological agents currently used in psychiatric practice was tested, of which only valproic acid (mood stabilizer and low-affinity class-I HDAC inhibitor) showed some effect on social deficits 
in SHANK3-deficient mice, which were not long-lasting. This did also hold true for the pan-HDAC inhibitor Trichostatin A [154]. In an attempt to increase the durability of the effects of Romidepsin even in adult SHANK3deficient mice, it was combined with GSK-LSD1, which selectively inhibits the histone demethylase KDM1A (also known as LSD1). Indeed this combination of compounds induced a long-lasting normalization of social behavior, aggression levels, synaptic protein levels, synaptic transmission, and histone acetylation even in adult animals for up to 21 days post-treatment. RNA-levels of Grin1 were also partly normalized. Monotherapy with GSK-LSD1 did not induce a long-lasting amelioration of phenotypes [198].

Another promising candidate to target epigenetic mechanisms seems to be Entinostat (MS-275), a potent, longlasting and PFC-selective class I HDAC-inhibitor. Treatment with Entinostat resued social behavior for up to 11 days post-treatment. Additionally, protein-levels of the NMDAR-subunits GRIN1/2A/2B on the cellular surface, RNA-levels of Arhgef7, the amount of F-actin, and deficits of synaptic transmission were normalized by Entinostat. However, repetitive behavior was not beneficially influenced [199].

Furthermore, increased levels of EHMT1 and EHMT2 were observed in mice of the models ex21|PRO (heterozygous) and ex4-9|ANK (homozygous), which lead to increased H3K9me2 di-methylation levels. This was then used as therapeutic target [156]. In the model ex21|PRO application of the highly potent and specific EHMT1/2 (histone methyltransferases) inhibitor UNC0642 induced a long-lasting improvement of social behavior, while dimethylation levels were also normalized. On a molecular level UNC0642 normalized the transcript-levels of 107 previously down-regulated and 84 previously upregulated genes. Among those genes were Homer1 and Arc. Additionally, H3K9me2-levels on the Arc-promotor were restored to WT-level. Interestingly, the RNA- and protein-level of Grin1 and Grin $2 a$, which had not been affected by SHANK3 deficiency, were upregulated upon UNC0642-treatment. Fitting this, the H3K9me2 occupancy at their respective promotor sites was reduced. On a physiological level UNC0642 also rescued NMDARmediated synaptic transmission. Notably, neither the beneficial effects of UNC0642 on social behavior, nor on synaptic transmission were present if an Arc shRNAconstruct was co-administered, even inducing similar phenotypes in WT-mice. On the other hand, lentiviral knockdown of Ehmt1 and Ehmt2 in the PFC also normalized social behavior and synaptic transmission. UNC0642-treatment had no effect on repetitive behaviors. A general health screening did not show any major organic or behavioral side effects of UNC0642. Similarly, UNC0642 also rescued social preference and di- methylation levels in mice of the model ex4-9|ANK. The low-potency EHMT1/2 inhibitor BIX01294 only elicited a transient amelioration of social deficits in heterozygous ex21|PRO mice.

ARC-activation Fitting some previously made assumptions derived from the observation of epigenetic dysregulation in SHANK3-deficient animals, local lentiviral activation of ARC in the PFC resulted in an increased social preference in heterozygous ex21|PRO mice [156].

Cofilin-inhibition It has been described that heterozygous SHANK3 deficiency in ex21|PRO mice resulted in a reduction of cortical F-actin and an associated impairment of RAC1/PAK activity that led to an increased actindepolymerization through increased activity of CFL1. Accordingly, inhibition of CFL1 via a brain-permeable CFL1 inhibitory peptide (TAT-p-cofilin peptide) was chosen as therapeutic strategy to rescue the phenotypes observed in these mice. The social deficits, repetitive behaviors, and NMDAR-hypofunction in the PFC and hippocampus were indeed alleviated by inhibiting CFL1 [177]. Notably, local injection into the PFC was sufficient to increase social preference and reduce self-grooming. These findings are in line with the previously made assumptions, concerning the affected pathways [177], and also findings from other studies [154].

RAC1-activation In the same study that targeted CFL1 as downstream effector in the RAC1/PAK-pathway, a constitutively active form of RAC1 (CA-RAC1, HSVdelivered) was injected into the PFC of mutant ex21|PRO mice to achieve similar effects. Indeed, social deficits and NMDAR-hypofunction in pyramidal neurons of the PFC were also alleviated by activating RAC1. Notably, the observed deficits were inducible by inhibiting PAK or RAC1 in wild-type mice [177]. Thus, targeting actin regulators and specifically the RAC1/PAK/LIMK1/CFL1pathway, which controls actin depolymerization, might provide a general strategy for future treatment of PMDS or SHANK3-associated ASD. Most interestingly, the RAC1dependent and ARP2/3-mediated actin polymerization process [204] and the associated subunits or regulators of the WAVE regulatory complex, such as WASF1 [94], NCKAP1 [202], ABI1 [94] or BAIAP2 [202], were also dysregulated in models of SHANK3 deficiency and might be potential therapeutic targets to influence neuronal actin dynamics.

CLK2-inhibition As phosphorylation of targets in the PI3K/AKT/MTOR-pathway was reduced in SHANK3deficient ex21|PRO mice, CLK2, which induces the inactivation of AKT via activation of a PPP2CA regulatory subunit (PPP2R5B), was chosen as a possible therapeutic 
target. Indeed, CLK2 inhibition via application of TG003 was beneficiary in a SHANK3-deficient state, restoring sociability, reducing repetitive behaviors, and reinstating AKT-phosphorylation. However, TG003 had no influence on avoidance behavior [178].

PKA-inhibition Since corticostriatal hyperactivity was observed in SHANK3-deficient mice of the model ex1316|PDZ, PKIA as potent peptidergic inhibitor of the PKA catalytic subunit was expressed in medial striatal neurons to normalize their glutamatergic synapse maturation. Indeed glutamatergic neurotransmission was reduced by PKIA. On a behavioral level PKIA expression partly normalized repetitive behavior, anxiety-levels, and hypoactivity in these mice [183].

NTRK2-agonism The NTRK2-agonist 7.8-DHF beneficially influenced spatial learning, but had no influence on social deficits, repetitive behavior, or hypoactivity in ex13-16|PDZ SHANK3-deficient mice [162].

Troponin-activation Although muscular hypotonia is a pivotal and early-onset feature of the PMDS, treatments for this symptom have not been investigated frequently. A similar phenotype was observed in ex11|SH3 SHANK3mutant mice, becoming manifest as an impaired neuromuscular performance in the hanging wire test, but also as morphological alterations of the spinal cord and the neuromuscular junction. The muscular dysfunction was partly normalized by Tirasemtiv (CK2017357), a fastacting skeletal muscle troponin activator [111].

\section{Genetic restoration}

Because ASD is a neurodevelopmental disorder [3], it is of great interest whether some of the synaptic and behavioral impairments are reversible in adults. Anyhow it is probably beneficial to initiate treatment as early as possible.

Thus, the finding that adult restoration of SHANK3expression in a cKI ex13-16|PDZ murine model reversed repetitive self-injurious grooming and social-interaction deficits is of great importance, although anxiety or motor coordination deficits were not alleviated. Furthermore, genetic restoration normalized deficitary neurotransmission, synaptic protein composition, and spine morphology. The behavioral deficits that were irreversible in adulthood were improved by early postnatal intervention and fully rescued by germline restoration [83]. Similarly, early genetic restoration in ex13|PDZ mice alleviated increased repetitive behaviors, social deficits, and hypoactivity [176]. Another study on Cre-mediated genetic rescue of Shank3 during adulthood demonstrated an apparent amelioration of avoidance behavior, motor performance, and synaptic transmission in ex21|PRO-InsG3728 mice, while hypoactivity was not improved. However, the authors considered these results to be uninterpretable, since extensive control conditions revealed that some phenotypes were also "rescued" in Cre-positive but vehicletreated mice, hinting at an effect of the Cre-transgene [187]. This study demonstrated that experiments, which are based on Cre-expression, should be carefully controlled.

Local genetic Shank3-restoration in the anterior cingulate cortex of adult ex13-16|PDZ cKI-mice was sufficient to normalize social deficits and synaptic protein levels, but only partly corrected alterations of synaptic transmission and spine density. Genetic restoration in this prefrontal area did not influence avoidance, repetitive, anxiety-like or hypoactive behavior [160]. Likewise, general, but also local restoration of Shank3 in the medial PFC was sufficient to normalize social behavior and ameliorate encoding deficits concerning neuronal activity, which is induced by either self-experience or experiences made by conspecifics. The onset and progression of the normalization process of social behavior also correlated with the changes in neuronal encoding [196].

Most interestingly, specific cKI-mediated restoration of SHANK3 levels in cells of the caudal embryo or somatosensory neurons (ex13-16|PDZ-Cdx2 $2^{\mathrm{Cre}}$, Advillin ${ }^{\mathrm{Cre}}$ ) was sufficient to normalize somatosensory deficits and abnormal tactile sensorimotor gating, as well as social interaction or recognition, avoidance behavior, and anxiety-like behaviors. However, SHANK3reexpression in these cells did not influence increased repetitive behaviors or cognitive deficits. Moreover, SHANK3-restoration in somatosensory neurons also normalized the number of PVALB-positive neurons in the somatosensory cortex and basolateral amygdala, but not in the visual cortex. Notably, Tamoxifeninduced Cre-expression in somatosensory neurons of

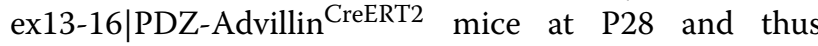
SHANK3-restoration via cKI also led to normalized tactile sensorimotor gating and social interaction behavior. Reexpression of SHANK3 at this later timepoint did not influence certain abnormal somatosensory properties, social recognition, avoidance behavior, anxiety-like behaviors, and long-term recognition memory deficits. Late SHANK3-restoration in somatosensory neurons normalized the number of PVALB-positive neurons exclusively in the somatosensory cortex, but not in the basolateral amygdala and visual cortex, suggesting differing therapeutic windows to influence certain brain regions, which might also affect the extend of rescued phenotypes [140].

Considering the abovementioned findings, genetic restoration of SHANK3 levels or of downstream mediators during adulthood or earlier timepoints might relieve 
some of the synaptic and behavioral impairments, in a brain region and cell-specific mode.

\section{Local neuronal activation}

Prefrontal areas As described above, genetic SHANK3 restoration specifically in the anterior cingulate cortex of adult ex13-16|PDZ cKI mice normalized social behavior and local synaptic protein levels, but only partly corrected alterations of synaptic transmission and spine density, and did not improve avoidance, repetitive, anxiety-like, or hypoactive behavior. Accordingly, optogenetic activation of this area normalized social behavior and anxiety-levels, but did not influence hypoactivity. Similar effects were observed upon DREADD-mediated activation of pyramidal cells localized in the anterior cingulate cortex, which rescued social deficits, but did not influence self grooming [160]. Another study reported that DREADD-mediated and Camk2-driven activation of the PFC normalized social behavior, NMDAR-mediated synaptic transmission, GRIN2A protein-levels, and $S g k 2$ mRNA-levels. These beneficial effects were short-lasting and not present, if a TAT-peptide blocking SGKs was co-administered [197].

Dorsal striatum In a study, which examined the differential effects of SHANK3 deficiency on either DRD1positive MSNs of the direct/striatonigral pathway or DRD2-positive MSNs of the striatopallidal/indirect pathway in the dorsal striatum of ex13-16|PDZ mice, it was described that neurons of the indirect pathway were generally more affected. Fittingly, DREADD-mediated activation of these neurons normalized repetitive behaviors as measured by time spent self-grooming, while neither activation nor inhibition of DRD1-positive MSNs had significant effects on behavioral or motor phenotypes. A trend towards attenuated hypoactivity upon activation of MSNs of the striatonigral pathway was not statistically significant [182].

Dorsal raphe nucleus Another study targeted the dorsal raphe nucleus as the major serotonergic nucleus to influence social interaction behavior in ex13-16|PDZ SHANK3-deficient mice. Optogenetic activation of these serotonergic neurons during a social interaction training paradigm enhanced social preference in SHANK3deficient mice. The effect persisted for at least 10 days, if the training lasted for 3 consecutive days [165]. This finding might implicate that the application of certain therapeutics might benefit from an adjusted behavioral therapy that is carried out in parallel.

Ventral tegmental area In the same study that investigated the serotonergic raphe nucleus, the VTA, representing a crucial part of the dopaminergic system, was also targeted via optogenetic activation. This did not influence the deficits of social behavior, but only induced a preference for certain spatial positions in the test cage [165].

\section{Diet-based therapy}

Zinc One of the environmental factors, which are associated with an increased risk of ASD, is Zinc deficiency $[53,54]$. As SHANK3 self-multimerizes in a Zincdependent manner via the SAM-domain [59, 102], Zinc supplementation has been investigated in the ex1316|PDZ model of SHANK3 deficiency. Oral Zinc supplementation (150 ppm) for 6 weeks fully normalized phenotypes like social recognition, repetitive behavior, and anxiety-like behavior, but only partly rescued hypoactivity in these mice. Interestingly, Zinc supplemented mutant mice exhibited normalized NMDAR decay kinetics, while the amplitude of NMDAR-EPSCs, which had originally been intact, was decreased after Zinc supplementation. In line with this, functional striatal LTP induction was lost in mutant animals after supplementation, but not in WT mice. Additionally, an increased intensity of SHANK2 was observed in corticostriatal and thalamostriatal synapses [168]. Another study investigated chronic maternal Zinc supplementation (150 ppm) as an alternative strategy to prevent ASD-like phenotypes in ex13-16|PDZ SHANK3-mutant animals. Deficits of social behavior, increased repetitive behavior, and elevated anxiety levels were permanently reversed by maternal $\mathrm{Zn}$ supplementation. Striatal NMDAR-mediated synaptic transmission and presynaptic short-term plasticity were rescued as well, while the AMPAR-mediated transmission was still impaired. Notably, maternal Zn supplementation resulted in an impaired AMPAR- and NMDAR-mediated transmission in wild-type animals, without affecting their behavior [164].

Lactobacillus reuteri Besides Zinc supplementation, another diet-based therapy studied in the murine model ex13-16|PDZ is the oral substitution of Lactobacillus reuteri specimen. Treatment with $L$. reuteri influenced social behavior beneficially [161, 211], and normalized induced synaptic transmission and plasticity in the VTA [161], while hypoactivity [161] or anxiety-like behavior [211] were not influenced. Notably, the beneficial effects of $L$. reuteri were dependent on vagal signals to the brain and OXTR-signaling [161].

\section{Conclusions and outlook}

Validity and role of animal models in PMDS research

Although different genetic modifications were applied in animal models of SHANK3 deficiency, especially exonspecific KO strategies (ex4-22|ALL, ex4-9|ANK, ex47|ANK, ex9|ANK, ex11|SH3, ex13|PDZ, ex13-16|PDZ, ex14-16|PDZ, ex21|PRO, ex11-21|SH3-PRO) result in similar phenotypes with varying severity. It had been 
hypothesized that the disruption of specific exons would result in diverging behavioral phenotypes, but such a clear isoform-related pattern cannot be observed in the literature reviewed. Regardless of which exons were targeted, all major ASD-related phenotypes have been reported in these SHANK3-deficient models across multiple studies.

However, the absence of such distinct patterns might not indicate the non-existence of such differential phenotypes in general, but rather imply that commonly applied testing paradigms lack specificity and sensitivity. Customizable and highly automatized analysis of freely interacting groups of mice enabled by solutions based on machine learning and other techniques, which should ideally be open-source, could reveal more nuanced, but also more comparable behavioral phenotypes in the future $[155,157,159,234,235]$. On the other hand, this lack of clear isoform-specific patterns could hint at the properties of ASD pathophysiology in general. Unlike a defined disorder, which follows the classical order of an underlying etiology and subsequently resulting clinical abnormality, ASD might rather be a compensatory process that emerges as the common outcome of various disturbances impacting neuronal physiology. The question whether ASD should be regarded as a compensatory mechanism to tackle multiple abnormalities of the nervous system is also raised by the apparent functional heterogeneity of ASD risk genes [14, 15]. If the appearance of ASD would rely at least partly on the initiation of compensatory mechanisms, the molecular changes, which can be observed in animal models of SHANK3 deficiency or other models of ASD, should not be principally regarded as disruptive, because such changes might be part of beneficial mechanisms. These could also represent potential therapeutic targets. Nevertheless, some studies suggest that the SHANK3-isoform composition contributes to the severity and reproducibility of the observed deficits. For instance, the model ex13-16|PDZ, which lacks the hypothetical protein isoforms SHANK3a-d, showed a more robust phenotype than ex4-9|ANK mice [155], lacking SHANK3a-b. Direct comparisons of SHANK3-deficient models are needed to eliminate confounding factors like methodological variability, which limit the comparability in the current literature. Such studies might then be able to elucidate isoform-specific functions, but also the compensatory mechanisms between them. Generally, full deletion models of SHANK3 encompassing exons 4-22 (ex4-22|ALL) and thus lacking all isoforms facilitate the study of SHANK3's basic biological functions by avoiding inter-isoform compensation. Such models also provide an improved construct validity regarding PMDS with a full deletion of SHANK3.

Additionally, the investigation of point/missense mutations provides an interesting option to study modular functions of SHANK3, as these animal models were shown to only recapitulate specific phenotypes. For instance, concerning the major ASD-related phenotypes the model ex8|ANK-Q321R only showed increased repetitive behavior [132], while in the model ex17|PRMS685I, affecting the ABI1-binding site, only social behavior was deficient [94]. An ASD-related mutation introduced in animals of the model ex21|PRO-InsG3680 had more general effects, resulting in abnormal social behavior, increased stereotyped behaviors, elevated anxietylevels, and impaired motor and sensory function [127]. Similar behavioral domains were affected in mice harboring a schizophrenia-associated mutation (ex21|PROR1117X), but these animals did not show stereotypies [127]. Notably, ex21|PRO-InsG3680 and -R1117X result in different isoform patterns with an almost complete deletion of SHANK3, and the expression of a truncated protein, respectively, which might be causative for their differing phenotype concerning stereotyped behaviors and subphenotypes of social behavior [127].

Conditional and thus cell-type-specific deletion of SHANK3 has also been insightful, concerning the cellular and regional foundation of certain deficits observed in constitutive deletion models. Targeted SHANK3 deletion in somatosensory neurons or the caudal part of the embryo and neural tube (ex13-16|PDZ-Advillin ${ }^{\mathrm{Cre}}$ or $\mathrm{Cdx2}{ }^{\mathrm{Cre}}$ [140]) was sufficient to induce social deficits, avoidance behavior, anxiety, and sensory dysfunction in these mice, but did not result in stereotyped behavior or cognitive deficits. When either inhibitory (ex1416|PDZ-Viaat ${ }^{\text {Cre }}$ [131], ex4-22|ALL-Dlx5/6 ${ }^{\text {Cre }}$ [129]) or excitatory neurons (ex14-16|PDZ-Emx1 ${ }^{\text {Cre }}$ [133], ex422|ALL-NEX ${ }^{C r e}$ [129]) were targeted seperately, stereotyped behavior was consistently observed in all models, while elevated anxiety levels were only present if GABAergic neurons were targeted. Finally, differential deletion of SHANK3 either affecting DRD1- or DRD2-positive neurons (ex4-22|ALL-Drd1 ${ }^{\text {Cre }}$ or -Drd2 ${ }^{\mathrm{Cre}}$ [129]) resulted in a minor anxiety-like phenotype and increased repetitive behavior, respectively. Neither of them resulted in deficient social behavior. Importantly, one study [140] also investigated the impact of different timepoints of inducing postnatal SHANK3 deficiency in the model ex13-16|PDZ-Advillin ${ }^{\text {CreERT2 }}$. Induction on postnatal day 5 (P5) recapitulated all major phenotypes observed in animals with prenatal Cre-expression, including abnormal social interaction and recognition, avoidance behavior, increased anxiety-levels, impaired sensorimotor gating and somatosensory function, and reduced numbers of PVALB-positive neurons in the somatosensory cortex and the amygdala. When induced at P10, SHANK3 deficiency did not result in avoidance behavior, anxiety, or an abnormal number of PVALB-neurons in the amygdala. Lastly, tamoxifen-mediated induction at P28 only resulted in abnormal social recognition, impaired sensorimotor 
gating and somatosensory function, and reduced numbers of PVALB-positive neurons in the somatosensory cortex. These results underline the importance of the developmental aspect of SHANK3-dependent phenotypes.

In summary, many deficits that were observed in SHANK3-deficient animals recapitulate symptoms that are observed in PMDS patients, ranging from ASD-related phenotypes such as social deficits or repetitive behaviors, to motor and sensory abnormalities resembling hypotonia or impaired nociception in human patients. Thus, such models provide a valid and valuable instrument to advance our understanding of the neurobiological basis of PMDS as SHANK3-associated syndrome, but also ASD or the functioning of the CNS and other organs in general.

\section{Translational implications for PMDS treatment}

A wide array of therapeutic strategies has been applied in animal studies investigating SHANK3 deficiency in rodents, ranging from mechanisms targeting glutamatergic neurotransmission to epigenetic regulation of gene expression. Although some of these treatments showed promising results, it has to be noted that a comprehensive screening for side effects has only rarely been reported. Considering the fact that the different compounds or strategies, and also timepoints of intervention had differential effects on the observed abnormalities, it seems likely that a combination of therapies might be beneficial. However, most of the pharmaceutical compounds or other strategies described in the sections above have not translated into clinical routine, although there has been preliminary evidence of beneficial effects for some of them in PMDS-patients. Thus, further clinical studies have to be conducted to strengthen the evidence. Several patient studies are underway to establish therapies, which might alleviate core symptoms of PMDS and increase quality of life in general. Despite the fact that the PMDS affects multiple organs, including the musculoskeletal or gastrointestinal system, most of these studies focus on neuropsychiatric symptoms. Therapies, which would improve symptoms associated to organs other than the CNS, should also be investigated, as they often affect everyday quality of life.

\section{Treatments used in clinical practice}

Generally, there is no specific treatment option for PMDSpatients. Clinical management of these patients focuses on comorbidities like epilepsy, for which general treatment guidelines are already available. The neuropsychiatric domain of PMDS, which also includes ASD, is approached according to the presently recommended strategies. These include parent-mediated, school-based, and therapist-delivered interventions. A primary objective should also be to support independence of the patients during adulthood. Medication can ameliorate symptoms caused by comorbidities like epilepsy, irritability, hyperactivity, and anxiety, but pharmacological therapy of core symptoms is difficult and an active field of research [3, 236-238].

Compounds, which have been shown to relieve some of the symptoms observed in PMDS patients specifically, include IGF1, insulin, lithium, and risperidone. Early studies reported beneficial effects of IGF1 on the synaptic transmission of patient-derived neurons [239] and on ASD-associated behaviors in PMDS patients [240]. The effects of IGF1 are now further investigated in a phase 2 trial (NCT01525901). Subtle effects were described for insulin, which improved motor development, cognition, and social skills [241, 242]. In a case report, low-dose risperidone alleviated psychomotor agitation, aggression, anxiety, and insomnia, which had previously been described in this PMDS-patient [243]. More recently, several case reports on the effects of lithium in PMDS-patients with a comorbid catatonia or bipolar disorder demonstrated a stabilization of mood and affect, reversal of the catatonia features, and an improvement of regression [244-246]. The efficacy of lithium is currently further studied in a phase 3 trial (NCT04623398). Other substances like recombinant human growth hormone (NCT04003207, completed phase 2 trial), OXT (NCT02710084, completed phase 2 trial, undergoing peer-review), Q10 Ubiquinol (NCT04312152), and the inhibitor of the RAS/RAF/MAPK pathway AMO-01 (NCT03493607, PMDS with epilepsy) are currently investigated or undergo peer-review for publication.

\section{Future perspectives}

Genetic restoration of Shank3 in rodents has been shown to reverse core deficits even in adult animals [83, 140, 160, 176]. Direct gene targeting in humans seems plausible as future treatment option for certain forms of ASD as the recent success of many techniques associated to the detection and treatment of genetic disorders might provide the neccessary tools. Especially therapies developed for spinal muscular atrophy type $1[247,248]$, or the manipulation of gene products rather than the DNA itself $[249,250]$ like targeting haploinsufficiencies by CRISPR-mediated gene activation via promotors or enhancers [249], might serve as a proof of principle for other genetic disorders. Earlyonset therapy, which might be crucial concerning ASD, will also be facilitated by the detection of mutations in utero and during early postnatal development, which is now possible [3]. Defects with a large effect seen in syndromes such as the PMDS or fragile $\mathrm{X}$ syndrome, but also mutations affecting high confidence ASD risk genes such as $S C N 2 A$ and CHD8 $[14,15]$ will represent primary targets of such new therapies [3]. With regard to SHANK3-insufficiency it has to be noted that the resulting behavioral phenotype is highly sensitive to gene dosage, 
which has been demonstrated in the abovementioned studies on SHANK3 deficiency or overexpression. Thus, the increase or decrease of expression induced by genetic targeting of SHANK3 in humans would have to be rather precise to enable individual dose adjustments to avoid side effects reminiscent of either manic- or ASD-like behavior, respectively.

Additionally, compounds that showed promising results in preclinical animal studies, such as epigenetic targe- ting via histone deacetylase inhibitors $[154,156,198,199]$ or modulation of peripheral GABAAR [140], should be tested in the setting of clinical trials to evaluate their efficacy in humans. In the long-term, the combination of multiple treatment strategies seems to be necessary, as none of the proposed compounds influences all domains affected in human patients.

New approaches in preclinical animal studies should take into account the evidence for certain therapeutic

Table 2 Summary of the models and respective literature used to generate the database. Experiments from a total of 94 publications on SHANK3 deficiency were included in the database and categorized as described in Table 1

\begin{tabular}{|c|c|c|c|}
\hline Code & Strategy & Addition & Literature \\
\hline ex4-22|ALL & $\mathrm{KO}$ & Murine & $\operatorname{HET}[92,128,130] ; \operatorname{HOM}[92,128-130]$ \\
\hline ex4-9|ANK & $\mathrm{KO}$ & Murine & $\begin{array}{l}\text { HET }[78,80,122,124,167,190,200,207,209,218, \\
220] ; \text { HOM }[78,80,124,128,140,154-156,167,177, \\
190,209,218,220,252]\end{array}$ \\
\hline ex4-7|ANK & $\mathrm{KO}$ & Murine & HOM [90] \\
\hline ex9|ANK & $\mathrm{KO}$ & Murine & $\operatorname{HOM}[82,175]$ \\
\hline ex11|SH3 & $\mathrm{KO}$ & Murine & $\begin{array}{l}\text { HET }[123,219] ; \text { HOM }[111,118,123,157,193,202 \text {, } \\
203,212,219]\end{array}$ \\
\hline ex13|PDZ & $\mathrm{KO}$ & Murine & $\operatorname{HET}[139,176] ; \operatorname{HOM}[139,176]$ \\
\hline ex13-16|PDZ & $\mathrm{KO}$ & Murine & $\begin{array}{l}\text { HET }[106,140,151,166,181,188,201,209,213,214] ; \\
\operatorname{HOM}[90,94,140,151,155,158-166,168,181-183 \\
188,189,192,205,206,208,209,211,213-215]\end{array}$ \\
\hline ex13-16|PDZ & $\mathrm{cKI}$ & Murine; Genetic restorationvia Cre-recombinase & $\operatorname{HET}[140,196] ; \operatorname{HOM}[83,160]$ \\
\hline ex14-16|PDZ & $\mathrm{KO}$ & Murine & $\operatorname{HOM}[131,133]$ \\
\hline ex21|PRO & $\mathrm{KO}$ & Murine & $\begin{array}{l}\text { HET }[154,156,177-179,194,197-199] ; \text { HOM [125, } \\
177-179,191]\end{array}$ \\
\hline SHANK1+SHANK3-ex11|SH3 & $\mathrm{KO}$ & Murine & HOM [138] \\
\hline ex6|ANK & $\mathrm{KO}$ & Rat & $\operatorname{HET}[134,180,216,217] ; \operatorname{HOM}[134,180,217]$ \\
\hline ex11-21|SH3-PRO & $\mathrm{KO}$ & Rat & HET [135]; HOM [135] \\
\hline ex6,ex12|ANK,SH3 & $\mathrm{KO}$ & Macaque & HET $[137,227]$ \\
\hline ex21|PRO & $\mathrm{KO}$ & Macaque & HET or HOM [136] \\
\hline ex8|ANK-Q321R & $\mathrm{KI}$ & Murine; Missense point mutation & HET [132]; HOM [132] \\
\hline ex17|PRM-S685| & $\mathrm{KI}$ & Murine; Missense point mutation & HET [94]; HOM [94] \\
\hline ex21|PRO-InsG3680 & $\mathrm{KI}$ & Murine; Frameshift mutation & $\operatorname{HET}[127] ; \operatorname{HOM}[127,210]$ \\
\hline ex21|PRO-R1117X & $\mathrm{KI}$ & Murine; Non-sense point mutation & HET [127]; HOM [127] \\
\hline ex21|PRO-InsG3728 & $\mathrm{KI}$ & Murine; Frameshift mutation & $\operatorname{HET}[126,187] ; \operatorname{HOM}[126,187]$ \\
\hline ex4-22|ALL-NEX Cre & $\mathrm{cKO}$ & Murine; Affecting neocortical excitatory neurons & HOM [129] \\
\hline ex4-22|ALL-DIx5/6 & $\mathrm{CKO}$ & Murine; Affecting GABAergic forebrain neurons & HOM [129] \\
\hline ex4-22|ALL-Drd1 1 Cre & $\mathrm{CKO}$ & Murine; Affecting DRD1-positive neurons & HOM [129] \\
\hline ex4-22|ALL-Drd2 ${ }^{C r e}$ & $\mathrm{CKO}$ & Murine; Affecting DRD2-positive neurons & HOM [129] \\
\hline ex4-22|ALL-Nav1.8Cre & $\mathrm{CKO}$ & Murine; Affecting Nav1.8-positive cells & HET [92]; HOM [92] \\
\hline ex13-16|PDZ-AdvillinCre & cKO & Murine; Affecting somatosensory neurons & HET [140]; HOM [140] \\
\hline ex13-16|PDZ-Cdx2 ${ }^{\text {re }}$ & $\mathrm{CKO}$ & Murine; Affecting caudal embryonic lineage & HET [140] \\
\hline ex14-16|PDZ-Viaat ${ }^{C r e}$ & cKO & Murine; Affecting GABAergic cells & $\operatorname{HOM}[131]$ \\
\hline ex14-16|PDZ-Em×1 ${ }^{C r e}$ & $\mathrm{CKO}$ & Murine; Affecting excitatory neurons and glia & HOM [133] \\
\hline SHANK3-eGFP & TG & Murine; Overexpression of SHANK3 & $\operatorname{HEM}[93,96,151,205,228-231]$ \\
\hline
\end{tabular}

KO knockout, KI knockin, $C K O$ conditional KO, CKI conditional KI, TG transgenic, HET heterozygous, HOM homozygous, HEM hemizygous 
windows to influence specific circuits and the associated behavioral phenotype [140], but also that it might be possible to reopen those critical periods of plasticity to enhance treatment efficacy. For instance, it has been reported recently, that the reopening of a critical period for social reward learning, which depends on OXT-mediated LTD in the nucleus accumbens, can be established by 3,4-methylenedioxymethamphetamine (MDMA) [251]. Thus, behavioral abnormalities, which are otherwise largely insusceptible to pharmaceutical compounds or behavioral interventions due to certain developmental time frames limiting neuronal plasticity, might be influencable by utilizing a sequential combination of therapeutic strategies including MDMA. In general, the goal of any translational and clinical scientific approach to symptoms of SHANK3 deficiency and the PMDS should be to address the complaints expressed by patients or their parents. This does not necessarily imply the normalization of their behavioral traits. Also apart from neuroscientific questions addressing ASD, more research is needed on other symptoms like sleep disturbances and gastrointestinal problems, which frequently occur in these patients.

\section{Appendix}

For the programming of the circular barplots a database containing abnormality scores $(1=$ no change, $2=$ abnormal with respect to control condition) for all the experiments, which were reported in the literature on SHANK3deficient animals included in this review (total of 94 publications, summarized in Table 2), was generated. Every data point was assigned to a category (Structure \& Function, Behavior, Neurology), a subcategory (Structure \& Function: Molecular, Physiology, Morphology; Behavior: Social, Stereotypies, Other; Neurology: Motor, Sensory, Cognition, Other), and an interpretation (e.g., protein composition, repetitive behavior, or somatosensory function; also see Table 1 for the full list). To compile the plots, the data was pooled according to the exons targeted and homo- or heterozygosity. Finally the mean was calculated for each interpretation and displayed as circular barplots. Notably, data was summarized in such a way, even if the same exons were targeted in independently published strains (e.g., ex4-22|ALL $[128,130]$ ). As studies on macaques either investigated individuals or genetically heterogenous groups, the data was pooled according to species (Macaca fascicularis). No statistical tests were applied, since this approach was used for visualization purposes only. R [253] was used to generate plots. Additional packages used were tidyr [254], plyr [255], dplyr [256], reshape2 [257], and ggplot2 [258].

Abbreviations and the writing format for genes and proteins were chosen according to the guidelines of the HUGO Gene Nomenclature Committee for humans and the Mouse Genome Informatics for rodents. They are not included in the abbreviations list, as they are regarded as symbols.

\section{Abbreviations \\ ASD: Autism spectrum disorder; SHANK: SH3 and multiple ankyrin repeat domains; ProSAP: Proline-rich synapse-associated protein; PMDS: Phelan-McDermid syndrome; DSM-5: Fifth edition of the American Psychiatric Association's Diagnostic and Statistical Manual of Mental Disorders; ADHD: Attention-deficit hyperactivity disorder; CNV: Copy number variation; PSD: Postsynaptic density; CNS: Central nervous system; PNS: Peripheral nervous system; PDZ: PSD95/DlgA/Zo-1; SH3: Src homology 3; SPN: \\ SHANK/ProSAP/N-terminal; PRO: Proline-rich; SAM: Sterile alpha motif; ANK: Ankyrin repeats; MSN: Medium spiny neuron; PRM: Proline-rich motif; PFC: Prefrontal cortex; VTA: Ventral tegmental area; PAM: Positive allosteric modulator; OXT: Oxytocin; MDMA: 3,4-Methylenedioxymethamphetamine}

\section{Acknowledgements}

Not applicable.

\section{Authors' contributions}

Conceptualization, methodology and visualization: JPD; writing — original draft preparation: JPD; writing — review and validation: TMB; financial support: TMB, supervision: TMB. The authors have read and approved the final version of the manuscript.

\section{Authors' information}

Not applicable.

\section{Funding}

TMB is supported by the DFG (A02, Project-ID 251293561 SFB1 149; BO1718/7-1 and BO1718/8-1), the Else Kroener Foundation, the Helmholtz Gesellschaft (DZNE UIm), and the Innovative Medicines Initiative (IMI) Joint Undertaking under grant agreement nos 777394 (AIMS2Trials) and 847818 (CANDY), resources of which are composed of financial contribution from the European Union's Seventh Framework Program and EFPIA companies' in kind contribution. Open Access funding enabled and organized by Projekt DEAL.

\section{Availability of data and materials}

The database, which was generated for the programming of the circular barplots, is available upon request.

\section{Declarations}

Ethics approval and consent to participate

Not applicable.

\section{Consent for publication}

Not applicable.

\section{Competing interests}

The authors declare that they have no competing interests.

Received: 15 July 2021 Accepted: 27 September 2021

Published online: 16 November 2021

\section{References}

1. Wang K, Gaitsch H, Poon H, Cox NJ, Rzhetsky A. Classification of common human diseases derived from shared genetic and environmental determinants. Nat Genet. 2017;49(9):1319-25. https:// doi.org/10.1038/ng.3931.

2. American Psychiatric Association (APA). Diagnostic and statistical manual of mental disorders: neurodevelopmental disorders. In: Diagnostic and Statistical Manual of Mental Disorders. 5th edn. Washington, DC: American Psychiatric Association; 2013. p. 271-9. https://doi.org/10.1176/appi.books.9780890425596.dsm01.

3. Lord C, Brugha TS, Charman T, Cusack J, Dumas G, Frazier T, Jones EJH, Jones RM, Pickles A, State MW, Taylor JL, Veenstra-VanderWeele J. 
Autism spectrum disorder. Nat Rev Dis Prim. 2020;6(1):5. https://doi.org/ 10.1038/s41572-019-0138-4

4. Geschwind DH. Advances in Autism. Annu Rev Med. 2009;60(1):367-80. https://doi.org/10.1146/annurev.med.60.053107.121225.

5. Huguet $G, E y E$, Bourgeron T. The genetic landscapes of autism spectrum disorders. Annu Rev Genomics Hum Genet. 2013;14(1): 191-213. https://doi.org/10.1146/annurev-genom-091212-153431.

6. Baxter AJ, Brugha TS, Erskine HE, Scheurer RW, Vos T, Scott JG. The epidemiology and global burden of autism spectrum disorders. Psychol Med. 2015;45(3):601-13. https://doi.org/10.1017/S003329171400172X.

7. Loomes R, Hull L, Mandy WPL. What is the male-to-female ratio in autism spectrum disorder? A systematic review and meta-analysis. J Am Acad Child Adolesc Psychiatry. 2017;56(6):466-74. https://doi.org/10. 1016/j.jaac.2017.03.013.

8. Brugha TS, Spiers N, Bankart J, Cooper S-A, McManus S, Scott FJ, Smith J, Tyrer F. Epidemiology of autism in adults across age groups and ability levels. Br J Psychiatry. 2016;209(6):498-503. https://doi.org/10. 1192/bjp.bp.115.174649.

9. Cross-Disorder Group of the Psychiatric Genomics Consortium. Genetic relationship between five psychiatric disorders estimated from genome-wide SNPs. Nat Genet. 2013;45(9):984-94. https://doi.org/10. 1038/ng.2711.

10. Gaugler T, Klei L, Sanders SJ, Bodea CA, Goldberg AP, Lee AB, Mahajan M, Manaa D, Pawitan Y, Reichert J, Ripke S, Sandin S, Sklar P, Svantesson O, Reichenberg A, Hultman CM, Devlin B, Roeder K, Buxbaum JD. Most genetic risk for autism resides with common variation. Nat Genet. 2014;46(8):881-5. https://doi.org/10.1038/ng.3039.

11. Rosenberg RE, Law JK, Yenokyan G, McGready J, Kaufmann WE, Law PA. Characteristics and concordance of autism spectrum disorders among 277 twin pairs. Arch Pediatr Adolesc Med. 2009;163(10):907. https://doi.org/10.1001/archpediatrics.2009.98.

12. Sanders SJ, Ercan-Sencicek AG, Hus V, Luo R, Murtha MT, Moreno-De-Luca D, Chu SH, Moreau MP, Gupta AR, Thomson SA, Mason CE, Bilguvar K, Celestino-Soper PBS, Choi M, Crawford EL, Davis L, Davis Wright NR, Dhodapkar RM, DiCola M, DiLullo NM, Fernandez TV, Fielding-Singh V, Fishman DO, Frahm S, Garagaloyan R, Goh GS, Kammela S, Klei L, Lowe JK, Lund SC, McGrew AD, Meyer KA, Moffat WJ, Murdoch JD, O'Roak BJ, Ober GT, Pottenger RS, Raubeson MJ, Song Y, Wang Q, Yaspan BL, Yu TW, Yurkiewicz IR, Beaudet AL, Cantor RM, Curland M, Grice DE, Günel M, Lifton RP, Mane SM, Martin DM, Shaw CA, Sheldon M, Tischfield JA, Walsh CA, Morrow EM, Ledbetter DH, Fombonne E, Lord C, Martin CL, Brooks Al, Sutcliffe JS, Cook EH, Geschwind D, Roeder K, Devlin B, State MW. Multiple Recurrent De Novo CNVs, Including Duplications of the 7q11.23 Williams Syndrome Region, Are Strongly Associated with Autism. Neuron. 2011;70(5): 863-85. https://doi.org/10.1016/j.neuron.2011.05.002.

13. Sanders SJ, Murtha MT, Gupta AR, Murdoch JD, Raubeson MJ, Willsey AJ, Ercan-Sencicek AG, DiLullo NM, Parikshak NN, Stein JL, Walker MF, Ober GT, Teran NA, Song Y, El-Fishawy P, Murtha RC, Choi M, Overton JD, Bjornson RD, Carriero NJ, Meyer KA, Bilguvar K, Mane SM, Šestan N, Lifton RP, Günel M, Roeder K, Geschwind DH, Devlin B, State MW. De novo mutations revealed by whole-exome sequencing are strongly associated with autism. Nature. 2012;485(7397):237-41. https://doi.org/ 10.1038/nature10945.

14. Sanders SJ, HeX, Willsey AJ, Ercan-Sencicek AG, Samocha KE, Cicek AE, Murtha MT, Bal VH, Bishop SL, Dong S, Goldberg AP, Jinlu C, Keaney JF, Klei L, Mandell JD, Moreno-De-Luca D, Poultney CS, Robinson EB, Smith L, Solli-Nowlan T, Su MY, Teran NA, Walker MF, Werling DM, Beaudet AL, Cantor RM, Fombonne E, Geschwind DH, Grice DE, Lord C, Lowe JK, Mane SM, Martin DM, Morrow EM, Talkowski ME, Sutcliffe JS, Walsh CA, Yu TW, Ledbetter DH, Martin CL, Cook EH, Buxbaum JD, Daly MJ, Devlin B, Roeder K, State MW. Insights into autism spectrum disorder genomic architecture and biology from 71 risk loci. Neuron. 2015;87(6):1215-33. https://doi.org/10.1016/j.neuron.2015.09.016.

15. Satterstrom FK, Kosmicki JA, Wang J, Breen MS, De Rubeis S, An J-Y, Peng M, Collins R, Grove J, Klei L, Stevens C, Reichert J, Mulhern MS, Artomov M, Gerges S, Sheppard B, Xu X, Bhaduri A, Norman U, Brand $H$, Schwartz G, Nguyen R, Guerrero EE, Dias C, Betancur C, Cook EH, Gallagher L, Gill M, Sutcliffe JS, Thurm A, Zwick ME, Børglum AD, State MW, Cicek AE, Talkowski ME, Cutler DJ, Devlin B, Sanders SJ, Roeder K, Daly MJ, Buxbaum JD, Aleksic B, Anney R, Barbosa M, Bishop S, Brusco
A, Bybjerg-Grauholm J, Carracedo A, Chan MCY, Chiocchetti AG, Chung BHY, Coon H, Cuccaro ML, Curró A, Dalla Bernardina B, Doan R, Domenici $\mathrm{E}$, Dong $\mathrm{S}$, Fallerini $\mathrm{C}$, Fernández-Prieto $\mathrm{M}$, Ferrero $\mathrm{GB}$, Freitag CM, Fromer M, Gargus JJ, Geschwind D, Giorgio E, González-Peñas J, Guter S, Halpern D, Hansen-Kiss E, He X, Herman GE, Hertz-Picciotto I, Hougaard DM, Hultman CM, Ionita-Laza I, Jacob S, Jamison J, Jugessur A, Kaartinen M, Knudsen GP, Kolevzon A, Kushima I, Lee SL, Lehtimäki T, Lim ET, Lintas C, Lipkin WI, Lopergolo D, Lopes F, Ludena Y, Maciel P, Magnus P, Mahjani B, Maltman N, Manoach DS, Meiri G, Menashe I, Miller J, Minshew N, Montenegro EMS, Moreira D, Morrow EM, Mors O, Mortensen PB, Mosconi M, Muglia P, Neale BM, Nordentoft M, Ozaki N, Palotie A, Parellada M, Passos-Bueno MR, Pericak-Vance M, Persico AM, Pessah I, Puura K, Reichenberg A, Renieri A, Riberi E, Robinson EB, Samocha KE, Sandin S, Santangelo SL, Schellenberg G, Scherer SW, Schlitt S, Schmidt R, Schmitt L, Silva IMW, Singh T, Siper PM, Smith M, Soares G, Stoltenberg C, Suren P, Susser $E_{\text {, }}$ Sweeney J, Szatmari P, Tang L, Tassone F, Teufel K, Trabetti E, Trelles M. d. P., Walsh CA, Weiss LA, Werge T, Werling DM, Wigdor EM, Wilkinson E, Willsey AJ, Yu TW, Yu MHC, Yuen R, Zachi E, Agerbo E, Als TD, Appadurai V, Bækvad-Hansen M, Belliveau R, Buil A, Carey CE, Cerrato F, Chambert K, Churchhouse C, Dalsgaard S, Demontis D, Dumont A, Goldstein J, Hansen CS, Hauberg ME, Hollegaard MV, Howrigan DP, Huang H, Maller J, Martin AR, Martin J, Mattheisen M, Moran J, Pallesen J, Palmer DS, Pedersen CB, Pedersen MG, Poterba T, Poulsen JB, Ripke S, Schork AJ, Thompson WK, Turley P, Walters RK. Large-scale exome sequencing study implicates both developmental and functional changes in the neurobiology of autism. Cell. 2020;180(3): 568-84. https://doi.org/10.1016/j.cell.2019.12.036.

16. O'Roak BJ, Vives L, Girirajan $S$, Karakoc E, Krumm N, Coe BP, Levy R, Ko A, Lee C, Smith JD, Turner EH, Stanaway IB, Vernot B, Malig M, Baker C, Reilly B, Akey JM, Borenstein E, Rieder MJ, Nickerson DA, Bernier R, Shendure J, Eichler EE. Sporadic autism exomes reveal a highly interconnected protein network of de novo mutations. Nature. 2012:485(7397):246-50. https://doi.org/10.1038/nature10989.

17. Neale BM, Kou Y, Liu L, Ma'ayan A, Samocha KE, Sabo A, Lin C-F, Stevens C, Wang L-S, Makarov V, Polak P, Yoon S, Maguire J, Crawford EL, Campbell NG, Geller ET, Valladares O, Schafer C, Liu H, Zhao T, Cai G, Lihm J, Dannenfelser R, Jabado O, Peralta Z, Nagaswamy U, Muzny D, Reid JG, Newsham I, Wu Y, Lewis L, Han Y, Voight BF, Lim E, Rossin E, Kirby A, Flannick J, Fromer M, Shakir K, Fennell T, Garimella K, Banks E, Poplin R, Gabriel S, DePristo M, Wimbish JR, Boone BE, Levy SE, Betancur C, Sunyaev S, Boerwinkle E, Buxbaum JD, Cook Jr EH, Devlin B, Gibbs RA, Roeder K, Schellenberg GD, Sutcliffe JS, Daly MJ. Patterns and rates of exonic de novo mutations in autism spectrum disorders. Nature. 2012;485(7397):242-5. https://doi.org/10.1038/nature11011.

18. Levy D, Ronemus M, Yamrom B, Lee Y.-h., Leotta A, Kendall J, Marks S, Lakshmi B, Pai D, Ye K, Buja A, Krieger A, Yoon S, Troge J, Rodgers L, Iossifov I, Wigler M. Rare De Novo and Transmitted Copy-Number Variation in Autistic Spectrum Disorders. Neuron. 2011;70(5):886-97. https://doi.org/10.1016/j.neuron.2011.05.015.

19. Iossifov I, O'Roak BJ, Sanders SJ, Ronemus M, Krumm N, Levy D, Stessman HA, Witherspoon KT, Vives L, Patterson KE, Smith JD, Paeper B, Nickerson DA, Dea J, Dong S, Gonzalez LE, Mandell JD, Mane SM, Murtha MT, Sullivan CA, Walker MF, Waqar Z, Wei L, Willsey AJ, Yamrom B, Lee Y.-h., Grabowska E, Dalkic E, Wang Z, Marks S, Andrews P, Leotta A, Kendall J, Hakker I, Rosenbaum J, Ma B, Rodgers L, Troge J, Narzisi G, Yoon S, Schatz MC, Ye K, McCombie WR, Shendure J, Eichler EE, State MW, Wigler M. The contribution of de novo coding mutations to autism spectrum disorder. Nature. 2014;515(7526):216-21. https://doi.org/10.1038/nature13908.

20. De Rubeis S, He X, Goldberg AP, Poultney CS, Samocha K, Ercument Cicek A, Kou Y, Liu L, Fromer M, Walker S, Singh T, Klei L, Kosmicki J, Fu S-C, Aleksic B, Biscaldi M, Bolton PF, Brownfeld JM, Cai J, Campbell NG, Carracedo A, Chahrour MH, Chiocchetti AG, Coon H, Crawford EL, Crooks L, Curran SR, Dawson G, Duketis E, Fernandez BA, Gallagher L, Geller E, Guter SJ, Sean Hill R, Ionita-Laza I, Jimenez Gonzalez P, Kilpinen H, Klauck SM, Kolevzon A, Lee I, Lei J, Lehtimäki T, Lin C-F, Ma'ayan A, Marshall CR, Mclnnes AL, Neale B, Owen MJ, Ozaki N, Parellada M, Parr JR, Purcell S, Puura K, Rajagopalan D, Rehnström K, Reichenberg A, Sabo A, Sachse M, Sanders SJ, Schafer C, SchulteRüther M, Skuse D, Stevens C, Szatmari P, Tammimies K, Valladares O, 
Voran A, Wang L-S, Weiss LA, Jeremy Willsey A, Yu TW, Yuen RKC, Cook EH, Freitag CM, Gill M, Hultman CM, Lehner T, Palotie A, Schellenberg GD, Sklar P, State MW, Sutcliffe JS, Walsh CA, Scherer SW, Zwick ME, Barrett JC, Cutler DJ, Roeder K, Devlin B, Daly MJ, Buxbaum JD. Synaptic, transcriptional and chromatin genes disrupted in autism. Nature. 2014;515(7526):209-15. https://doi.org/10.1038/nature13772.

21. Gilman SR, lossifov I, Levy D, Ronemus M, Wigler M, Vitkup D. Rare de novo variants associated with autism implicate a large functional network of genes involved in formation and function of synapses. Neuron. 2011;70(5):898-907. https://doi.org/10.1016/j.neuron.2011.05.021.

22. Parikshak NN, Luo R, Zhang A, Won H, Lowe JK, Chandran V, Horvath $\mathrm{S}$, Geschwind DH. Integrative functional genomic analyses implicate specific molecular pathways and circuits in autism. Cell. 2013;155(5): 1008-21. https://doi.org/10.1016/j.cell.2013.10.031.

23. Ben-David E, Shifman S. Combined analysis of exome sequencing points toward a major role for transcription regulation during brain development in autism. Mol Psychiatry. 2013;18(10):1054-6. https://doi. org/10.1038/mp.2012.148

24. Pinto D, Pagnamenta AT, Klei L, Anney R, Merico D, Regan R, Conroy J, Magalhaes TR, Correia C, Abrahams BS, Almeida J, Bacchelli E, Bader GD, Bailey AJ, Baird G, Battaglia A, Berney T, Bolshakova N, Bölte S, Bolton PF, Bourgeron T, Brennan S, Brian J, Bryson SE, Carson AR, Casallo G, Casey J, Chung BHY, Cochrane L, Corsello C, Crawford EL, Crossett A, Cytrynbaum C, Dawson G, de Jonge M, Delorme R, Drmic I, Duketis E, Duque F, Estes A, Farrar P, Fernandez BA, Folstein SE, Fombonne E, Freitag CM, Gilbert J, Gillberg C, Glessner JT, Goldberg J, Green A, Green J, Guter SJ, Hakonarson H, Heron EA, Hill M, Holt R, Howe JL, Hughes G, Hus V, Igliozzi R, Kim C, Klauck SM, Kolevzon A, Korvatska O, Kustanovich V, Lajonchere CM, Lamb JA, Laskawiec M, Leboyer M, Le Couteur A, Leventhal BL, Lionel AC, Liu X-Q, Lord C, Lotspeich L, Lund SC, Maestrini E, Mahoney W, Mantoulan C, Marshall CR, McConachie H, McDougle CJ, McGrath J, McMahon WM, Merikangas A, Migita O, Minshew NJ, Mirza GK, Munson J, Nelson SF, Noakes C, Noor A, Nygren G, Oliveira G, Papanikolaou K, Parr JR, Parrini B, Paton T, Pickles A, Pilorge M, Piven J, Ponting CP, Posey DJ, Poustka A, Poustka F, Prasad A, Ragoussis J, Renshaw K, Rickaby J, Roberts W, Roeder K, Roge B, Rutter ML, Bierut LJ, Rice JP, Salt J, Sansom K, Sato $D$, Segurado R, Sequeira AF, Senman L, Shah N, Sheffield VC, Soorya L, Sousa I, Stein O, Sykes N, Stoppioni V, Strawbridge C, Tancredi R, Tansey K, Thiruvahindrapduram B, Thompson AP, Thomson S, Tryfon A, Tsiantis J, Van Engeland H, Vincent JB, Volkmar F, Wallace S, Wang K, Wang Z, Wassink TH, Webber C, Weksberg R, Wing K, Wittemeyer K, Wood S, Wu J, Yaspan BL, Zurawiecki D, Zwaigenbaum L, Buxbaum JD, Cantor RM, CookEH, Coon H, Cuccaro ML, Devlin B, Ennis S, Gallagher L, Geschwind DH, Gill M, Haines JL, Hallmayer J, Miller J, Monaco AP, Nurnberger Jr Jl, Paterson AD, Pericak-Vance MA, Schellenberg GD, Szatmari P, Vicente AM, Vieland VJ, Wijsman EM, Scherer SW, Sutcliffe JS, Betancur C. Functional impact of global rare copy number variation in autism spectrum disorders. Nature. 2010;466(7304):368-72. https://doi.org/10.1038/nature09146.

25. de la Torre-Ubieta L, Won H, Stein JL, Geschwind DH. Advancing the understanding of autism disease mechanisms through genetics. Nat Med. 2016;22(4):345-61. https://doi.org/10.1038/nm.4071.

26. Krishnan A, Zhang R, Yao V, Theesfeld CL, Wong AK, Tadych A, Volforsky N, Packer A, Lash A, Troyanskaya OG. Genome-wide prediction and functional characterization of the genetic basis of autism spectrum disorder. Nat Neurosci. 2016;19(11):1454-62. https://doi.org/ 10.1038/nn.4353

27. Bonaglia MC, Giorda R, Borgatti R, Felisari G, Gagliardi C, Selicorni A, Zuffardi O. Disruption of the ProSAP2 Gene in a t(12;22)(q24.1; 13.3 ) Is Associated with the 22q13.3 Deletion Syndrome. Am J Hum Genet. 2001;69(2):261-8. https://doi.org/10.1086/321293.

28. Durand CM, Betancur C, Boeckers TM, Bockmann J, Chaste P, Fauchereau F, Nygren G, Rastam M, Gillberg IC, Anckarsäter H, Sponheim E, Goubran-Botros H, Delorme R, Chabane N, MourenSimeoni M-C, de Mas P, Bieth E, Rogé B, Héron D, Burglen L, Gillberg C, Leboyer M, Bourgeron T. Mutations in the gene encoding the synaptic scaffolding protein SHANK3 are associated with autism spectrum disorders. Nat Genet. 2007;39(1):25-7. https://doi.org/10.1038/ng1933.

29. Jamain S, Quach H, Betancur C, Råstam M, Colineaux C, Gillberg IC, Soderstrom H, Giros B, Leboyer M, Gillberg C, Bourgeron T. Mutations of the X-linked genes encoding neuroligins NLGN3 and NLGN4 are associated with autism. Nat Genet. 2003;34(1):27-9. https://doi.org/10. 1038/ng1136.

30. Blundell J, Blaiss CA, Etherton MR, Espinosa F, Tabuchi K, Walz C, Bolliger MF, Sudhof TC, Powell CM. Neuroligin-1 deletion results in impaired spatial memory and increased repetitive behavior. J Neurosci. 2010;30(6):2115-29. https://doi.org/10.1523/JNEUROSCI.4517-09.2010.

31. Blundell J, Tabuchi K, Bolliger MF, Blaiss CA, Brose N, Liu X, Südhof TC, Powell CM. Increased anxiety-like behavior in mice lacking the inhibitory synapse cell adhesion molecule neuroligin 2. Genes Brain Behav. 2009;8(1):114-26. https://doi.org/10.1111/j.1601-183X.2008.00455.x.

32. Wöhr M, Silverman JL, Scattoni ML, Turner SM, Harris MJ, Saxena R, Crawley JN. Developmental delays and reduced pup ultrasonic vocalizations but normal sociability in mice lacking the postsynaptic cell adhesion protein neuroligin2. Behav Brain Res. 2013;251:50-64. https:// doi.org/10.1016/j.bbr.2012.07.024.

33. Tabuchi K, Blundell J, Etherton MR, Hammer RE, Liu X, Powell CM, Sudhof TC. A Neuroligin-3 mutation implicated in autism increases inhibitory synaptic transmission in mice. Science. 2007;318(5847):71-6. https://doi.org/10.1126/science.1146221.

34. Chadman KK, Gong S, Scattoni ML, Boltuck SE, Gandhy SU, Heintz N, Crawley JN. Minimal aberrant behavioral phenotypes of neuroligin-3 R451C knockin mice. Autism Res. 2008;1(3):147-58. https://doi.org/10. 1002/aur.22.

35. Radyushkin K, Hammerschmidt K, Boretius S, Varoqueaux F, El-Kordi A, Ronnenberg A, Winter D, Frahm J, Fischer J, Brose N, Ehrenreich $\mathrm{H}$. Neuroligin-3-deficient mice: model of a monogenic heritable form of autism with an olfactory deficit. Genes Brain Behav. 2009;8(4):416-25. https://doi.org/10.1111/j.1601-183X.2009.00487.x.

36. Jaramillo TC, Liu S, Pettersen A, Birnbaum SG, Powell CM. Autism-related neuroligin-3 mutation alters social behavior and spatial learning. Autism Res. 2014;7(2):264-72. https://doi.org/10.1002/aur.1362.

37. Jaramillo TC, Escamilla CO, Liu S, Peca L, Birnbaum SG, Powell CM. Genetic background effects in Neuroligin-3 mutant mice: Minimal behavioral abnormalities on $C 57$ background. Autism Res. 2018;11(2): 234-44. https://doi.org/10.1002/aur.1857.

38. Delattre V, La Mendola D, Meystre J, Markram H, Markram K. Nlgn4 knockout induces network hypo-excitability in juvenile mouse somatosensory cortex in vitro. Sci Rep. 2013;3(1):2897. https://doi.org/ 10.1038/srep02897.

39. Jamain S, Radyushkin K, Hammerschmidt K, Granon S, Boretius S, Varoqueaux F, Ramanantsoa N, Gallego J, Ronnenberg A, Winter D, Frahm J, Fischer J, Bourgeron T, Ehrenreich H, Brose N. Reduced social interaction and ultrasonic communication in a mouse model of monogenic heritable autism. Proc Natl Acad Sci. 2008;105(5):1710-5. https://doi.org/10.1073/pnas.0711555105.

40. Etherton MR, Blaiss CA, Powell CM, Sudhof TC. Mouse neurexin-1 deletion causes correlated electrophysiological and behavioral changes consistent with cognitive impairments. Proc Natl Acad Sci. 2009;106(42): 17998-8003. https://doi.org/10.1073/pnas.0910297106.

41. Grayton HM, Missler M, Collier DA, Fernandes C. Altered Social Behaviours in Neurexin $1 \alpha$ Knockout Mice Resemble Core Symptoms in Neurodevelopmental Disorders. PLoS ONE. 2013;8(6):67114. https://doi. org/10.1371/journal.pone.0067114.

42. Rabaneda LG, Robles-Lanuza E, Nieto-González J, Scholl FG. Neurexin dysfunction in adult neurons results in autistic-like behavior in mice. Cell Rep. 2014;8(2):338-46. https://doi.org/10.1016/j.celrep.2014.06.022.

43. Born G, Grayton HM, Langhorst H, Dudanova I, Rohlmann A, Woodward BW, Collier DA, Fernandes C, Missler M. Genetic targeting of NRXN2 in mice unveils role in excitatory cortical synapse function and social behaviors. Front Synaptic Neurosci. 2015;7:1-16. https://doi.org/ 10.3389/fnsyn.2015.00003.

44. Dachtler J, Glasper J, Cohen RN, Ivorra JL, Swiffen DJ, Jackson AJ, Harte MK, Rodgers RJ, Clapcote SJ. Deletion of $\alpha$-neurexin II results in autism-related behaviors in mice. Transl Psychiatry. 2014;4(11):484. https://doi.org/10.1038/tp.2014.123.

45. Bader PL, Faizi M, Kim LH, Owen SF, Tadross MR, Alfa RW, Bett GCL, Tsien RW, Rasmusson RL, Shamloo M. Mouse model of Timothy syndrome recapitulates triad of autistic traits. Proc Natl Acad Sci. 2011;108(37):15432-7. https://doi.org/10.1073/pnas.1112667108.

46. Peñagarikano $\mathrm{O}$, Abrahams BS, Herman El, Winden KD, Gdalyahu A, Dong H, Sonnenblick LI, Gruver R, Almajano J, Bragin A, Golshani P, 
Trachtenberg JT, Peles E, Geschwind DH. Absence of CNTNAP2 leads to epilepsy, neuronal migration anormalities, and core autism-related deficits. Cell. 2011;147(1):235-46. https://doi.org/10.1016/j.cell.2011.08. 040.

47. DeLorey TM, Handforth A, Anagnostaras SG, Homanics GE, Minassian BA, Asatourian A, Fanselow MS, Delgado-Escueta A, Ellison GD, Olsen RW. Mice lacking the $\beta 3$ subunit of the GABA A receptor have the epilepsy phenotype and many of the behavioral characteristics of Angelman syndrome. J Neurosci. 1998;18(20):8505-14. https://doi.org/ 10.1523/JNEUROSCl.18-20-08505.1998

48. Willsey AJ, Sanders SJ, Li M, Dong S, Tebbenkamp AT, Muhle RA, Reilly SK, Lin L, Fertuzinhos S, Miller JA, Murtha MT, Bichsel C, Niu W, Cotney J, Ercan-Sencicek AG, Gockley J, Gupta AR, Han W, He X, Hoffman EJ, Klei L, Lei J, Liu W, Liu L, Lu C, Xu X, Zhu Y, Mane SM, Lein ES, Wei L, Noonan JP, Roeder K, Devlin B, Sestan N, State MW. Coexpression networks implicate human midfetal deep cortical projection neurons in the pathogenesis of autism. Cell. 2013;155(5): 997-1007. https://doi.org/10.1016/j.cell.2013.10.020.

49. Velmeshev D, Schirmer L, Jung D, Haeussler M, Perez Y, Mayer S, Bhaduri A, Goyal N, Rowitch DH, Kriegstein AR. Single-cell genomics identifies cell type-specific molecular changes in autism. Science. 2019;364(6441):685-9. https://doi.org/10.1126/science.aav8130.

50. Fuccillo MV. Striatal circuits as a common node for autism pathophysiology. Front Neurosci. 2016;10:27. https://doi.org/10.3389/ fnins.2016.00027.

51. Modabbernia A, Velthorst E, Reichenberg A. Environmental risk factors for autism: an evidence-based review of systematic reviews and meta-analyses. Mol Autism. 2017;8(1):13. https://doi.org/10.1186/ s13229-017-0121-4.

52. Wu S, Wu F, Ding Y, Hou J, Bi J, Zhang Z. Advanced parental age and autism risk in children: a systematic review and meta-analysis. Acta Psychiatr Scand. 2017;135(1):29-41. https://doi.org/10.1111/acps.12666.

53. Yasuda H, Yoshida K, Yasuda Y, Tsutsui T. Infantile zinc deficiency: association with autism spectrum disorders. Sci Rep. 2011;1(129):1-5. https://doi.org/10.1038/srep00129.

54. Goyal D, Neil J, Simmons S, Mansab F, Benjamin S, Pitfield V, Boulet S, Miyan J. Zinc deficiency in autism: a controlled study. Insights Biomed. 2019;04(03):1-10. https://doi.org/10.36648/2572-5610.4.3.63.

55. Böckers TM, Kreutz MR, Winter C, Zuschratter W, Smalla K-H, Sanmarti-Vila L, Wex H, Langnaese K, Bockmann J, Garner CC, Gundelfinger ED. Proline-rich synapse-associated protein-1/cortactin binding protein 1 (ProSAP1/CortBP1) is a PDZ-domain protein highly enriched in the postsynaptic density. J Neurosci. 1999;19(15):6506-18. https://doi.org/10.1523/JNEUROSCI.19-15-06506.1999.

56. Böckers TM, Winter C, Smalla K-H, Kreutz MR, Bockmann J, Seidenbecher C, Garner CC, Gundelfinger ED. Proline-rich synapse-associated proteins ProSAP1 and ProSAP2 interact with synaptic proteins of the SAPAP/GKAP family. Biochem Biophys Res Commun. 1999;264(1):247-52. https://doi.org/10.1006/bbrc.1999.1489.

57. Sheng M, Kim E. The Shank family of scaffold proteins. J Cell Sci. 2000;113(11):1851-6.

58. Böckers TM, Liedtke T, Spilker C, Dresbach T, Bockmann J, Kreutz MR Gundelfinger ED. C-terminal synaptic targeting elements for postsynaptic density proteins ProSAP1/Shank2 and ProSAP2/Shank3. J Neurochem. 2005;92(3):519-24. https://doi.org/10.1111/j.1471-4159. 2004.02910.x.

59. Naisbitt S, Kim E, Tu JC, Xiao B, Sala C, Valtschanoff J, Weinberg RJ, Worley PF, Sheng M. Shank, a novel family of postsynaptic density proteins that binds to the NMDA receptor/PSD-95/GKAP complex and cortactin. Neuron. 1999;23(3):569-82. https://doi.org/10.1016/S08966273(00)80809-0.

60. Böckers TM, Bockmann J, Kreutz MR, Gundelfinger ED. ProSAP/Shank proteins - a family of higher order organizing molecules of the postsynaptic density with an emerging role in human neurological disease. J Neurochem. 2002;81(5):903-10. https://doi.org/10.1046/j. 1471-4159.2002.00931.x

61. Böckers TM. The postsynaptic density. Cell Tissue Res. 2006;326(2): 409-22. https://doi.org/10.1007/s00441-006-0274-5.

62. Raab M, Böckers TM, Neuhuber WL. Proline-rich synapse-associated protein-1 and 2 (ProSAP1/Shank2 and ProSAP2/Shank3)-scaffolding proteins are also present in postsynaptic specializations of the peripheral nervous system. Neuroscience. 2010;171(2):421-33. https:// doi.org/10.1016/j.neuroscience.2010.08.041.

63. Sheng M, Kim E. The postsynaptic organization of synapses. Cold Spring Harb Perspect Biol. 2011;3(12):005678. https://doi.org/10.1101/ cshperspect.a005678.

64. Zitzer H, Hönck H-H, Bächner D, Richter D, Kreienkamp H-J. Somatostatin receptor interacting protein defines a novel family of multidomain proteins present in human and rodent brain. J Biol Chem. 1999;274(46):32997-3001. https://doi.org/10.1074/jbc.274.46.32997.

65. Tu JC, Xiao B, Naisbitt S, Yuan JP, Petralia RS, Brakeman P, Doan A, Aakalu VK, Lanahan AA, Sheng M, Worley PF. Coupling of mGluR/Homer and PSD-95 complexes by the Shank family of postsynaptic density proteins. Neuron. 1999;23(3):583-92. https://doi. org/10.1016/S0896-6273(00)80810-7.

66. Lim S, Naisbitt S, Yoon J, Hwang J-I, Suh P-G, Sheng M, Kim E. Characterization of the Shank family of synaptic proteins. J Biol Chem. 1999;274(41):29510-8. https://doi.org/10.1074/jbc.274.41.29510.

67. Romorini S, Piccoli G, Jiang M, Grossano P, Tonna N, Passafaro M, Zhang M, Sala C. A Functional role of postsynaptic density-95-guanylate kinase-associated protein complex in regulating Shank assembly and stability to synapses. J Neurosci. 2004;24(42):9391-404. https://doi.org/ 10.1523/JNEUROSCI.3314-04.2004.

68. Tao-Cheng JH, Dosemeci A, Gallant PE, Smith C, Reese T. Activity induced changes in the distribution of Shanks at hippocampal synapses. Neuroscience. 2010;168(1):11-7. https://doi.org/10.1016/j.neuroscience. 2010.03.041.

69. Tao-Cheng J-H, Yang Y, Reese TS, Dosemeci A. Differential distribution of Shank and GKAP at the postsynaptic density. PLoS ONE. 2015;10(3): 0118750. https://doi.org/10.1371/journal.pone.0118750

70. Kano M, Hashimoto K. Synapse elimination in the central nervous system. Curr Opin Neurobiol. 2009;19(2):154-61. https://doi.org/10. 1016/j.conb.2009.05.002

71. Monteiro P, Feng G. SHANK proteins: roles at the synapse and in autism spectrum disorder. Nat Rev Neurosci. 2017;18(3):147-57. https://doi.org/ 10.1038/nrn.2016.183.

72. Leblond CS, Heinrich J, Delorme R, Proepper C, Betancur C, Huguet G, Konyukh M, Chaste P, Ey E, Rastam M, Anckarsäter H, Nygren G, Gillberg IC, Melke J, Toro R, Regnault B, Fauchereau F, Mercati O, Lemière N, Skuse D, Poot M, Holt R, Monaco AP, Järvelä I, Kantojärvi K, Vanhala R, Curran S, Collier DA, Bolton P, Chiocchetti A, Klauck SM, Poustka F, Freitag CM, Waltes R, Kopp M, Duketis E, Bacchelli E, Minopoli F, Ruta L, Battaglia A, Mazzone L, Maestrini E, Sequeira AF, Oliveira B, Vicente A, Oliveira G, Pinto D, Scherer SW, Zelenika D, Delepine M, Lathrop M, Bonneau D, Guinchat V, Devillard F, Assouline B, Mouren M-C, Leboyer M, Gillberg C, Boeckers TM, Bourgeron T. Genetic and Functional Analyses of SHANK2 Mutations Suggest a Multiple Hit Model of Autism Spectrum Disorders. PLoS Genet. 2012;8(2): 1002521. https://doi.org/10.1371/journal.pgen.1002521.

73. Leblond CS, Nava C, Polge A, Gauthier J, Huguet G, Lumbroso S, Giuliano F, Stordeur C, Depienne C, Mouzat K, Pinto D, Howe J, Lemière N, Durand CM, Guibert J, Ey E, Toro R, Peyre H, Mathieu A, Amsellem F, Rastam M, Gillberg IC, Rappold GA, Holt R, Monaco AP, Maestrini E, Galan P, Heron D, Jacquette A, Afenjar A, Rastetter A, Brice A, Devillard F, Assouline B, Laffargue F, Lespinasse J, Chiesa J, Rivier F, Bonneau D, Regnault B, Zelenika D, Delepine M, Lathrop M, Sanlaville D, Schluth-Bolard C, Edery P, Perrin L, Tabet AC, Schmeisser MJ, Boeckers TM, Coleman M, Sato D, Szatmari P, Scherer SW, Rouleau GA, Betancur C, Leboyer M, Gillberg C, Delorme R, Bourgeron T. Meta-analysis of SHANK mutations in autism spectrum disorders: a gradient of severity in cognitive impairments. PLoS Genet. 2014;10(9): 1004580. https://doi.org/10.1371/journal.pgen.1004580.

74. Gauthier J, Spiegelman D, Piton A, Lafrenière RG, Laurent S, St-Onge J, Lapointe L, Hamdan FF, Cossette P, Mottron L, Fombonne É, Joober R, Marineau C, Drapeau P, Rouleau GA. Novel de novo SHANK3 mutation in autistic patients. Am J Med Genet B Neuropsychiatr Genet. 2009;150(3):421-4. https://doi.org/10.1002/ajmg.b.30822.

75. Gauthier J, Champagne N, Lafrenière RG, Xiong L, Spiegelman $D$, Brustein E, Lapointe M, Peng H, Côté M, Noreau A, Hamdan FF, Addington AM, Rapoport JL, DeLisi LE, Krebs M-O, Joober R, Fathalli F, Mouaffak F, Haghighi AP, Néri C, Dubé M-P, Samuels ME, Marineau C, Stone EA, Awadalla P, Barker PA, Carbonetto S, Drapeau P, Rouleau 
GA. De novo mutations in the gene encoding the synaptic scaffolding protein SHANK3 in patients ascertained for schizophrenia. Proc Natl Acad Sci. 2010;107(17):7863-8. https://doi.org/10.1073/pnas.0906232107.

76. Boccuto L, Lauri M, Sarasua SM, Skinner CD, Buccella D, Dwivedi A, Orteschi D, Collins JS, Zollino M, Visconti P, DuPont B, Tiziano D, Schroer RJ, Neri G, Stevenson RE, Gurrieri F, Schwartz CE. Prevalence of SHANK3 variants in patients with different subtypes of autism spectrum disorders. Eur J Hum Genet. 2013;21(3):310-6. https://doi.org/10.1038/ ejhg.2012.175.

77. Berkel S, Marshall CR, Weiss B, Howe J, Roeth R, Moog U, Endris V, Roberts W, Szatmari P, Pinto D, Bonin M, Riess A, Engels H, Sprengel R, Scherer SW, Rappold GA. Mutations in the SHANK2 synaptic scaffolding gene in autism spectrum disorder and mental retardation. Nat Genet. 2010;42(6):489-91. https://doi.org/10.1038/ng.589.

78. Wang X, McCoy PA, Rodriguiz RM, Pan Y, Je HS, Roberts AC, Kim CJ, Berrios J, Colvin JS, Bousquet-Moore D, Lorenzo I, Wu G, Weinberg RJ, Ehlers MD, Philpot BD, Beaudet AL, Wetsel WC, Jiang Y-h. Synaptic dysfunction and abnormal behaviors in mice lacking major isoforms of Shank3. Hum Mol Genet. 2011;20(15):3093-108. https://doi.org/10.1093/ $\mathrm{hmg} / \mathrm{ddr} 212$.

79. Wang $X, X u Q$, Bey AL, Lee $Y$, Jiang $Y$-h. Transcriptional and functional complexity of Shank3 provides a molecular framework to understand the phenotypic heterogeneity of SHANK3 causing autism and Shank3 mutant mice. Mol Autism. 2014;5(1):30. https://doi.org/10.1186/20402392-5-30

80. Jaramillo TC, Speed HE, Xuan Z, Reimers JM, Liu S, Powell CM. Altered Striatal Synaptic Function and Abnormal Behaviour in Shank3 Exon4-9 Deletion Mouse Model of Autism. Autism Res. 2016;9(3):350-75. https:// doi.org/10.1002/aur.1529.

81. Beri S, Tonna N, Menozzi G, Bonaglia MC, Sala C, Giorda R. DNA methylation regulates tissue-specific expression of Shank3. J Neurochem. 2007;101(5):1380-91. https://doi.org/10.1111/j.1471-4159. 2007.04539.x.

82. Lee J, Chung C, Ha S, Lee D, Kim D-Y, Kim H, Kim E. Shank3-mutant mice lacking exon 9 show altered excitation/inhibition balance, enhanced rearing, and spatial memory deficit. Front Cell Neurosci. 2015;9(94):1-14. https://doi.org/10.3389/fncel.2015.00094.

83. Mei Y, Monteiro P, Zhou Y, Kim J-A, Gao X, Fu Z, Feng G. Adult restoration of Shank3 expression rescues selective autistic-like phenotypes. Nature. 2016;530(7591):481-4. https://doi.org/10.1038/nature16971.

84. Senior AW, Evans R, Jumper J, Kirkpatrick J, Sifre L, Green T, Qin C, Žídek A, Nelson AWR, Bridgland A, Penedones H, Petersen S, Simonyan K, Crossan S, Kohli P, Jones DT, Silver D, Kavukcuoglu K, Hassabis D. Improved protein structure prediction using potentials from deep learning. Nature. 2020;577(7792):706-10. https://doi.org/10.1038/ s41586-019-1923-7.

85. Jumper J, Evans R, Pritzel A, Green T, Figurnov M, Ronneberger O, Tunyasuvunakool K, Bates R, Žídek A, Potapenko A, Bridgland A, Meyer C, KohI SAA, Ballard AJ, Cowie A, Romera-Paredes B, Nikolov S, Jain R, Adler J, Back T, Petersen S, Reiman D, Clancy E, Zielinski M, Steinegger M, Pacholska M, Berghammer T, Bodenstein S, Silver D, Vinyals O, Senior AW, Kavukcuoglu K, Kohli P, Hassabis D. Highly accurate protein structure prediction with AlphaFold. Nature. 2021;596(7873):583-9. https://doi.org/10.1038/s41586-021-03819-2.

86. Tunyasuvunakool K, Adler J, Wu Z, Green T, Zielinski M, Žídek A, Bridgland A, Cowie A, Meyer C, Laydon A, Velankar S, Kleywegt GJ, Bateman A, Evans R, Pritzel A, Figurnov M, Ronneberger O, Bates R, Kohl SAA, Potapenko A, Ballard AJ, Romera-Paredes B, Nikolov S, Jain $R$, Clancy E, Reiman D, Petersen S, Senior AW, Kavukcuoglu K, Birney E, Kohli P, Jumper J, Hassabis D. Highly accurate protein structure prediction for the human proteome. Nature. 2021;596(7873):590-6. https://doi.org/10.1038/s41586-021-03828-1.

87. Ching T-T, Maunakea AK, Jun P, Hong C, Zardo G, Pinkel D, Albertson DG, Fridlyand J, Mao J-H, Shchors K, Weiss WA, Costello JF. Epigenome analyses using BAC microarrays identify evolutionary conservation of tissue-specific methylation of SHANK3. Nat Genet. 2005;37(6):645-51. https://doi.org/10.1038/ng1563.

88. Maunakea AK, Nagarajan RP, Bilenky M, Ballinger TJ, D'Souza C, Fouse SD, Johnson BE, Hong C, Nielsen C, Zhao Y, Turecki G, Delaney A, Varhol R, Thiessen N, Shchors K, Heine VM, Rowitch DH, Xing X, Fiore C, Schillebeeckx M, Jones SJM, Haussler D, Marra MA, Hirst M, Wang T, Costello JF. Conserved role of intragenic DNA methylation in regulating alternative promoters. Nature. 2010;466(7303):253-7. https://doi.org/10. 1038/nature09165.

89. Zhu L, Wang $X$, Li X-L, Towers A, Cao X, Wang P, Bowman R, Yang H, Goldstein J, Li Y-J, Jiang Y-H. Epigenetic dysregulation of SHANK3 in brain tissues from individuals with autism spectrum disorders. Hum Mol Genet. 2014;23(6):1563-78. https://doi.org/10.1093/hmg/ddt547.

90. Peça J, Feliciano C, Ting JT, Wang W, Wells MF, Venkatraman TN, Lascola CD, Fu Z, Feng G. Shank3 mutant mice display autistic-like behaviours and striatal dysfunction. Nature. 2011;472(7344):437-42. https://doi.org/10.1038/nature09965.

91. Böckers TM, Segger-Junius M, Iglauer P, Bockmann J, Gundelfinger ED, Kreutz MR, Richter D, Kindler S, Kreienkamp H-J. Differential expression and dendritic transcript localization of Shank family members: identification of a dendritic targeting element in the $3^{\prime}$ untranslated region of Shank1 mRNA. Mol Cell Neurosci. 2004;26(1):182-90. https:// doi.org/10.1016/j.men.2004.01.009.

92. Han Q, Kim YH, Wang X, Liu D, Zhang Z-J, Bey AL, Lay M, Chang W, Berta T, Zhang $Y$, Jiang $Y-H$, Ji R-R. SHANK3 deficiency impairs heat hyperalgesia and TRPV1 signaling in primary sensory neurons. Neuron. 2016;92(6):1279-93. https://doi.org/10.1016/j.neuron.2016.11.007.

93. Han K, Holder Jr JL, Schaaf CP, Lu H, Chen H, Kang H, Tang J, Wu Z, Hao S, Cheung SW, Yu P, Sun H, Breman AM, Patel A, Lu H-C, Zoghbi HY. SHANK3 overexpression causes manic-like behaviour with unique pharmacogenetic properties. Nature. 2013;503(7474):72-7. https://doi. org/10.1038/nature12630.

94. Wang L, Pang K, Han K, Adamski CJ, Wang W, He L, Lai JK, Bondar W Duman JG, Richman R, Tolias KF, Barth P, Palzkill T, Liu Z, Holder JL, Zoghbi HY. An autism-linked missense mutation in SHANK3 reveals the modularity of Shank3 function. Mol Psychiatry. 2020;25(10):2534-55. https://doi.org/10.1038/s41380-018-0324-x

95. Proepper C, Johannsen S, Liebau S, Dahl J, Vaida B, Bockmann J, Kreutz MR, Gundelfinger ED, Boeckers TM. Abelson interacting protein 1 (Abi-1) is essential for dendrite morphogenesis and synapse formation. EMBO J. 2007;26(5):1397-409. https://doi.org/10.1038/sj.emboj.7601569.

96. Lee Y, Kang H, Lee B, Zhang Y, Kim Y, Kim S, Kim W-K, Han K. Integrative analysis of brain region-specific Shank3 interactomes for understanding the heterogeneity of neuronal pathophysiology related to SHANK3 mutations. Front Mol Neurosci. 2017;10:1-13. https://doi. org/10.3389/fnmol.2017.00110.

97. Mameza MG, Dvoretskova E, Bamann M, Hönck H-H, Güler T, Boeckers TM, Schoen M, Verpelli C, Sala C, Barsukov I, Dityatev A, Kreienkamp $\mathrm{H}$-J. SHANK3 gene mutations associated with autism facilitate ligand binding to the Shank3 ankyrin repeat region. J Biol Chem. 2013;288(37): 26697-708. https://doi.org/10.1074/jbc.M112.424747.

98. Lim S, Sala C, Yoon J, Park S, Kuroda S, Sheng M, Kim E. Sharpin, a novel postsynaptic density protein that directly interacts with the Shank family of proteins. Mol Cell Neurosci. 2001;17(2):385-97. https://doi.org/ 10.1006/mcne.2000.0940.

99. Böckers TM, Mameza MG, Kreutz MR, Bockmann J, Weise C, Buck F, Richter D, Gundelfinger ED, Kreienkamp H-J. Synaptic scaffolding proteins in rat brain. J Biol Chem. 2001;276(43):40104-12. https://doi. org/10.1074/jbc.M102454200.

100. Uchino S, Wada H, Honda S, Nakamura Y, Ondo Y, Uchiyama T, Tsutsumi M, Suzuki E, Hirasawa T, Kohsaka S. Direct interaction of postsynaptic density-95/Dlg/ZO-1 domain-containing synaptic molecule Shank3 with GluR1 alpha-amino-3-hydroxy-5-methyl-4-isoxazole propionic acid receptor. J Neurochem. 2006;97(4):1203-14. https://doi. org/10.1111/j.1471-4159.2006.03831.x.

101. Hayashi MK, Tang C, Verpelli C, Narayanan R, Stearns MH, Xu R-M, Li H, Sala C, Hayashi Y. The postsynaptic density proteins Homer and Shank form a polymeric network structure. Cell. 2009;137(1):159-71. https:// doi.org/10.1016/j.cell.2009.01.050.

102. Baron MK, Böckers TM, Vaida B, Faham S, Gingery M, Sawaya MR, Salyer D, Gundelfinger ED, Bowie JU. An architectural framework that may lie at the core of the postsynaptic density. Science. 2006;311(5760): 531-5. https://doi.org/10.1126/science.1118995.

103. Grabrucker AM, Knight MJ, Proepper C, Bockmann J, Joubert M, Rowan M, Nienhaus GU, Garner CC, Bowie JU, Kreutz MR, Gundelfinger ED, Boeckers TM. Concerted action of zinc and ProSAP/Shank in synaptogenesis and synapse maturation. EMBO J. 2011;30(3):569-81. https://doi.org/10.1038/emboj.2010.336. 
104. Hassani Nia F, Woike D, Martens V, Klüssendorf M, Hönck H-H, Harder $\mathrm{S}$, Kreienkamp $\mathrm{H}$-J. Targeting of $\delta$-catenin to postsynaptic sites through interaction with the Shank3 N-terminus. Mol Autism. 2020;11(1):85. https://doi.org/10.1186/s13229-020-00385-8.

105. Hassani Nia F, Woike D, Kloth K, Kortüm F, Kreienkamp H. Truncating mutations in SHANK3 associated with global developmental delay interfere with nuclear $\beta$-catenin signaling. J Neurochem. 2020;155(3): 250-63. https://doi.org/10.1111/jnc.15014.

106. Wang L, Adamski CJ, Bondar W, Craigen E, Collette JR, Pang K, Han K, Jain A, Y Jung S, Liu Z, Sifers RN, Holder JL, Zoghbi HY. A kinome-wide RNAi screen identifies ERK2 as a druggable regulator of Shank3 stability. Mol Psychiatry. 2020;25(10):2504-16. https://doi.org/10.1038/s41380018-0325-9.

107. Thomas GM, Rumbaugh GR, Harrar DB, Huganir RL. Ribosomal S6 kinase 2 interacts with and phosphorylates PDZ domain-containing proteins and regulates AMPA receptor transmission. Proc Natl Acad Sci. 2005;102(42):15006-11. https://doi.org/10.1073/pnas.0507476102.

108. Ehlers MD. Activity level controls postsynaptic composition and signaling via the ubiquitin-proteasome system. Nat Neurosci. 2003;6(3): 231-42. https://doi.org/10.1038/nn1013.

109. Shin SM, Zhang N, Hansen J, Gerges NZ, Pak DTS, Sheng M, Lee SH. GKAP orchestrates activity-dependent postsynaptic protein remodeling and homeostatic scaling. Nat Neurosci. 2012;15(12):1655-66. https://doi. org/10.1038/nn.3259.

110. Halbedl S, Schoen M, Feiler MS, Boeckers TM, Schmeisser MJ. Shank3 is localized in axons and presynaptic specializations of developing hippocampal neurons and involved in the modulation of NMDA receptor levels at axon terminals. J Neurochem. 2016;137(1):26-32. https://doi.org/10.1111/jnc.13523.

111. Lutz A-K, Pfaender S, Incearap B, loannidis V, Ottonelli I, Föhr KJ, Cammerer J, Zoller M, Higelin J, Giona F, Stetter M, Stoecker N, Alami NO, Schön M, Orth M, Liebau S, Barbi G, Grabrucker AM, Delorme R, Fauler M, Mayer B, Jesse S, Roselli F, Ludolph AC, Bourgeron T, Verpelli C, Demestre M, Boeckers TM. Autism-associated SHANK3 mutations impair maturation of neuromuscular junctions and striated muscles. Sci Transl Med. 2020;12(547):3267. https://doi.org/10.1126/scitranslmed. aaz3267.

112. Grabrucker S, Proepper C, Mangus K, Eckert M, Chhabra R, Schmeisser MJ, Boeckers TM, Grabrucker AM. The PSD protein ProSAP2/Shank3 displays synapto-nuclear shuttling which is deregulated in a schizophrenia-associated mutation. Exp Neurol. 2014;253:126-37. https://doi.org/10.1016/j.expneurol.2013.12.015.

113. Perfitt TL, Wang X, Dickerson MT, Stephenson JR, Nakagawa T, Jacobson DA, Colbran RJ. Neuronal L-type calcium channel signaling to the nucleus requires a novel CaMKIl $\alpha$-Shank3 interaction. J Neurosci. 2020;40(10):2000-14. https://doi.org/10.1523/JNEUROSCI.0893-19.2020.

114. Hung AY, Futai K, Sala C, Valtschanoff JG, Ryu J, Woodworth MA, Kidd FL, Sung CC, Miyakawa T, Bear MF, Weinberg RJ, Sheng M. Smaller dendritic spines, weaker synaptic transmission, but enhanced spatial learning in mice lacking Shank1. J Neurosci. 2008;28(7):1697-708. https://doi.org/10.1523/JNEUROSCI.3032-07.2008.

115. Silverman JL, Turner SM, Barkan CL, Tolu SS, Saxena R, Hung AY, Sheng M, Crawley JN. Sociability and motor functions in Shank1 mutant mice. Brain Res. 2011;1380:120-37. https://doi.org/10.1016/j.brainres. 2010.09.026

116. Mao W, Watanabe T, Cho S, Frost JL, Truong T, Zhao X, Futai K. Shank1 regulates excitatory synaptic transmission in mouse hippocampal parvalbumin-expressing inhibitory interneurons. Eur J Neurosci. 2015;41(8):1025-35. https://doi.org/10.1111/ejn.12877.

117. Wöhr M, Roullet Fl, Hung AY, Sheng M, Crawley JN. Communication impairments in mice lacking Shank1: reduced levels of ultrasonic vocalizations and scent marking behavior. PLOS ONE. 2011;6(6):20631. https://doi.org/10.1371/journal.pone.0020631.

118. Schmeisser MJ, Ey E, Wegener S, Bockmann J, Stempel AV, Kuebler A, Janssen A-L, Udvardi PT, Shiban E, Spilker C, Balschun D, Skryabin BV, tom Dieck S, Smalla K-H, Montag D, Leblond CS, Faure P, Torquet N, Le Sourd A-M, Toro R, Grabrucker AM, Shoichet SA, Schmitz D, Kreutz MR, Bourgeron T, Gundelfinger ED, Boeckers TM. Autistic-like behaviours and hyperactivity in mice lacking ProSAP1/Shank2. Nature. 2012;486(7402):256-60. https://doi.org/10.1038/nature11015.
119. Won H, Lee H-R, Gee HY, Mah W, Kim J-I, Lee J, Ha S, Chung C, Jung ES, Cho YS, Park S-G, Lee J-S, Lee K, Kim D, Bae YC, Kaang B-K, Lee MG, Kim E. Autistic-like social behaviour in Shank2-mutant mice improved by restoring NMDA receptor function. Nature. 2012;486(7402): 261-5. https://doi.org/10.1038/nature11208.

120. Lim C-S, Kim H, Yu N-K, Kang SJ, Kim T, Ko H-G, Lee J, Yang J-e, Ryu H-H, Park T, Gim J, Nam HJ, Baek SH, Wegener S, Schmitz D, Boeckers TM, Lee MG, Kim E, Lee J-H, Lee Y-S, Kaang B-K. Enhancing inhibitory synaptic function reverses spatial memory deficits in Shank2 mutant mice. Neuropharmacology. 2017;112:104-12. https://doi.org/10.1016/j. neuropharm.2016.08.016.

121. Peter S, ten Brinke MM, Stedehouder J, Reinelt CM, Wu B, Zhou H, Zhou K, Boele H-J, Kushner SA, Lee MG, Schmeisser MJ, Boeckers TM, Schonewille M, Hoebeek FE, De Zeeuw Cl. Dysfunctional cerebellar Purkinje cells contribute to autism-like behaviour in Shank2-deficient mice. Nat Commun. 2016;7(1):12627. https://doi.org/10.1038/ ncomms12627.

122. Bozdagi $O$, Sakurai T, Papapetrou D, Wang X, Dickstein DL, Takahashi $N$ Kajiwara Y, Yang M, Katz AM, Scattoni M, Harris MJ, Saxena R, Silverman $J$, Crawley JN, Zhou Q, Hof PR, Buxbaum JD. Haploinsufficiency of the autism-associated Shank3 gene leads to deficits in synaptic function, social interaction, and social communication. Mol Autism. 2010;1(1):15. https://doi.org/10.1186/2040-2392-1-15.

123. Vicidomini C, Ponzoni L, Lim D, Schmeisser MJ, Reim D, Morello N, Orellana D, Tozzi A, Durante V, Scalmani P, Mantegazza M, Genazzani AA, Giustetto M, Sala M, Calabresi P, Boeckers TM, Sala C, Verpelli C. Pharmacological enhancement of $m$ Glu5 receptors rescues behavioral deficits in SHANK3 knock-out mice. Mol Psychiatry. 2017;22(5):689-702. https://doi.org/10.1038/mp.2016.30.

124. Yang M, Bozdagi $O$, Scattoni ML, Wohr M, Roullet FI, Katz AM, Abrams DN, Kalikhman D, Simon H, Woldeyohannes L, Zhang JY, Harris MJ, Saxena R, Silverman JL, Buxbaum JD, Crawley JN. Reduced excitatory neurotransmission and mild autism-relevant phenotypes in adolescent Shank3 null mutant mice. J Neurosci. 2012;32(19):6525-41. https://doi. org/10.1523/JNEUROSCI.6107-11.2012.

125. Kouser M, Speed HE, Dewey CM, Reimers JM, Widman AJ, Gupta N, Liu S, Jaramillo TC, Bangash M, Xiao B, Worley PF, Powell CM. Loss of predominant Shank3 isoforms results in hippocampus-dependent impairments in behavior and synaptic transmission. J Neurosci. 2013;33(47): 18448-68. https://doi.org/10.1523/JNEUROSCI.3017-13.2013.

126. Speed HE, Kouser M, Xuan Z, Reimers JM, Ochoa CF, Gupta N, Liu S, Powell CM. Autism-associated insertion mutation (InsG) of shank3 exon 21 causes impaired synaptic transmission and behavioral deficits. J Neurosci. 2015;35(26):9648-65. https://doi.org/10.1523/JNEUROSCI. 3125-14.2015.

127. Zhou Y, Kaiser T, Monteiro P, Zhang X, Van der Goes MS, Wang D, Barak B, Zeng M, Li C, Lu C, Wells M, Amaya A, Nguyen S, Lewis M, Sanjana N, Zhou Y, Zhang M, Zhang F, Fu Z, Feng G. Mice with Shank3 mutations associated with ASD and schizophrenia display both shared and distinct defects. Neuron. 2016;89(1):147-62. https://doi.org/10. 1016/j.neuron.2015.11.023.

128. Wang X, Bey AL, Katz BM, Badea A, Kim N, David LK, Duffney LJ, Kumar S, Mague SD, Hulbert SW, Dutta N, Hayrapetyan V, Yu C, Gaidis E, Zhao S, Ding J-D, Xu Q, Chung L, Rodriguiz RM, Wang F, Weinberg RJ, Wetsel WC, Dzirasa K, Yin H, Jiang Y-h. Altered mGluR5-Homer scaffolds and corticostriatal connectivity in a Shank3 complete knockout model of autism. Nat Commun. 2016;7(1):11459. https://doi.org/10. 1038/ncomms11459.

129. Bey AL, Wang $X$, Yan $H$, Kim N, Passman RL, Yang Y, Cao X, Towers AJ, Hulbert SW, Duffney LJ, Gaidis E, Rodriguiz RM, Wetsel WC, Yin HH, Jiang Y-h. Brain region-specific disruption of Shank3 in mice reveals a dissociation for cortical and striatal circuits in autism-related behaviors. Transl Psychiatry. 2018;8(1):94. https://doi.org/10.1038/s41398-0180142-6.

130. Drapeau E, Riad M, Kajiwara Y, Buxbaum JD. Behavioral phenotyping of an improved mouse model of Phelan-McDermid syndrome with a complete deletion of the Shank3 gene. eNeuro. 2018:5(3):0046-182018. https://doi.org/10.1523/ENEURO.0046-18.2018.

131. Yoo T, Cho H, Lee J, Park H, Yoo Y-E, Yang E, Kim JY, Kim H, Kim E. GABA neuronal deletion of Shank3 exons 14-16 in mice suppresses striatal excitatory synaptic input and induces social and locomotor 
abnormalities. Front Cell Neurosci. 2018;12:1-16. https://doi.org/10. 3389/fncel.2018.00341.

132. Yoo Y-E, YooT, Lee S, Lee J, Kim D, Han H-M, Bae Y-C, Kim E. Shank3 mice carrying the human Q321R mutation display enhanced self-grooming, abnormal electroencephalogram patterns, and suppressed neuronal excitability and seizure susceptibility. Front $\mathrm{Mol}$ Neurosci. 2019;12:1-23. https://doi.org/10.3389/fnmol.2019.00155.

133. Yoo T, Cho H, Park H, Lee J, Kim E. Shank3 exons 14-16 deletion in glutamatergic neurons leads to social and repetitive behavioral deficits associated with increased cortical layer 2/3 neuronal excitability. Front Cell Neurosci. 2019;13:1-17. https://doi.org/10.3389/fncel.2019.00458.

134. Harony-Nicolas H, Kay M, du Hoffmann J, Klein ME, Bozdagi-Gunal O, Riad M, Daskalakis NP, Sonar S, Castillo PE, Hof PR, Shapiro ML, Baxter MG, Wagner S, Buxbaum JD. Oxytocin improves behavioral and electrophysiological deficits in a novel Shank3-deficient rat. eLife. 2017;6: 1-2. https://doi.org/10.7554/eLife.18904.

135. Song T-J, Lan X-Y, Wei M-P, Zhai F-J, Boeckers TM, Wang J-N, Yuan S, Jin M-Y, Xie Y-F, Dang W-W, Zhang C, Schön M, Song P-W, Qiu M-H, Song Y-Y, Han S-P, Han J-S, Zhang R. Altered behaviors and impaired synaptic function in a novel rat model with a complete Shank3 deletion. Front Cell Neurosci. 2019;13:1-17. https://doi.org/10.3389/fncel.2019. 00111

136. Zhou Y, Sharma J, Ke Q, Landman R, Yuan J, Chen H, Hayden DS, Fisher JW, Jiang M, Menegas W, Aida T, Yan T, Zou Y, Xu D, Parmar S, Hyman JB, Fanucci-Kiss A, Meisner O, Wang D, Huang $Y$, Li $Y$, Bai $Y$, Ji W, Lai X, Li W, Huang L, Lu Z, Wang L, Anteraper SA, Sur M, Zhou H, Xiang AP, Desimone R, Feng G, Yang S. Atypical behaviour and connectivity in SHANK3-mutant macaques. Nature. 2019;570(7761): 326-31. https://doi.org/10.1038/s41586-019-1278-0.

137. Zhao H, Tu Z, Xu H, Yan S, Yan H, Zheng Y, Yang W, Zheng J, Li Z, Tian R, Lu Y, Guo X, Jiang Y-h, Li X-J, Zhang YQ. Altered neurogenesis and disrupted expression of synaptic proteins in prefrontal cortex of SHANK3-deficient non-human primate. Cell Res. 2017;27(10):1293-7. https://doi.org/10.1038/cr.2017.95.

138. Mossa A, Pagano J, Ponzoni L, Tozzi A, Vezzoli E, Sciaccaluga M, Costa C, Beretta S, Francolini M, Sala M, Calabresi P, Boeckers TM, Sala C, Verpelli C. Developmental impaired Akt signaling in the Shank1 and Shank3 double knock-out mice. Mol Psychiatry. 2021;14(12):3506-37. https://doi.org/10.1038/s41380-020-00979-x.

139. Jaramillo TC, Speed HE, Xuan Z, Reimers JM, Escamilla CO, Weaver TP, Liu S, Filonova I, Powell CM. Novel Shank3 mutant exhibits behaviors with face validity for autism and altered striatal and hippocampal function. Autism Res. 2017;10(1):42-65. https://doi.org/10.1002/aur.1664.

140. Orefice LL, Mosko JR, Morency DT, Wells MF, Tasnim A, Mozeika SM, Ye M, Chirila AM, Emanuel AJ, Rankin G, Fame RM, Lehtinen MK, Feng G, Ginty DD. Targeting peripheral somatosensory neurons to improve tactile-related phenotypes in ASD models. Cell. 2019;178(4):867-86. https://doi.org/10.1016/j.cell.2019.07.024.

141. Phelan MC, Rogers RC, Saul RA, Stapleton GA, Sweet K, McDermid H, Shaw SR, Claytor J, Willis J, Kelly DP. 22q13 deletion syndrome. Am J Med Genet. 2001;101(2):91-9. https://doi.org/10.1002/10968628(20010615)101:2<91::AID-AJMG1340>3.0.CO;2-C.

142. Phelan K, McDermid HE. The 22q13.3 Deletion Syndrome (Phelan-McDermid Syndrome). Mol Syndromology. 2011;2(3-5):186-201. https://doi.org/10.1159/000334260.

143. Bonaglia MC, Giorda R, Beri S, De Agostini C, Novara F, Fichera M, Grillo L, Galesi O, Vetro A, Ciccone R, Bonati MT, Giglio S, Guerrini R, Osimani S, Marelli S, Zucca C, Grasso R, Borgatti R, Mani E, Motta C, Molteni M, Romano C, Greco D, Reitano S, Baroncini A, Lapi E, Cecconi A, Arrigo G, Patricelli MG, Pantaleoni C, D’Arrigo S, Riva D, Sciacca F, Dalla Bernardina B, Zoccante L, Darra F, Termine C, Maserati E, Bigoni S, Priolo E, Bottani A, Gimelli S, Bena F, Brusco A, di Gregorio E, Bagnasco I, Giussani U, Nitsch L, Politi P, Martinez-Frias ML, Martínez-Fernández ML, Martínez Guardia N, Bremer A, Anderlid B-M, Zuffardi O. Molecular Mechanisms Generating and Stabilizing Terminal 22q13 Deletions in 44 Subjects with Phelan/McDermid Syndrome. PLoS Genet. 2011;7(7): 1002173. https://doi.org/10.1371/journal.pgen.1002173.

144. Bonaglia MC, Giorda R, Mani E, Aceti G, Anderlid B-M, Baroncini A, Pramparo T, Zuffardi O. Identification of a recurrent breakpoint within the SHANK3 gene in the 22q13.3 deletion syndrome. J Med Genet. 2006;43(10):822-8. https://doi.org/10.1136/jmg.2005.038604.
145. De Rubeis S, Siper PM, Durkin A, Weissman J, Muratet F, Halpern D, Trelles MDP, Frank Y, Lozano R, Wang AT, Holder JL, Betancur C, Buxbaum JD, Kolevzon A. Delineation of the genetic and clinical spectrum of Phelan-McDermid syndrome caused by SHANK3 point mutations. Mol Autism. 2018;9(1):31. https://doi.org/10.1186/s13229018-0205-9.

146. Wilson HL, Wong ACC, Shaw SR, Tse WY, Stapleton GA, Phelan MC, Hu S, Marshall J, McDermid HE. Molecular characterisation of the $22 q 13$ deletion syndrome supports the role of haploinsufficiency of SHANK3/PROSAP2 in the major neurological symptoms. J Med Genet. 2003;40(8):575-84. https://doi.org/10.1136/jmg.40.8.575.

147. Wilson HL, Crolla JA, Walker D, Artifoni L, Dallapiccola B, Takano T, Vasudevan P, Huang S, Maloney V, Yobb T, Quarrell O, McDermid HE. Interstitial 22q13 deletions: genes other than SHANK3 have major effects on cognitive and language development. Eur J Hum Genet. 2008;16(11): 1301-10. https://doi.org/10.1038/ejhg.2008.107.

148. Simenson K, Õiglane-Shlik E, Teek R, Kuuse K, Õunap K. A patient with the classic features of Phelan-McDermid syndrome and a high immunoglobulin E level caused by a cryptic interstitial 0.72-Mb deletion in the 22q13.2 region. Am J Med Genet A. 2014;164(3):806-9. https://doi. org/10.1002/ajmg.a.36358.

149. Upadia J, Gonzales PR, Atkinson TP, Schroeder HW, Robin NH, Rudy $\mathrm{NL}$, Mikhail FM. A previously unrecognized 22q13.2 microdeletion syndrome that encompasses TCF20 and TNFRSF13C. Am J Med Genet A. 2018;176(12):2791-7. https://doi.org/10.1002/ajmg.a.40492.

150. Moessner R, Marshall CR, Sutcliffe JS, Skaug J, Pinto D, Vincent J, Zwaigenbaum L, Fernandez B, Roberts W, Szatmari P, Scherer SW. Contribution of SHANK3 Mutations to Autism Spectrum Disorder. Am J Hum Genet. 2007;81 (6):1289-97. https://doi.org/10.1086/522590.

151. Jin C, Kang HR, Kang H, Zhang Y, Lee Y, Kim Y, Han K. Unexpected compensatory increase in Shank3 transcripts in Shank3 knock-out mice having partial deletions of exons. Front Mol Neurosci. 2019;12:1-7. https://doi.org/10.3389/fnmol.2019.00228.

152. Soorya L, Kolevzon A, Zweifach J, Lim T, Dobry Y, Schwartz L, Frank $Y$, Wang A, Cai G, Parkhomenko E, Halpern D, Grodberg D, Angarita B, Willner JP, Yang A, Canitano R, Chaplin W, Betancur C, Buxbaum JD. Prospective investigation of autism and genotype-phenotype correlations in 22q13 deletion syndrome and SHANK3 deficiency. Mol Autism. 2013;4(1):18. https://doi.org/10.1186/2040-2392-4-18.

153. Wang AT, Lim T, Jamison J, Bush L, Soorya LV, Tavassoli T, Siper PM, Buxbaum JD, Kolevzon A. Neural selectivity for communicative auditory signals in Phelan-McDermid syndrome. J Neurodev Dis. 2016;8(1):5. https://doi.org/10.1186/s11689-016-9138-9.

154. Qin L, Ma K, Wang Z-J, Hu Z, Matas E, Wei J, Yan Z. Social deficits in Shank3-deficient mouse models of autism are rescued by histone deacetylase (HDAC) inhibition. Nat Neurosci. 2018;21(4):564-75. https:// doi.org/10.1038/s41593-018-0110-8.

155. Kabitzke PA, Brunner D, He D, Fazio PA, Cox K, Sutphen J, Thiede L, Sabath E, Hanania T, Alexandrov V, Rasmusson R, Spooren W, Ghosh A, Feliciano P, Biemans B, Benedetti M, Clayton AL. Comprehensive analysis of two Shank3 and the Cacna1c mouse models of autism spectrum disorder. Genes Brain Behav. 2018;17(1):4-22. https://doi.org/ 10.1111/gbb.12405.

156. Wang Z-J, Zhong P, Ma K, Seo J-S, Yang F, Hu Z, Zhang F, Lin L, Wang J, Liu T, Matas E, Greengard P, Yan Z. Amelioration of autism-like social deficits by targeting histone methyltransferases EHMT1/2 in Shank3-deficient mice. Mol Psychiatry. 2020;25(10):2517-33. https://doi. org/10.1038/s41380-019-0351-2.

157. de Chaumont F, Ey E, Torquet N, Lagache T, Dallongeville S, Imbert A, Legou T, Le Sourd A-M, Faure P, Bourgeron T, Olivo-Marin J-C. Real-time analysis of the behaviour of groups of mice via a depth-sensing camera and machine learning. Nat Biomed Eng. 2019;3(11):930-42. https://doi.org/10.1038/s41551-019-0396-1.

158. Pagani M, Bertero A, Liska A, Galbusera A, Sabbioni M, Barsotti N, Colenbier N, Marinazzo D, Scattoni ML, Pasqualetti M, Gozzi A. Deletion of autism risk gene Shank3 disrupts pefrontal connectivity. J Neurosci. 2019;39(27):5299-310. https://doi.org/10.1523/JNEUROSCI. 2529-18.2019.

159. Kabitzke P, Morales D, He D, Cox K, Sutphen J, Thiede L, Sabath E, Hanania T, Biemans B, Brunner D. Mouse model systems of autism spectrum disorder: Replicability and informatics signature. Genes Brain Behav. 2020;19(7):1-20. https://doi.org/10.1111/gbb.12676. 
160. Guo B, Chen J, Chen Q, Ren K, Feng D, Mao H, Yao H, Yang J, Liu H, Liu Y, Jia F, Qi C, Lynn-Jones T, Hu H, Fu Z, Feng G, Wang W, Wu S. Anterior cingulate cortex dysfunction underlies social deficits in Shank3 mutant mice. Nat Neurosci. 2019;22(8):1223-34. https://doi.org/10.1038/ s41593-019-0445-9.

161. Sgritta M, Dooling SW, Buffington SA, Momin EN, Francis MB, Britton RA, Costa-Mattioli M. Mechanisms underlying microbial-mediated changes in social behavior in mouse models of autism spectrum disorder. Neuron. 2019;101(2):246-59. https://doi.org/10.1016/j.neuron. 2018.11.018.

162. Rhine MA, Parrott JM, Schultz MN, Kazdoba TM, Crawley JN. Hypothesis-driven investigations of diverse pharmacological targets in two mouse models of autism. Autism Res. 2019;12(3):401-21. https:// doi.org/10.1002/aur.2066.

163. Dhamne SC, Silverman JL, Super CE, Lammers SHT, Hameed MQ, Modi ME, Copping NA, Pride MC, Smith DG, Rotenberg A, Crawley JN, Sahin M. Replicable in vivo physiological and behavioral phenotypes of the Shank3B null mutant mouse model of autism. Mol Autism. 2017;8(1): 26. https://doi.org/10.1186/s13229-017-0142-z.

164. Vyas Y, Lee K, Jung Y, Montgomery JM. Influence of maternal zinc supplementation on the development of autism-associated behavioural and synaptic deficits in offspring Shank3-knockout mice. Mol Brain. 2020;13(1):110. https://doi.org/10.1186/s13041-020-00650-0.

165. Luo J, Feng Q, Wei L, Luo M. Optogenetic activation of dorsal raphe neurons rescues the autistic-like social deficits in Shank3 knockout mice. Cell Res. 2017;27(7):950-3. https://doi.org/10.1038/cr.2017.52.

166. Rendall AR, Perrino PA, Buscarello AN, Fitch RH. Shank3B mutant mice display pitch discrimination enhancements and learning deficits. Int J Dev Neurosci. 2019;72(1):13-21. https://doi.org/10.1016/j.ijdevneu.2018. 10.003.

167. Drapeau E, Dorr NP, Elder GA, Buxbaum JD. Absence of strong strain effects in behavioral analyses of Shank3-deficient mice. Dis Models Mech. 2014;7(6):667-81. https://doi.org/10.1242/dmm.013821.

168. Fourie C, Vyas Y, Lee K, Jung Y, Garner CC, Montgomery JM. Dietary zinc supplementation prevents autism related behaviors and striatal synaptic dysfunction in Shank3 exon 13-16 mutant mice. Front Cell Neurosci. 2018;12:1-14. https://doi.org/10.3389/fncel.2018.00374.

169. Panganiban G, Rubenstein JLR. Developmental functions of the Distal-less /Dlx homeobox genes. Development. 2002;129(19):4371-86. https://doi.org/10.1242/dev.129.19.4371.

170. Cobos I, Long JE, Thwin MT, Rubenstein JL. Cellular patterns of transcription factor expression in developing cortical interneurons. Cereb Cortex. 2006;16(suppl 1):82-8. https://doi.org/10.1093/cercor/bhk003.

171. Ghanem N, Yu M, Poitras L, Rubenstein JLR, Ekker M. Characterization of a distinct subpopulation of striatal projection neurons expressing the DIX genes in the basal ganglia through the activity of the 156 ii enhancer. Dev Biol. 2008;322(2):415-24. https://doi.org/10.1016/j.ydbio.2008.07.029.

172. Wang Y, Dye CA, Sohal V, Long JE, Estrada RC, Roztocil T, Lufkin T, Deisseroth K, Baraban SC, Rubenstein JLR. DIX5 and DIx6 regulate the development of parvalbumin-expressing cortical interneurons. J Neurosci. 2010;30(15):5334-45. https://doi.org/10.1523/JNEUROSCI. 5963-09.2010.

173. Dimidschstein J, Chen Q, Tremblay R, Rogers SL, Saldi G-A, Guo L, Xu Q, Liu R, Lu C, Chu J, Grimley JS, Krostag A-R, Kaykas A, Avery MC, Rashid MS, Baek M, Jacob AL, Smith GB, Wilson DE, Kosche G, Kruglikov I, Rusielewicz T, Kotak VC, Mowery TM, Anderson SA, Callaway EM, Dasen JS, Fitzpatrick D, Fossati V, Long MA, Noggle S, Reynolds JH, Sanes DH, Rudy B, Feng G, Fishell G. A viral strategy for targeting and manipulating interneurons across vertebrate species. Nat Neurosci. 2016;19(12):1743-9. https://doi.org/10.1038/nn.4430.

174. de Lombares C, Heude E, Alfama G, Fontaine A, Hassouna R, Vernochet $C$, de Chaumont F, Olivo-Marin C, Ey E, Parnaudeau S, Tronche F, Bourgeron T, Luquet S, Levi G, Narboux-Nême N. Dlx5 and Dlx6 expression in GABAergic neurons controls behavior, metabolism, healthy aging and lifespan. Aging. 2019;11(17):6638-56. https://doi.org/ 10.18632/aging.102141.

175. Han KA, Yoon TH, Shin J, Um JW, Ko J. Differentially altered social dominance- and cooperative-like behaviors in Shank2- and Shank3-mutant mice. Mol Autism. 2020;11(1):87. https://doi.org/10. 1186/s13229-020-00392-9.
176. Jaramillo TC, Xuan Z, Reimers JM, Escamilla CO, Liu S, Powell CM. Early Restoration of Shank3 expression in Shank3 knock-out mice prevents core ASD-like behavioral phenotypes. eNeuro. 2020;7(3):0332-192020. https://doi.org/10.1523/ENEURO.0332-19.2020.

177. Duffney LJ, Zhong P, Wei J, Matas E, Cheng J, Qin L, Ma K, Dietz DM, Kajiwara Y, Buxbaum JD, Yan Z. Autism-like deficits in Shank3-deficient mice are rescued by targeting actin regulators. Cell Rep. 2015;11(9): 1400-13. https://doi.org/10.1016/j.celrep.2015.04.064

178. Bidinosti M, Botta P, Krüttner S, Proenca CC, Stoehr N, Bernhard M, Fruh I, Mueller M, Bonenfant D, Voshol H, Carbone W, Neal SJ, McTighe SM, Roma G, Dolmetsch RE, Porter JA, Caroni P, Bouwmeester T, Lüthi A, Galimberti I. CLK2 inhibition ameliorates autistic features associated with SHANK3 deficiency. Science. 2016;351(6278):1199-203. https://doi.org/10.1126/science.aad5487.

179. Matas E, Maisterrena A, Thabault M, Balado E, Francheteau M, Balbous A, Galvan L, Jaber M. Major motor and gait deficits with sexual dimorphism in a Shank3 mutant mouse model. Mol Autism. 2021;12(1): 2. https://doi.org/10.1186/s13229-020-00412-8.

180. Berg EL, Copping NA, Rivera JK, Pride MC, Careaga M, Bauman MD, Berman RF, Lein PJ, Harony-Nicolas H, Buxbaum JD, Ellegood J, Lerch JP, Wöhr M, Silverman JL. Developmental social communication deficits in the Shank3 rat model of Phelan-McDermid syndrome and autism spectrum disorder. Autism Res. 2018;11(4):587-601. https://doi. org/10.1002/aur.1925.

181. Tatavarty V, Torrado Pacheco A, Groves Kuhnle C, Lin H, Koundinya P, Miska NJ, Hengen KB, Wagner FF, Van Hooser SD, Turrigiano GG. Autism-associated Shank3 is essential for homeostatic compensation in rodent V1. Neuron. 2020;106(5):769-77. https://doi.org/10.1016/j. neuron.2020.02.033.

182. Wang W, Li C, Chen Q, van der Goes M-S, Hawrot J, Yao AY, Gao X, Lu C, Zang Y, Zhang Q, Lyman K, Wang D, Guo B, Wu S, Gerfen CR, Fu Z, Feng $\mathrm{G}$. Striatopallidal dysfunction underlies repetitive behavior in Shank3-deficient model of autism. J Clin Investig. 2017;127(5):1978-90. https://doi.org/10.1172/JCl87997.

183. Peixoto RT, Chantranupong L, Hakim R, Levasseur J, Wang W, Merchant T, Gorman K, Budnik B, Sabatini BL. Abnormal striatal development underlies the early onset of behavioral deficits in Shank3B mice. Cell Rep. 2019;29(7):2016-27. https://doi.org/10.1016/j.celrep.2019.10.021.

184. Dhar SU, del Gaudio D, German JR, Peters SU, Ou Z, Bader PI, Berg JS, Blazo M, Brown CW, Graham BH, Grebe TA, Lalani S, Irons M, Sparagana S, Williams M, Phillips JA, Beaudet AL, Stankiewicz P, Patel A, Cheung SW, Sahoo T. 22q13.3 deletion syndrome: clinical and molecular analysis using array CGH. Am J Med Genet A. 2010;152A(3): 573-81. https://doi.org/10.1002/ajmg.a.33253.

185. Green J, Absoud M, Grahame V, Malik O, Simonoff E, Le Couteur A, Baird G. Pathological demand avoidance: symptoms but not a syndrome. Lancet Child Adolesc Health. 2018;2(6):455-64. https://doi. org/10.1016/S2352-4642(18)30044-0.

186. Kanani F, Study D, Balasubramanian M. SHANK3 variant as a cause of nonsyndromal autism in an 11-year-old boy and a review of published literature. Clin Dysmorphol. 2018;27(4):113-5. https://doi.org/10.1097/ MCD.0000000000000232.

187. Speed HE, Kouser M, Xuan Z, Liu S, Duong A, Powell CM. Apparent genetic rescue of adult Shank3 exon 21 insertion mutation mice tempered by appropriate control experiments. eNeuro. 2019;6(5): 0317-192019. https://doi.org/10.1523/ENEURO.0317-19.2019.

188. Copping NA, Berg EL, Foley GM, Schaffler MD, Onaga BL, Buscher N, Silverman $J$, Yang $M$. Touchscreen learning deficits and normal social approach behavior in the Shank3B model of Phelan-McDermid syndrome and autism. Neuroscience. 2017;345:155-65. https://doi.org/ 10.1016/j.neuroscience.2016.05.016.

189. Angelakos CC, Tudor JC, Ferri SL, Jongens TA, Abel T. Home-cage hypoactivity in mouse genetic models of autism spectrum disorder. Neurobiol Learn Mem. 2019;165:107000. https://doi.org/10.1016/j.nlm. 2019.02.010.

190. Saré RM, Lemons A, Song A, Smith CB. Sleep duration in mouse models of neurodevelopmental disorders. Brain Sci. 2020;11(1):31. https://doi. org/10.3390/brainsci11010031

191. Ingiosi AM, Schoch $H$, Wintler T, Singletary KG, Righelli D, Roser LG, Medina E, Risso D, Frank MG, Peixoto L. Shank3 modulates sleep and 
expression of circadian transcription factors. eLife. 2019;8:465799. https://doi.org/10.7554/eLife.42819.

192. Chen Q, Deister CA, Gao X, Guo B, Lynn-Jones T, Chen N, Wells MF, Liu R, Goard MJ, Dimidschstein J, Feng S, Shi Y, Liao W, Lu Z, Fishell G, Moore Cl, Feng G. Dysfunction of cortical GABAergic neurons leads to sensory hyper-reactivity in a Shank3 mouse model of ASD. Nat Neurosci. 2020;23(4):520-32. https://doi.org/10.1038/s41593-020-0598-6.

193. Ponzoni L, Sala C, Verpelli C, Sala M, Braida D. Different attentional dysfunctions in eEF2K -/-, IL1RAPL1 -/- and SHANK3 11 -/- mice. Genes Brain Behav. 2019;18(5):12563. https://doi.org/10.1111/gbb.12563.

194. Kloth AD, Badura A, Li A, Cherskov A, Connolly SG, Giovannucci A, Bangash MA, Grasselli G, Peñagarikano O, Piochon C, Tsai PT, Geschwind DH, Hansel C, Sahin M, Takumi T, Worley PF, Wang SSH. Cerebellar associative sensory learning defects in five mouse autism models. eLife. 2015;4:1-26. https://doi.org/10.7554/eLife.06085.

195. Holder JL, Quach MM. The spectrum of epilepsy and electroencephalographic abnormalities due to SHANK3 loss-of-function mutations. Epilepsia. 2016;57(10):1651-9. https://doi.org/10.1111/epi. 13506.

196. Lee DK, Li SW, Bounni F, Friedman G, Jamali M, Strahs L, Zeliger O, Gabrieli P, Stankovich MA, Demaree J, Williams ZM. Reduced sociability and social agency encoding in adult Shank3-mutant mice are restored through gene re-expression in real time. Nat Neurosci. 2021;24(9): 1243-55. https://doi.org/10.1038/s41593-021-00888-4.

197. Qin L, Ma K, Yan Z. Chemogenetic activation of prefrontal cortex in Shank3-deficient mice ameliorates social deficits, NMDAR Hypofunction, and Sgk2 Downregulation. iScience. 2019;17:24-35. https://doi.org/10. 1016/j.isci.2019.06.014.

198. Zhang F, Rein B, Zhong P, Shwani T, Conrow-Graham M, Wang Z-J, Yan Z. Synergistic inhibition of histone modifiers produces therapeutic effects in adult Shank3-deficient mice. Transl Psychiatry. 2021;11(1):99. https://doi.org/10.1038/s41398-021-01233-w.

199. Ma K, Qin L, Matas E, Duffney LJ, Liu A, Yan Z. Histone deacetylase inhibitor MS-275 restores social and synaptic function in a Shank3-deficient mouse model of autism. Neuropsychopharmacology 2018;43(8):1779-88. https://doi.org/10.1038/s41386-018-0073-1.

200. Bozdagi O, Tavassoli T, Buxbaum JD. Insulin-like growth factor-1 rescues synaptic and motor deficits in a mouse model of autism and developmental delay. Mol Autism. 2013;4(1):9. https://doi.org/10.1186/ 2040-2392-4-9.

201. Orefice LL, Zimmerman AL, Chirila AM, Sleboda SJ, Head JP, Ginty DD. Peripheral mechanosensory neuron dysfunction underlies tactile and behavioral deficits in mouse models of ASDs. Cell. 2016;166(2):299-313. https://doi.org/10.1016/j.cell.2016.05.033.

202. Reim D, Distler U, Halbedl S, Verpelli C, Sala C, Bockmann J, Tenzer S, Boeckers TM, Schmeisser MJ. Proteomic analysis of post-synaptic density fractions from Shank3 mutant mice reveals brain region specific changes relevant to autism spectrum disorder. Front Mol Neurosci. 2017;10:1-10. https://doi.org/10.3389/fnmol.2017.00026.

203. Heise C, Preuss JM, Schroeder JC, Battaglia CR, Kolibius J, Schmid R, Kreutz MR, Kas MJH, Burbach JPH, Boeckers TM. Heterogeneity of cell surface glutamate and GABA receptor expression in Shank and CNTN4 autism mouse models. Front Mol Neurosci. 2018;11:1-13. https://doi. org/10.3389/fnmol.2018.00212.

204. Takenawa T, Suetsugu S. The WASP-WAVE protein network: connecting the membrane to the cytoskeleton. Nat Rev Mol Cell Biol. 2007;8(1): 37-48. https://doi.org/10.1038/nrm2069.

205. Jin C, Kim S, Kang H, Yun KN, Lee Y, Zhang Y, Kim Y, Kim JY, Han K. Shank3 regulates striatal synaptic abundance of Cyld, a deubiquitinase specific for Lys63-linked polyubiquitin chains. J Neurochem. 2019;150(6): 776-86. https://doi.org/10.1111/jnc.14796.

206. Filice F, Vörckel KJ, Sungur AÖ, Wöhr M, Schwaller B. Reduction in parvalbumin expression not loss of the parvalbumin-expressing GABA interneuron subpopulation in genetic parvalbumin and shank mouse models of autism. Mol Brain. 2016;9(1):10. https://doi.org/10.1186/ s13041-016-0192-8.

207. Torossian A, Saré RM, Loutaev I, Smith CB. Increased rates of cerebral protein synthesis in Shank3 knockout mice: Implications for a link between synaptic protein deficit and dysregulated protein synthesis in autism spectrum disorder/intellectual disability. Neurobiol Dis. 2021;148: 105213. https://doi.org/10.1016/j.nbd.2020.105213.
208. Gogolla N, Takesian AE, Feng G, Fagiolini M, Hensch TK. Sensory integration in mouse insular cortex reflects GABA circuit maturation. Neuron. 2014;83(4):894-905. https://doi.org/10.1016/j.neuron.2014.06.033.

209. Zhu M, Idikuda VK, Wang J, Wei F, Kumar V, Shah N, Waite CB, Liu Q, Zhou L. Shank3-deficient thalamocortical neurons show HCN channelopathy and alterations in intrinsic electrical properties. J Physiol. 2018:596(7):1259-76. https://doi.org/10.1113/JP275147.

210. Amal H, Barak B, Bhat V, Gong G, Joughin BA, Wang X, Wishnok JS, Feng G, Tannenbaum SR. Shank3 mutation in a mouse model of autism leads to changes in the s-nitroso-proteome and affects key proteins involved in vesicle release and synaptic function. Mol Psychiatry. 2020;25:1835-48. https://doi.org/10.1038/s41380-018-0113-6.

211. Tabouy L, Getselter D, Ziv O, Karpuj M, Tabouy T, Lukic I, Maayouf R, Werbner N, Ben-Amram H, Nuriel-Ohayon M, Koren O, Elliott E. Dysbiosis of microbiome and probiotic treatment in a genetic model of autism spectrum disorders. Brain Behav Immun. 2018;73:310-9. https:// doi.org/10.1016/j.bbi.2018.05.015.

212. Sauer AK, Bockmann J, Steinestel K, Boeckers TM, Grabrucker AM. Altered intestinal morphology and microbiota composition in the autism spectrum disorders associated SHANK3 mouse model. Int J Mol Sci. 2019;20(9):2134. https://doi.org/10.3390/ijms20092134.

213. Yi F, Danko T, Botelho SC, Patzke C, Pak C, Wernig M, Sudhof TC. Autism-associated SHANK3 haploinsufficiency causes Ih channelopathy in human neurons. Science. 2016;352(6286):2669. https://doi.org/10. 1126/science.aaf2669.

214. Peixoto RT, Wang W, Croney DM, Kozorovitskiy Y, Sabatini BL. Early hyperactivity and precocious maturation of corticostriatal circuits in Shank3B-/- mice. Nat Neurosci. 2016;19(5):716-24. https://doi.org/10. 1038/nn.4260.

215. Lu C, Chen Q, Zhou T, Bozic D, Fu Z, Pan JQ, Feng G. Micro-electrode array recordings reveal reductions in both excitation and inhibition in cultured cortical neuron networks lacking Shank3. Mol Psychiatry. 2015;21(2):159-68. https://doi.org/10.1038/mp.2015.173.

216. Engineer CT, Rahebi KC, Borland MS, Buell EP, Im KW, Wilson LG, Sharma P, Vanneste S, Harony-Nicolas H, Buxbaum JD, Kilgard MP. Shank3-deficient rats exhibit degraded cortical responses to sound. Autism Res. 2018;1 1(1):59-68. https://doi.org/10.1002/aur.1883.

217. Jacot-Descombes $S$, Keshav NU, Dickstein DL, Wicinski B, Janssen WGM, Hiester LL, Sarfo EK, Warda T, Fam MM, Harony-Nicolas H, Buxbaum JD, Hof PR, Varghese M. Altered synaptic ultrastructure in the prefrontal cortex of Shank3-deficient rats. Mol Autism. 2020;11(1):89. https://doi.org/10.1186/s13229-020-00393-8.

218. Uppal N, Puri R, Yuk F, Janssen WGM, Bozdagi-Gunal O, Harony-Nicolas H, Dickstein DL, Buxbaum JD, Hof PR. Ultrastructural analyses in the hippocampus CA1 field in Shank3-deficient mice. Mol Autism. 2015;6(1):41. https://doi.org/10.1186/s13229-015-0036-x.

219. Schoen M, Asoglu H, Bauer HF, Müller H-P, Abaei A, Sauer AK, Zhang R, Song T.-j., Bockmann J, Kassubek J, Rasche V, Grabrucker AM, Boeckers TM. Shank3 transgenic and prenatal zinc-deficient autism mouse models show convergent and individual alterations of brain structures in MRI. Front Neural Circ. 2019;13:1-11. https://doi.org/10. 3389/fncir.2019.00006.

220. Ellegood J, Anagnostou E, Babineau BA, Crawley JN, Lin L, Genestine M, DiCicco-Bloom E, Lai JKY, Foster JA, Peñagarikano O, Geschwind DH, Pacey LK, Hampson DR, Laliberté CL, Mills AA, Tam E, Osborne LR, Kouser M, Espinosa-Becerra F, Xuan Z, Powell CM, Raznahan A, Robins DM, Nakai N, Nakatani J, Takumi T, van Eede MC, Kerr TM, Muller C, Blakely RD, Veenstra-VanderWeele J, Henkelman RM, Lerch JP. Clustering autism: using neuroanatomical differences in 26 mouse models to gain insight into the heterogeneity. Mol Psychiatry. 2015;20(1):118-25. https://doi.org/10.1038/mp.2014.98.

221. McElhanon BO, McCracken C, Karpen S, Sharp WG. Gastrointestinal symptoms in autism spectrum disorder: A meta-analysis. Pediatrics. 2014;133(5):872-83. https://doi.org/10.1542/peds.2013-3995.

222. Lee M, Krishnamurthy J, Susi A, Sullivan C, Gorman GH, Hisle-Gorman E, Erdie-Lalena CR, Nylund CM. Association of autism spectrum disorders and inflammatory bowel disease. J Autism Dev Disord. 2018;48(5):1523-9. https://doi.org/10.1007/s10803-017-3409-5.

223. Witmer C, Mattingly A, D'Souza P, Thurm A, Hadigan C. Incontinence in Phelan-McDermid syndrome. J Pediatr Gastroenterol Nutr. 2019;69(2): 39-42. https://doi.org/10.1097/MPG.0000000000002342. 
224. Mayer EA. Gut feelings: the emerging biology of gut-brain communication. Nat Rev Neurosci. 2011;12(8):453-66. https://doi.org/ 10.1038/nrn3071.

225. Curtis K, Stewart CJ, Robinson M, Molfese DL, Gosnell SN, Kosten TR, Petrosino JF, De La Garza R, Salas R. Insular resting state functional connectivity is associated with gut microbiota diversity. Eur J Neurosci. 2019;50(3):2446-52. https://doi.org/10.1111/ejn.14305.

226. Kercher C, Azinfar L, Dinalankara DMR, Takahashi TN, Miles JH, Yao G. A longitudinal study of pupillary light reflex in 6- to 24-month children. Sci Rep. 2020;10(1):1205. https://doi.org/10.1038/s41598-020-58254-6.

227. Tu Z, Zhao H, Li B, Yan S, Wang L, Tang Y, Li Z, Bai D, Li C, Lin Y, Li Y, Liu J, Xu H, Guo X, Jiang Y-h, Zhang YQ, Li X-J. CRISPR/Cas9-mediated disruption of SHANK3 in monkey leads to drug-treatable autism-like symptoms. Hum Mol Genet. 2019;28(4):561-71. https://doi.org/10.1093/ hmg/ddy367.

228. Lee Y, Kim SG, Lee B, Zhang Y, Kim Y, Kim S, Kim E, Kang H, Han K. Striatal Transcriptome and Interactome Analysis of Shank3-overexpressing Mice Reveals the Connectivity between Shank3 and mTORC1 Signaling. Front Mol Neurosci. 2017;10:1-14. https://doi. org/10.3389/fnmol.2017.00201.

229. Jin $C$, Lee $Y$, Kang $H$, Jeong $K$, Park J, Zhang $Y$, Kang HR, Ma R, Seong $H$, Kim Y, Jung H, Kim JY, Kim YK, Han K. Increased ribosomal protein levels and protein synthesis in the striatal synaptosome of Shank3-overexpressing transgenic mice. Mol Brain. 2021;14(1):39. https://doi.org/10.1186/s13041-021-00756-z.

230. Jin C, Kang H, Ryu JR, Kim S, Zhang Y, Lee Y, Kim Y, Han K. Integrative brain transcriptome analysis reveals region-specific and broad molecular changes in Shank3-overexpressing mice. Front Mol Neurosci. 2018;11: 1-14. https://doi.org/10.3389/fnmol.2018.00250.

231. Jin C, Kang H, Kim S, Zhang Y, Lee Y, Kim Y, Han K. Transcriptome analysis of Shank3-overexpressing mice reveals unique molecular changes in the hypothalamus. Mol Brain. 2018;11(1):71. https://doi.org/ 10.1186/s13041-018-0413-4

232. Modahl C, Fein D, Waterhouse L, Newton N. Does oxytocin deficiency mediate social deficits in autism? J Autism Dev Disord. 1992;22(3): 449-51. https://doi.org/10.1007/BF01048246.

233. Dai Z, Ramesh V, Locasale JW. The evolving metabolic landscape of chromatin biology and epigenetics. Nat Rev Genet. 2020;21(12):737-53. https://doi.org/10.1038/s41576-020-0270-8.

234. Lopes G, Monteiro P. New open-source tools: using Bonsai for behavioral tracking and closed-loop experiments. Front Behav Neurosci. 2021;15:1-9. https://doi.org/10.3389/fnbeh.2021.647640.

235. Geuther BQ, Peer A, He H, Sabnis G, Philip VM, Kumar V. Action detection using a neural network elucidates the genetics of mouse grooming behavior. eLife. 2021;10:1-32. https://doi.org/10.7554/eLife. 63207

236. Warren Z, Veenstra-VanderWeele J, Stone W, Bruzek J, Nahmias A, Foss-Feig J, Jerome R, Krishnaswami S, Sathe N, Glasser A, SurawiczT, McPheeters M. Therapies for Children With Autism Spectrum Disorders. AHRQ Comp Eff Rev. 2011;26:1-146.

237. Weitlauf A, McPheeters M, Peters B, Sathe N, Travis R, Aiello R, Williamson E, Veenstra-VanderWeele J, Krishnaswami S, Jerome R, Warren Z. Therapies for children with autism spectrum disorder: behavioral interventions update. AHRQ Comp Eff Rev. 2014;137:1-115.

238. Williamson E, Sathe N, Andrews J, Krishnaswami S, McPheeters M, Fonnesbeck C, Sanders K, Weitlauf A, Warren Z. Medical therapies for children with autism spectrum disorder-an update. AHRQ Comp Eff Rev. 2017;189:1-106. https://doi.org/10.23970/AHRQEPCCER189.

239. Shcheglovitov A, Shcheglovitova O, Yazawa M, Portmann T, Shu R, Sebastiano V, Krawisz A, Froehlich W, Bernstein JA, Hallmayer JF, Dolmetsch RE. SHANK3 and IGF1 restore synaptic deficits in neurons from 22q13 deletion syndrome patients. Nature. 2013;503(7475):267-71. https://doi.org/10.1038/nature12618.

240. Kolevzon A, Bush L, Wang A, Halpern D, Frank Y, Grodberg D, Rapaport R, Tavassoli T, Chaplin W, Soorya L, Buxbaum JD. A pilot controlled trial of insulin-like growth factor-1 in children with Phelan-McDermid syndrome. Mol Autism. 2014;5(1):54. https://doi.org/ 10.1186/2040-2392-5-54.

241. Zwanenburg RJ, Bocca G, Ruiter SAJ, Dillingh JH, Flapper BCT, van den Heuvel ER, van Ravenswaaij-Arts CMA. Is there an effect of intranasal insulin on development and behaviour in Phelan-McDermid syndrome?
A randomized, double-blind, placebo-controlled trial. Eur J Hum Genet. 2016;24(12):1696-701. https://doi.org/10.1038/ejhg.2016.109.

242. Schmidt H, Kern W, Giese R, Hallschmid M, Enders A. Intranasal insulin to improve developmental delay in children with 22q13 deletion syndrome: an exploratory clinical trial. J Med Genet. 2009;46(4):217-22. https://doi.org/10.1136/jmg.2008.062141.

243. Pasini A, D'Agati E, Casarelli L, Curatolo P. Dose-dependent effect of risperidone treatment in a case of 22q13.3 deletion syndrome. Brain Dev. 2010;32(5):425-7. https://doi.org/10.1016/j.braindev.2009.04.005.

244. Serret S, Thümmler S, Dor E, Vesperini S, Santos A, Askenazy F. Lithium as a rescue therapy for regression and catatonia features in two SHANK3 patients with autism spectrum disorder: case reports. BMC Psychiatry. 2015;15(1):107. https://doi.org/10.1186/s12888-015-0490-1.

245. Rowland T, Pathania R, Roy A. Phelan-McDermid syndrome, bipolar disorder and treatment with lithium. Br J Learn Disabil. 2018;46(3):202-5. https://doi.org/10.1111/bld.12235

246. Egger JIM, Verhoeven WMA, Groenendijk-Reijenga R, Kant SG. PhelanMcDermid syndrome due to SHANK3 mutation in an intellectually disabled adult male: successful treatment with lithium. BMJ Case Rep. 2017;2017:2017-220778. https://doi.org/10.1136/bcr-2017-220778.

247. Mendell JR, Al-Zaidy S, Shell R, Arnold WD, Rodino-Klapac LR, Prior TW Lowes L, Alfano L, Berry K, Church K, Kissel JT, Nagendran S, L'Italien J, Sproule DM, Wells C, Cardenas JA, Heitzer MD, Kaspar A, Corcoran S, Braun L, Likhite S, Miranda C, Meyer K, Foust KD, Burghes AHM, Kaspa BK. Single-dose gene-replacement therapy for spinal muscular atrophy. N Engl J Med. 2017;377(18):1713-22. https://doi.org/10.1056/ NEJMoa1706198.

248. Mercuri E, Darras BT, Chiriboga CA, Day JW, Campbell C, Connolly AM lannaccone ST, Kirschner J, Kuntz NL, Saito K, Shieh PB, Tulinius M, Mazzone ES, Montes J, Bishop KM, Yang Q, Foster R, Gheuens S, Bennett CF, Farwell W, Schneider E, De Vivo DC, Finkel RS. Nusinersen versus Sham control in later-onset spinal muscular atrophy. N Engl J Med. 2018;378(7):625-35. https://doi.org/10.1056/NEJMoa1710504.

249. Matharu N, Rattanasopha S, Tamura S, Maliskova L, Wang Y, Bernard A Hardin A, Eckalbar WL, Vaisse C, Ahituv N. CRISPR-mediated activation of a promoter or enhancer rescues obesity caused by haploinsufficiency. Science. 2019;363(6424):0629. https://doi.org/10.1126/science.aau0629.

250. Abudayyeh OO, Gootenberg JS, Essletzbichler P, Han S, Joung J, Belanto JJ, Verdine V, Cox DBT, Kellner MJ, Regev A, Lander ES, Voytas DF, Ting AY, Zhang F. RNA targeting with CRISPR-Cas13. Nature. 2017;550(7675):280-4. https://doi.org/10.1038/nature24049.

251. Nardou R, Lewis EM, Rothhaas R, Xu R, Yang A, Boyden E, Dölen G. Oxytocin-dependent reopening of a social reward learning critical period with MDMA. Nature. 2019;569(7754):116-20. https://doi.org/10 1038/s41586-019-1075-9.

252. Bariselli S, Bellone C. VTA DA neuron excitatory synapses in Shank3 $\Delta$ ex 4-9 mouse line. Synapse. 2017;71(6):21955. https://doi.org/10.1002/syn. 21955.

253. R Core Team. R: A language and environment for statistical computing. R Foundation for Statistical Computing. 2017. Vienna, Austria.

254. Wickham H. tidyr: Easily Tidy Data with 'spread()' and 'gather()' Functions. 2016. https://cran.r-project.org/package=tidyr.

255. Wickham H. The Split-Apply-Combine Strategy for Data Analysis. J Stat Softw. 2011:40(1):1-29.

256. Wickham H, Francois R. dplyr: a grammar of data manipulation. 2015. https://cran.r-project.org/package=dplyr.

257. Wickham H. Reshaping data with the reshape Package. J Stat Softw. 2007;21(12):1-20.

258. Wickham H. Ggplot2: Elegant graphics for data analysis. New York, USA: Springer; 2009.

\section{Publisher's Note}

Springer Nature remains neutral with regard to jurisdictional claims in published maps and institutional affiliations. 